\title{
EVALUATION OF DIFFERENT TYPES OF FATS FOR USE IN HIGH-RATIO
} LAYER CAKES

by

\author{
JIANMIN ZHOU \\ B.S., WUHAN POLYTECHINIC UNIVERSITY, 1998
}

\begin{abstract}
A THESIS
submitted in partial fulfillment of the requirements for the degree

MASTER OF SCIENCE

Department of Grain Science and Industry

College of Agriculture
\end{abstract}

\section{KANSAS STATE UNIVERSITY \\ Manhattan, Kansas}

2010

Approved by:

Co-Major Professor

Dr. J. M. Faubion

Approved by:

Co-Major Professor

Dr. C. E. Walker 


\begin{abstract}
Shortening is a major ingredient used in high-ratio layer cakes. Plastic shortenings are most commonly used by the U.S. baking industry, but high levels of trans- or saturated fats cause health concerns. Compared to plastic shortenings, liquid shortenings could significantly reduce the dependence on high melting point fats and the emulsifiers used would enhance the shortening's functionality.
\end{abstract}

The objective of this research was to compare the influence of different types of fats on the texture and shelf-life of high-ratio layer cakes. Cakes were baked with soybean oil to evaluate the function of three emulsifiers (PGMS, GMS, and Lecithin) on layer cake quality, including volume, cake score, interior visual texture (C-Cell), and firmness (Voland-Stevens). An optimum emulsifier combination was chosen (PGMS 1.8\%, GMS 1.0\% and Lecithin 0.8\%) for addition to the liquid oil. Four groups of layer cakes were baked using: plastic shortening, liquid shortening, liquid oil, or liquid oil plus emulsifier combination. Cake performance and firming over-time were evaluated. The liquid shortening provided the best fresh cake characteristics and cake firmness performance. Liquid oil combined with a combination of added emulsifiers performed very similar in terms of firmness, as did the liquid shortening. This indicated that emulsifiers played an important role on the improvement of cake firmness shelflife. 


\section{Table of Contents}

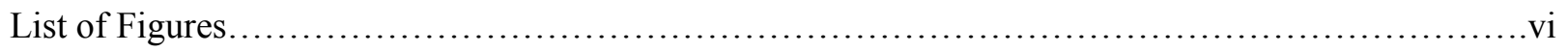

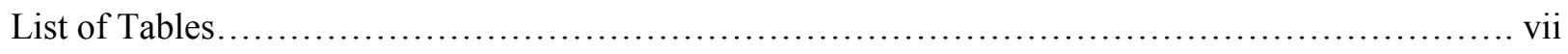

Acknowledgements......................................................................

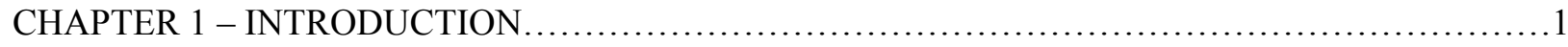

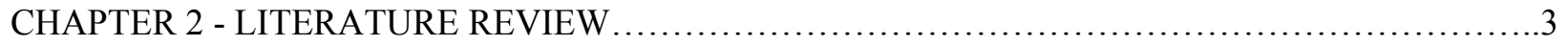

2.1 High-ratio layer cakes...........................................................

2.2 Fats and Oils............................................................... 5

2.2.1 Structure and properties................................................ 5

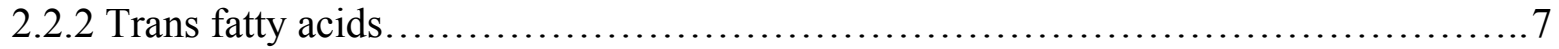

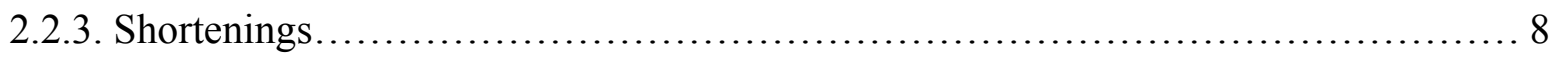

Crystal structure........................................................ 8

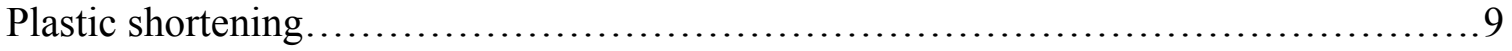

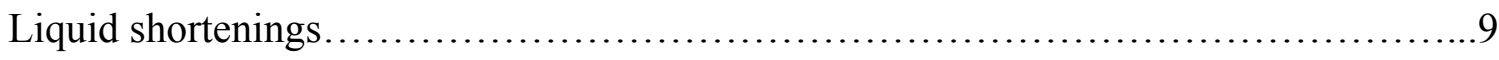

2.3 Emulsifiers............................................................... 11

2.3.1 Classification....................................................... 12

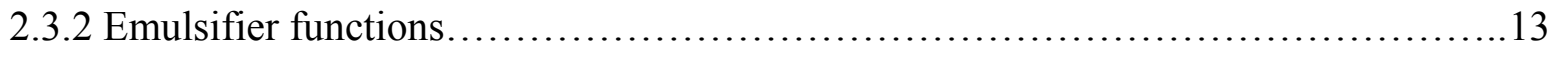

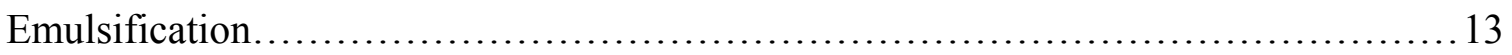

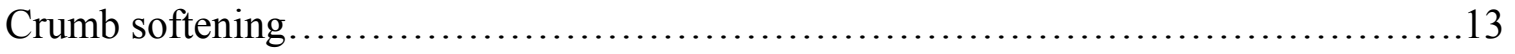

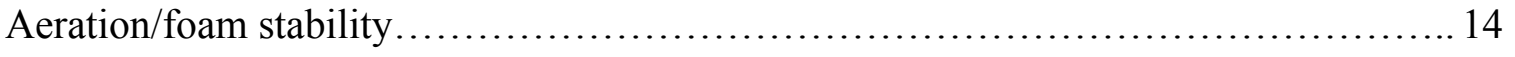

Crystal modification................................................... 14

2.3.3 Emulsifier combinations.............................................. 15

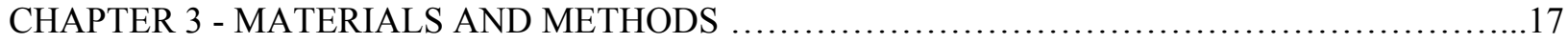

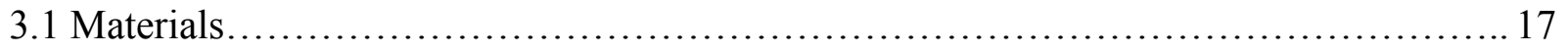

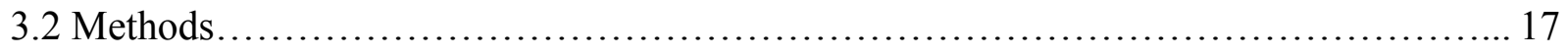

3.2.1 High Ratio Yellow Cake Formulation.................................... 18

Modification of standard AACC formula..................................... 18

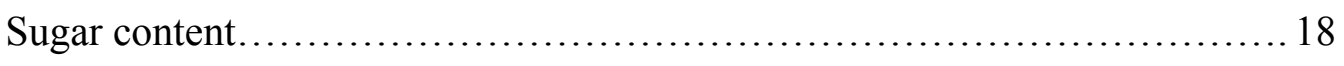

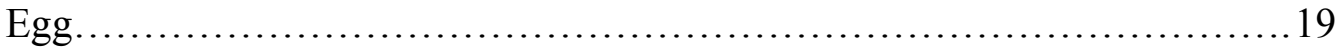


Fat content .......................................................... 19

Mixing procedures.................................................. 19

Water absorption.................................................. 20

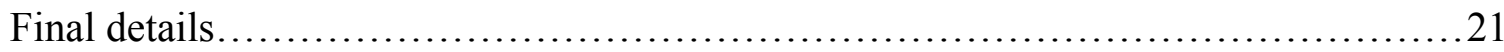

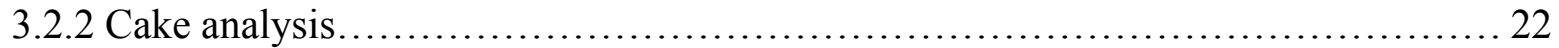

Batter Specific Gravity ...................................................... 22

Cake measurement........................................................... 22

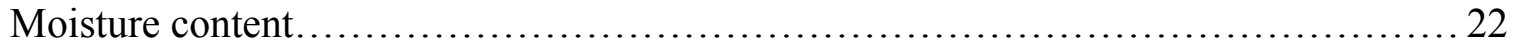

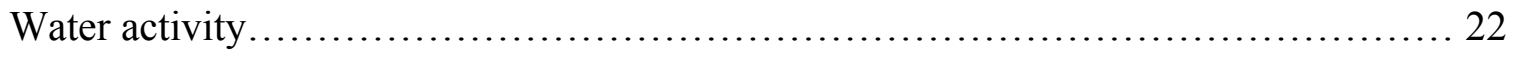

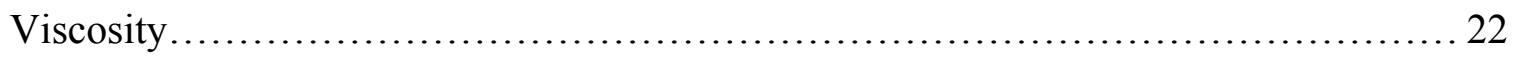

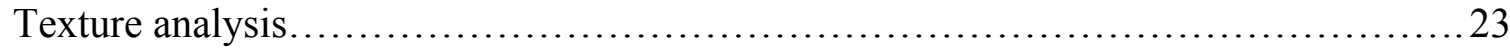

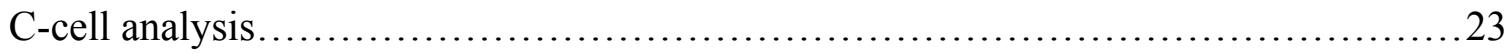

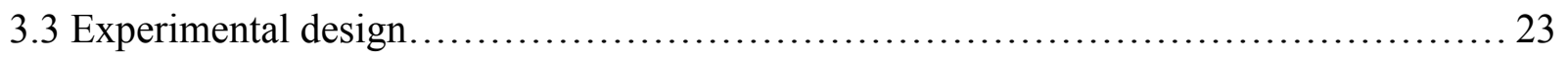

Emulsifier combination tests.................................................. 23

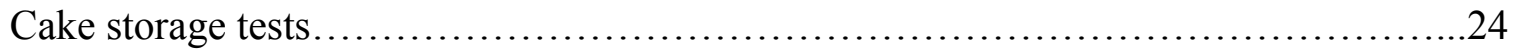

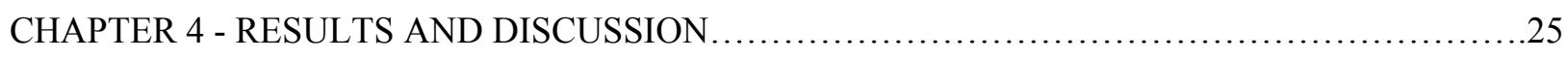

4.1 EMULSIFIER COMBINATION..................................................... 25

4.1.1 Batters Properties............................................................ 31

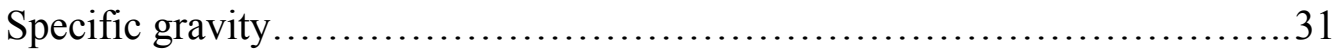

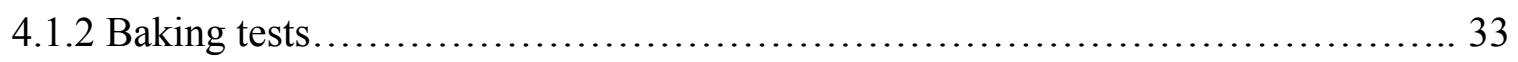

4.1.2.1 Cake Volume................................................ 33

4.1.2.2 Cake Score ........................................................... 36

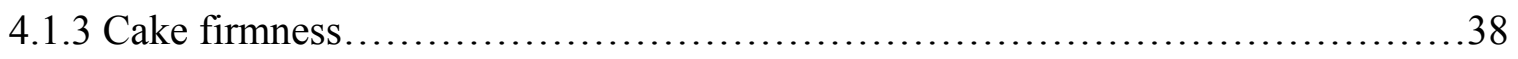

4.2 CAKE STORAGE TEST ......................................................... 41

4.2.1 Batter Properties............................................................. 43

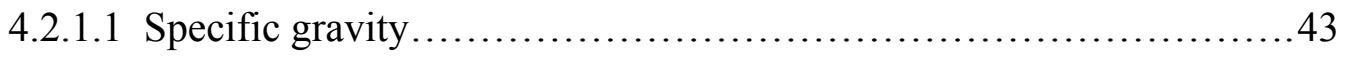

4.2 .1 .2 Viscosity .................................................... 44

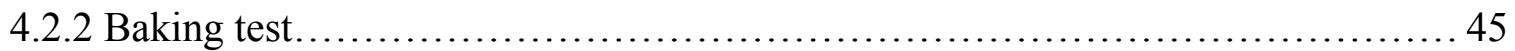

4.2.2.1 Cake volume................................................ 45

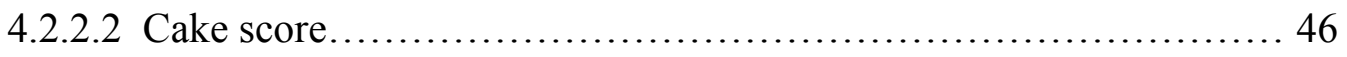

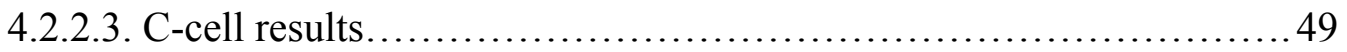


Slice brightness.............................................. 49

Cell wall thickness..............................................50

Numbers of cells.............................................. 51

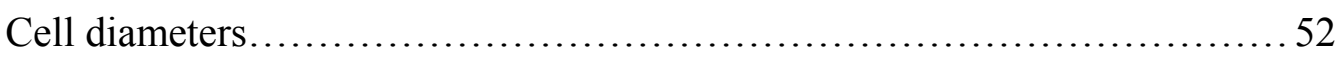

4.2.3 Cake firmness........................................................... 53

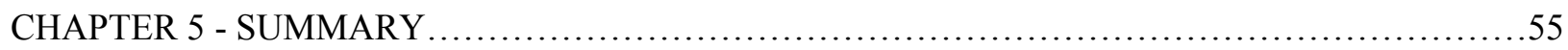

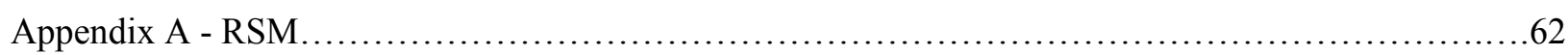

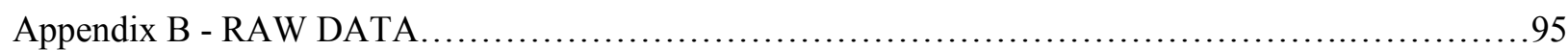




\section{List of Figures}

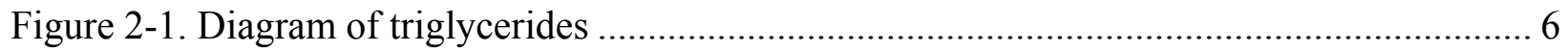

Figure 2-2. Diagrams of saturated and unsaturated bonds.................................................. 6

Figure 2-3. Diagram of cis- and trans fatty acids............................................................... 7

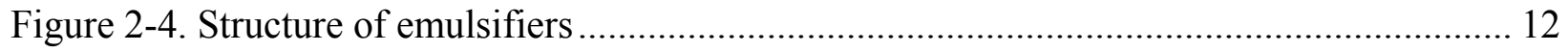

Figure 4-1. RSM plots for first day firmness. GMS= 1.0 ............................................ 27

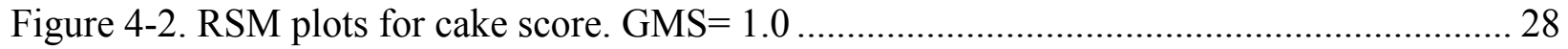

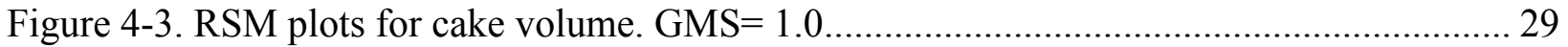

Figure 4-5. Cake batter specific gravity for different emulsifier combinations ....................... 32

Figure 4-6. Cake volume with different emulsifier combinations .......................................... 34

Figure 4-7. Cake volume VS. batter specific gravity .......................................................... 35

Figure 4-8. Cake scores for different emulsifier combinations .......................................... 37

Figure 4-9. Cake firmness with different emulsifier combinations and storage time................. 39

Figure 4-10. Cake volume with cake firmness ....................................................................... 40

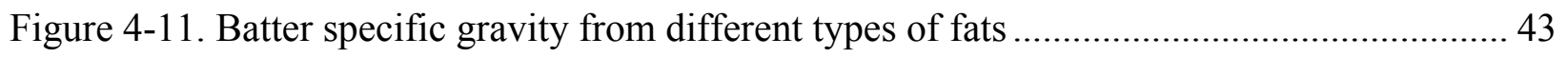

Figure 4-12. Batter viscosity from different types of fats................................................... 45

Figure 4-13. Cake volumes baked with different types of fats ............................................. 46

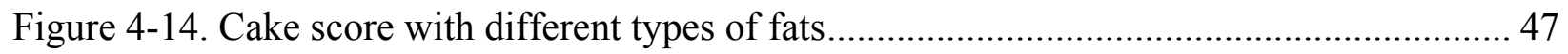

Figure 4-15. Cake crumb (a. plastic shortening; b. liquid oil; c. liquid shortening; d. liquid oil

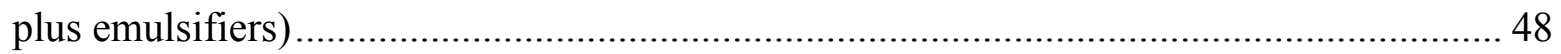

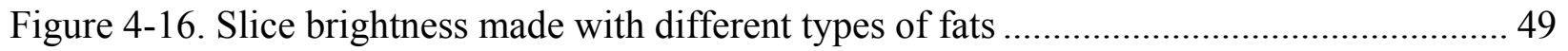

Figure 4-17. Cell wall thickness of cakes made with different types of fats ........................... 50

Figure 4-18. Number of cells in cakes made with different types of fats ............................... 51

Figure 4-19. Cell diameter in cakes made from different types of fats ................................... 52

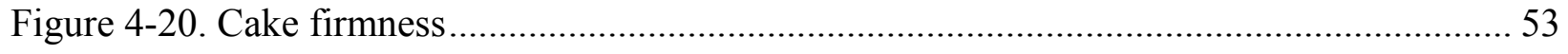




\section{List of Tables}

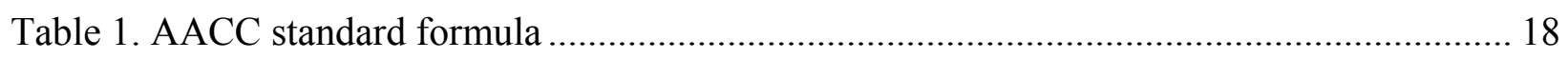

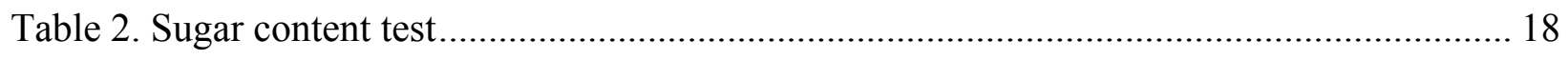

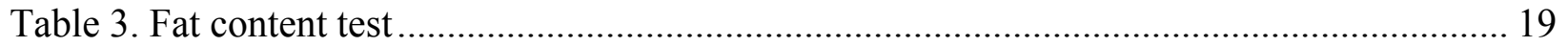

Table 4. Liquid shortening with different water content ..................................................... 20

Table 5. Plastic shortening with different water content .................................................... 20

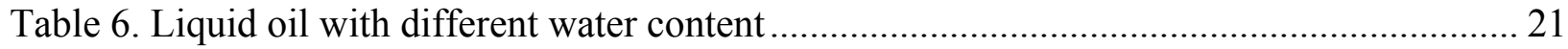

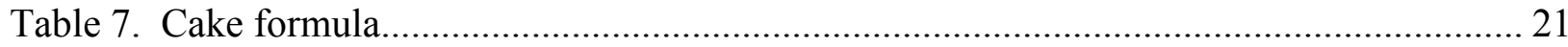

Table 8. Response Surface Methodology (RSM) design.................................................... 24

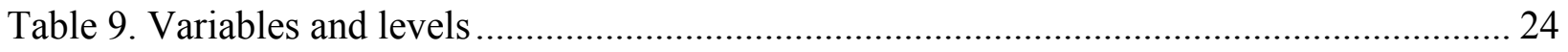

Table 10. Effect of different emulsifier combinations on cake quality ................................... 26

Table 11. Cake properties baked for different types of fats................................................ 42

Table 12. Cake volume index with different types of fats .................................................... 46

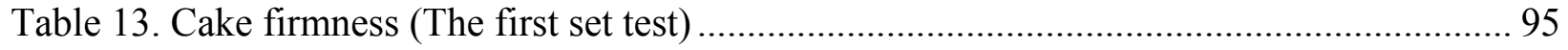

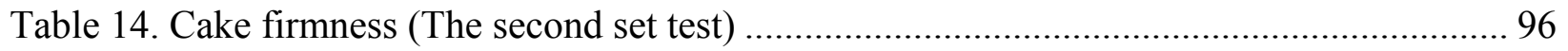

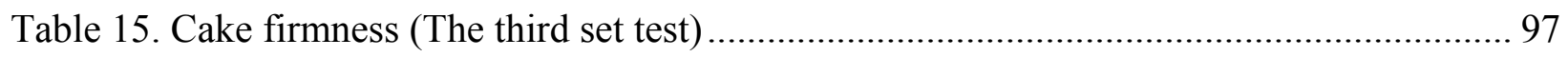

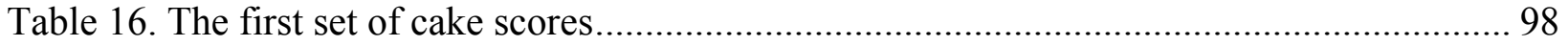

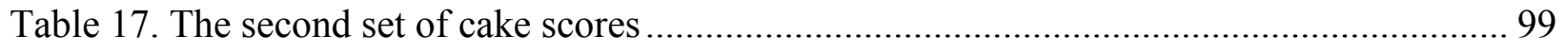

Table 18. The third set of cake scores............................................................................. 100 


\section{Acknowledgements}

I would like to thank following people:

Appreciation is given to Dr. Chuck Walker, my co-major advisor, for his patience, advice and guidance throughout the course of this study. He was and is always ready to help me both with my academics and my life in the USA.

And to Dr. Faubion, my co-major advisor, who is very knowledgeable and gave me a lot of good advice during my study. Appreciation also extended to Dr. Debi Rogers, my committee member, for her help and suggestions. Another thank-you is given to Mr. Dave Krishock. Dave was always nice to let me use the baking lab and ingredients, and he also gave me a lot of good suggestions for cake baking. Mr. Ron Stevenson, my friend, was always patient to talk to me and help me. Thanks to Dr. Becky miller who gave me a chance to work in the wheat quality lab; I learned a lot from her. Thank you Sue, Jane, and Camila; you were my best friends in this department, you helped me a lot in these two years, and we had so much fun together. Thank

you Shuping, for helping me to use the $\mathrm{C}$-cell and water activity machines. Last, I would like to thank my family in China and my husband. Without their love and support, I could not have finished my work. 


\section{CHAPTER 1 - INTRODUCTION}

Shortening is a major ingredient in high-ratio layer cakes, i.e., those in which there is more sugar than flour in the formula. Shortening performs three basic functions in high ratio cake production: (a) it entraps air during the creaming process to aid in the proper aeration or leavening of the batter and the finished cake; (b) it coats the protein and starch particles, thereby disrupting the continuity of the gluten and starch to provide tenderization and lubrication to the texture and mouth-feel; (c) it emulsifies large amounts of liquid thereby contributing to increased crumb moisture and softness in the product (Pyler, 1988).

Plastic shortenings are the type most commonly used in the U.S. baking industry. They can be used in most types of cakes. In the USA, plastic shortening is often made from partially hydrogenated soybean oil. However, the consumption of trans- fats formed during hydrogenation increases the risk of coronary heart disease by raising the levels of LDL bad cholesterol and lowering levels of HDL good cholesterol (Juttelstad, 2004). With more and more people concerned about health problems and the FDA's finding that there is no safe level of trans fat consumption, many companies began to use palm oil instead of hydrogenated soybean oil to make zero-trans shortenings. Ironically, the high levels of saturated fatty acids in palm oil result in the same cardiovascular problem as trans fats do (List, 2004).

Liquid shortening has been developed for bulk handling and metering at room temperature. The designation "liquid" covers all fluid suspensions that consist of a small amount of hard fat, usually the beta-tending crystal form, and emulsifiers dispersed in liquid oil (O’Brien, 1998). Few publications have assessed the performance of liquid shortenings in cake baking systems. In general, liquid cake shortenings function much like solid shortening in baking systems, but they offer the user certain advantages. First, as a liquid shortening is a fluid- like material at room temperature, it is pumpable, which leads to great savings in labor cost. It is easier to handle and there are no boxes or liners to unpack or dispose of (McGill, 1973). Second, it has no trans fatty acids and much lower saturated fatty acids content.

Compared to plastic shortening, liquid shortening would significantly reduce the dependence on solid fats for their performance. Further, it is possible that additives, for example emulsifiers, could supplement the functionality previously performed solely by the fats and oils. 
Consequently, the overall objective of this research was to compare the influence of different types of oils and fats on the texture and stability of high ratio layer cakes. The expectation is that the results will expand the applications for liquid cake shortening in the baking industry.

The specific objectives of this research were: (a) compare the effects of different types of fats (plastic shortening, liquid cake shortening, and liquid oil) on the texture and other properties of high-ratio layer cakes; (b) determine the effects of those fats on cake texture and storage stability; (c) examine the abilities of different combinations of emulsifiers to contribute positively to cake texture and storage stability. 


\section{CHAPTER 2 - LITERATURE REVIEW}

\subsection{High-ratio layer cakes}

Cake has been defined as a semi-dry foam produced by the setting of a fluid medium that has been expanded by gas resulting from chemicals dissolved in the medium (Zelch, 2001). Starting with a few basic formulas, changes in the cake ingredients and/ or processing techniques have resulted in the development of many products having a wide range of characteristics. These can range from light angel food cakes to dense, rich, cheese cakes. Cakes can generally be classified into one of three categories: foam cakes, batter cakes, or chiffon cakes. The aeration properties of batter cakes are based on the shortening/ oil included in the formula. Batter cakes include two subdivisions: layer cake and pound cake, based on the forms of leavening that are used. Layer cake contains chemical leavening agents in the formula and pound cakes are leavened only by air incorporated and entrapped during the mixing process. The original pound cakes were so named because they were made with one pound each of sugar, flour, lard, and eggs. High ratio cakes are those in which the weight of the sugar is equal to or greater than that of the flour (Pyler, 1988 and Zelch, 2001).

Incorporating air into a cake batter can be accomplished by three methods: creaming mixing, single stage mixing, or continuous mixing. In the creaming mixing, shortening and sugar are mixed vigorously to incorporate air into the shortening; this is followed by the incorporation of the eggs, while the creaming action is continued. The last stage is mixing the milk and flour into the batter. In the single-stage method, all the ingredients are introduced into the mixing bowl at one time and mixed into a homogeneous mass. This method requires surfactants to facilitate air incorporation. In continuous mixing, the batter is homogenized and emulsified by a high speed rotor and aerated by the incorporation of pressurized air (Plyer, 1988 and Bath et al, 1992).

Cake quality is governed by three major factors: the suitability of the individual ingredients for the specific type of cake being made, a properly balanced formula, and the optimum mixing and baking procedures (Pyler, 1988). 
There are many publications about the functionality of various layer cake components (Howard, 1972; Johnson and Hoseney, 1979; Brooker, 1993; Donelson, et al 2000; Zelch, 2001). In general, cake ingredients may be classified as tougheners, tenderizers, moisteners, or driers. In order to make a satisfactory cake, tougheners and tenderizers must be properly balanced (Pyler, 1988; Mizukoshi, 1985). Flour is classed as a structure builder as it is involved in establishing the crumb structure of most types of cake and is considered a toughener. Chlorination is generally used on those soft wheat flours that are intended for cake production in order to produce better cakes. The functional effect of chlorination is on the flour starch, partially de-polymerizing and oxidizing it (Pyler, 1988). Oxidized starch granules are able to swell more rapidly after the starch reaches the gelatinization temperature and the resulting batter system will be sufficiently viscous to support the cake's structure without collapsing (Pyler, 1988). Kissell and Yamazaki (1979) tested the effect of 14 different levels of chlorination on baking performance. They found batter expansion was greater for treated flours, even at the lowest chlorination rate, than for untreated flour. Due to safety concerns, a number of researchers including Donelson et al (2000) have tried to replace chlorine treatment of cake flour. They found that replacement of non-chlorine-treated flour with up to $43 \%$ starch produced a pasting curve with curve areas that were equivalent to those produced by chlorine-treated flours. Increasing the concentration of dried egg albumen plus adding soya lecithin and xanthan gum produced a new basic ingredient set capable of producing cakes of very similar cake quality to those produced using chlorinated flour (Donelson et al, 2000).

Johnson and Hoseney (1979) measured the effect of different cake ingredients on the baking properties of chlorine-treated and untreated flours. They found that untreated cake flours gave lower volumes as the shortening content in the formula increased. Egg whites improved both the volume and grain of cakes baked from untreated flour, but did not materially improve the baking properties of chlorine-treated flours. Whole eggs affected the baking properties of untreated flour but did not significantly affect the baking properties of chlorine-treated flours. Wheat or corn starch improved cake volume but did not improve cake grain.

Although much research has been conducted on the staling of bread, little has been reported on the problem of the staling of cakes (Hodge, 1977; Walker et al, 1988; Lahtinen et al, 1998 and Gelinas et al, 1999). Hodge (1977) found a rapid increase in crumb firmness during the first few hours after baking and that the crumb continues to firm at a reduced rate in storage 
even in the absence of any moisture loss. Walker et al (1988) found that the firmness testing method approved for bread is also applicable to cakes and can be used to differentiate cakes of different formulations and ages. Staling is much slower in cake than in breads, partly because cakes contain more fat and less flour. Therefore, lower concentrations of starch might slow the staling rates. Lahtinen et al (1998) studied the factors affecting cake firmness and cake moisture content by Response Surface Methodology. They found that cake firmness increased notably with increasing initial fat temperature; increasing the mass ratio of fat to sucrose ( $\mathrm{F} / \mathrm{S}$ ratio) increased cake firmness at each of the fat temperatures. Mixing time and size of sucrose granules either did not affect cake firmness and cake moisture or their influence on them was weak.

\subsection{Fats and Oils}

Fats and oils are principal and essential constituents of the human diet. Fats and oils are major energy sources, supplying 9 calories per gram, as compared with 4 calories per gram for

protein and carbohydrates. They also enhance many foods by providing texture, mouth feel, and imparting or covering flavor.

\subsubsection{Structure and properties}

The fats and oils of commerce are mixtures of lipids. They are comprised mainly of triacylglycerols (commonly referred to as triglycerides) accompanied by lower levels of diacylglycerols (diglycerides), monoacylglycerols (monoglycerides) and free fatty acids, and with other minor components such as sterols, triterpene alcohols, tocols, hydrocarbons, and the fat soluble vitamins (Gunstone, 1999). 


\section{Figure 2-1. Diagram of triglycerides}<smiles></smiles>

(Adapted from Anon, 2006)

A triglyceride (Figure 2-1) consists of three fatty acids attached to one glycerol molecule. The three fatty acids can be identical or different. The fatty acids in a triglyceride define its properties and characteristics. They are classified by their degree of saturation. Saturated fatty acids contain only single carbon-to-carbon bonds. The melting point of fatty acids increases with chain length. Unsaturated fatty acids (Figure 2-2) contain one or more double carbon-tocarbon bonds. Oleic acid (cis-9- octadecenoic acid) is the unsaturated fatty acid that occurs most frequently in nature. Polyunsaturated fatty acids, for example, Linoleic and Linolenic, are the most important polyunsaturated fatty acids as they are essential fatty acids, required by humans but not synthesized by the body, and therefore must be obtained through the diet (Anon, 2006).

Figure 2-2. Diagrams of saturated and unsaturated bonds

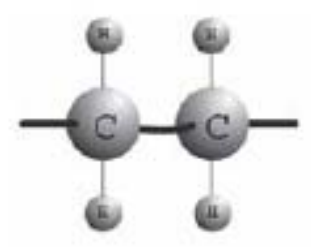

\section{Saturated Bond}

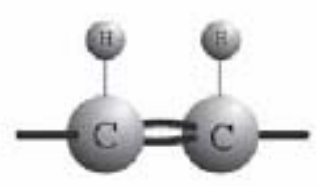

\section{Unsaturated Bond}

(Adapted from Anon, 2006) 


\subsubsection{Trans fatty acids}

Trans, in Latin, means "on opposite sides". In this context, it refers to the locations of hydrogen atoms attached to carbons involved in double bonds. A cis-fatty acid has two hydrogen atoms that attached to carbons in double bonds on the same side. The principal transfatty acid source in the U.S. is partially hydrogenated fats used as food ingredients, such as plastic shortening and deep-frying oil. However, small amounts of trans fats also occur naturally in foods such as milk, butter, cheese, beef, and tallow (2-5\%) as a result of biohydrogenation in ruminant animals (List, 2004).

Trans- fatty acids have a very different biological function than do the "cis" fatty acids. Some research (Moon et al, 2009; Bhattacharya et al, 2006; Juttelstad, 2004; Ramli, et al, 2008) showed that trans fatty acids could raise the bad (LDL) cholesterol, lower the good blood lipids (HDL), and increased the risk of heart disease. On July 2003, the U.S. Food and Drug Administration published final rules that required trans acid content to be included on food labels by January 1, 2006 (List, 2004). Consequently, food companies have had to change their formulas to reduce the trans fat contents in their food products.

\section{Figure 2-3. Diagram of cis- and trans fatty acids}
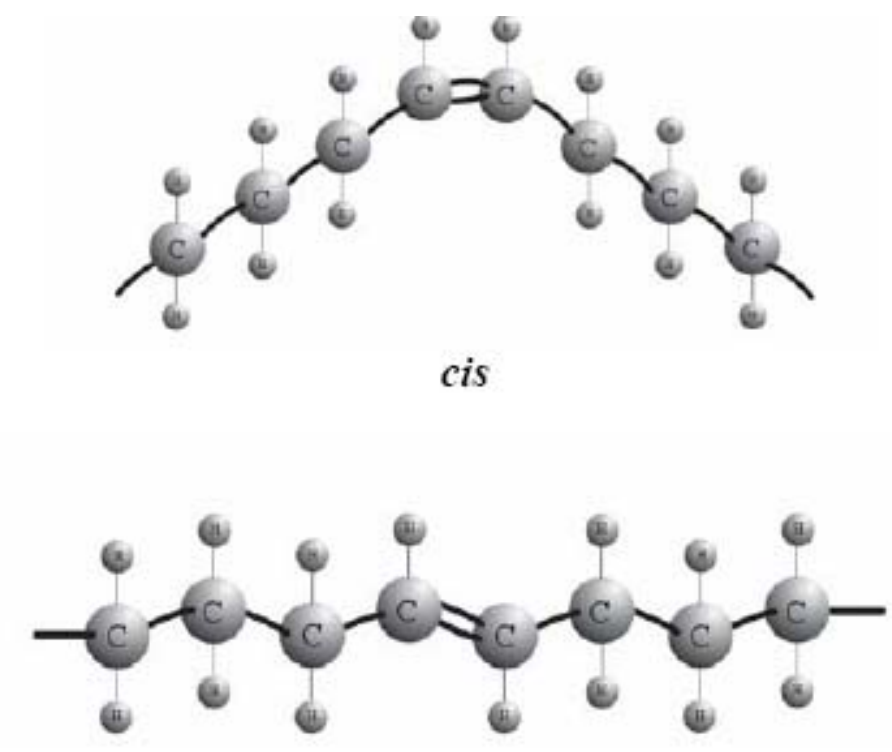

Trans

(Adapted from Anon, 2006) 


\subsubsection{Shortenings}

\section{Crystal structure}

The application of fats in bakery products depends on their fats' crystallization and melting properties. The crystal structure of a shortening is determined by source oil composition, processing, and tempering. Fatty acid triglycerides are polymorphic, exhibiting four crystal forms as follows: Alpha form $(\alpha)$, Beta prime form $\left(\beta^{\prime}\right)$, intermediate, and Beta form (ß) (Birnbaum 1978). Crystal melting points increase from the alpha to the beta form. Crystals in the alpha form are fragile, small (about 5 microns in size), and are readily transformed to higher melting forms. Beta-prime crystal forms are up to 1 micron in length, delicate, needlelike shapes that can pack together to dense fine-grained structures. Beta crystal forms are on average 25-50 microns in length and can grow to over 100 microns. They have the highest melting point and they are large and coarse. Intermediate crystal forms may exist in a mixture of several different crystals forms (O’Brien, 1998). Upon rapid cooling, melted fat crystallizes in the alpha form, which is the least stable type. This transitory crystalline phase undergoes an irreversible transformation from alpha to beta prime to intermediate to beta. Of these four forms, Beta prime is the most suitable for cake making (Birnbaum, 1978 and Gunstone, 1999).

The crystal form of the solidified fat product has a major influence upon its textural properties (Heertje and Leunis 1997). Fats in the stable ß' form appear smooth, provide good aeration, and have excellent creaming properties. On the other hand, the $\beta$ form crystal shortening is waxy and grainy and provides poor aeration. Consequently in cake baking, the $\beta^{\prime}$ crystal is preferred (Gunstone, 1999).

Berger et al. (1979) found that air bubbles in creamed batters were entirely within the fat phase and that their surface was lined with oil which was stabilized by an underlying layer of packed fat crystals. The small $\beta$ ' crystals could arrange themselves around the interface of small bubbles more easily than could the larger $\beta$ polymorph, and could incorporate air very well. Brooker (1993) showed the role of fat crystals in the stabilization of air bubbles in cake batters. Specifically the adsorption of fat crystals helps to stabilize large numbers of small bubbles, which must expand without rupturing during baking if the batter is not to collapse. This model also explains why oils cannot produce the same degree of cake aeration as the same weight of crystalline fats. 


\section{Plastic shortening}

The term "Shortening" comes from shortens. Fat tenderizes (shortens the texture of) baked goods by preventing cohesion of gluten strands during mixing and baking (O'Brien, 1998). Plastic shortenings are composed of a solid phase of fat crystals intimately mixed with a liquid phase of fluid oil. They are semi-solid in room temperature.

Shortenings are a very important ingredient in the baking industry because they can comprise up to $30 \%$ of baked products' composition. They contribute to baked products in a number of ways, such as imparting shortness, richness, and tenderness, improving flavor and eating characteristics, providing flakiness, providing lubrication, retarding staling, and providing structure for icing and fillings (O’Brien, 1998).

The role of shortening in the cake baking process has been described as the aeration of batters for the incorporation of air into the plastic shortening phase during batter-mixing. Photographs of batters show the air cells to be associated with fat. The stability of these cells during mixing and in the early stages of baking is, therefore, associated with certain characteristics of the shortening (Wootton et al, 1967).

Shortening and oils serve a variety of functions in the processing of batter cakes. Their main function is as a tenderizer, in that they provide lubrication and a crumb softening effect. Shortenings also aid in the aeration process during leavening. During mixing, fat crystals become coated with an interfacial layer of adsorbed protein (crystal-water interface). An oil-inwater emulsion is thus formed, with the fat being well distributed. These irregularly shaped fat regions contain the nucleating or initial air cells (Zelch, 2001). During baking, the fat crystals melt and the oil exposed over the internal surface of the cells, providing an extra interface during its expansion. This activity combined with the effect of moisture vapor expansion, and the $\mathrm{CO}_{2}$ from leavening causes the cake to rise.

Most cake shortenings contain emulsifiers. These assist in maintaining the oil-in-water emulsion that is necessary for processing cakes.

\section{Liquid shortenings}

Liquid shortenings are distinguished from liquid oils by their compositions and properties. Both are pourable, but liquid oils are clear while liquid shortenings are opaque due to 
their suspended solids. Liquid shortening has been defined as "a stable dispersion of crystalline solids in a liquid oil matrix that is fluid and pumpable at room temperature" (Pyler, 1988). The liquid oil phase may or may not be hydrogenated, depending on the finished product's consistency and oxidative stability requirement. Low -IV (Iodine value is defined as the grams of iodine that can add to 100 gram fat or oil, which measures the fat saturation degree) $\beta$ crystal hard fats are used as seeds for crystallization. Their concentration in liquid shortening varies from $1 \%$ or higher to usually no more than $10 \%$. $\beta$ crystal hard fats are used for liquid shortening products to convert the whole system to a stable crystal form so that the liquid phase and solid phase will not separate. For use in cakes, liquid shortenings require balanced emulsifier systems, generally consisting of several components. They also must contain a minimum of about $10 \%$ of either solid emulsifiers or crystalline triglycerides (O'Brien, 1996).

Even with the addition of emulsifiers and antioxidants, the crystal form and saturation levels of the base oils are still important. Emulsifiers have significantly reduced the dependence on solid fats solely for their performance. This, in turn, led to the development and introduction of liquid shortenings for use in both yeast-raised and chemically-leavened baked products. Liquid shortenings combine the highly functional characteristics exhibited by plastic shortening with the bulk handling characteristics of liquid oil. A liquid shortening is a stable dispersion of solids with proper polymorphic form in a continuous oil phase that is both flowable and pumpable over a temperature range of 60 to $90^{\circ} \mathrm{F}$ (O’Brien, 1998).

Liquid shortenings are dependent upon a balanced emulsifier system and are designed to provide most of the functionality necessary for cakes. Therefore, different combinations of emulsifiers will have significant effects on the performance of liquid shortening. A variety of emulsifiers, including glyceryl lacto esters, propylene glycol monoester, and mono-and diglycerides etc. could provide aeration, tenderizing, and moisture retention properties to liquid shortening (O’Brien, 1998).

The processing of liquid shortening is much different from that of plastic shortening. Liquid shortenings need a special crystallization process. Many different crystallization procedures for liquid shortenings have been patented. The most popular crystallization procedure is "gradual cooling of melted product to form large $\beta$ crystals with gentle agitation. This procedure normally requires 3-4 days elapsed time." (O’Brien, 1996). The other procedures still in use include: gradual cooling followed by comminution with a homogenizer or colloid 
mill; rapid cooling with a swept-surface heat exchanger followed by a holding period of at least 16 hours with gentle agitation; suspension of finely ground hard fat or emulsifier in a cooling liquid oil with subsequent comminution using a homogenizer, colloid mill or shear pump.

McGill (1973) discussed the advantages and economy of liquid shortening. Liquid shortenings are easy to handle and there are no boxes or liners to unpack or dispose of. There is a saving in labor. However, their distribution cost is higher than that of plastic products because they must be held at a constant temperature. Storage temperatures are critical with liquid shortenings. Storage below $65^{\circ} \mathrm{F}$ will cause the liquid shortening to solidify and lose pumpability. Storage above $95^{\circ} \mathrm{F}$ will cause melting or partial melting of the suspended solids. None of the damage caused by temperature changes can be reversed (O'Brien, 1996). Because of their very high content of liquid oil, the trans- and saturated fatty acid contents are much lower than those of normal plastic shortening. This can help the baked products meet the FDA's transfree requirement (Anon, 2007).

\subsection{Emulsifiers}

A "surfactant" is a surface active agent. The term is applied to "molecules that migrate to interfaces between two physical phases, and thus are more concentrated in the interfacial region than in the bulk solution phase" (Stauffer, 1990). The key molecular characteristic of a surfactant is that it is amphiphilic in nature, the lipophilic (or hydrophobic) part of the molecule preferring to be in a lipid (nonpolar) environment, and the hydrophilic part preferring to be in an aqueous (polar) environment.

Emulsifiers, a subset of surfactants, are commonly used in many food products. The bakery industry is the largest user of food emulsifiers (Schuster and Adams, 1984). Emulsifiers are made up of molecules that have a non-polar (fatty acid) end, which carries no charge and has an affinity for oil, and a polar (glycerol) end, which carries a charge and has an affinity for water. Such a molecule can situate itself at the interface between oil and water. The polar end will immerse itself in the aqueous phase and the non-polar end will immerse itself in the lipid phase and prevent coalescence of the oil droplets. This helps the two phases to stay intimately mixed and form a stable emulsion (Schuster and Adams, 1984). 
Figure 2-4. Structure of emulsifiers

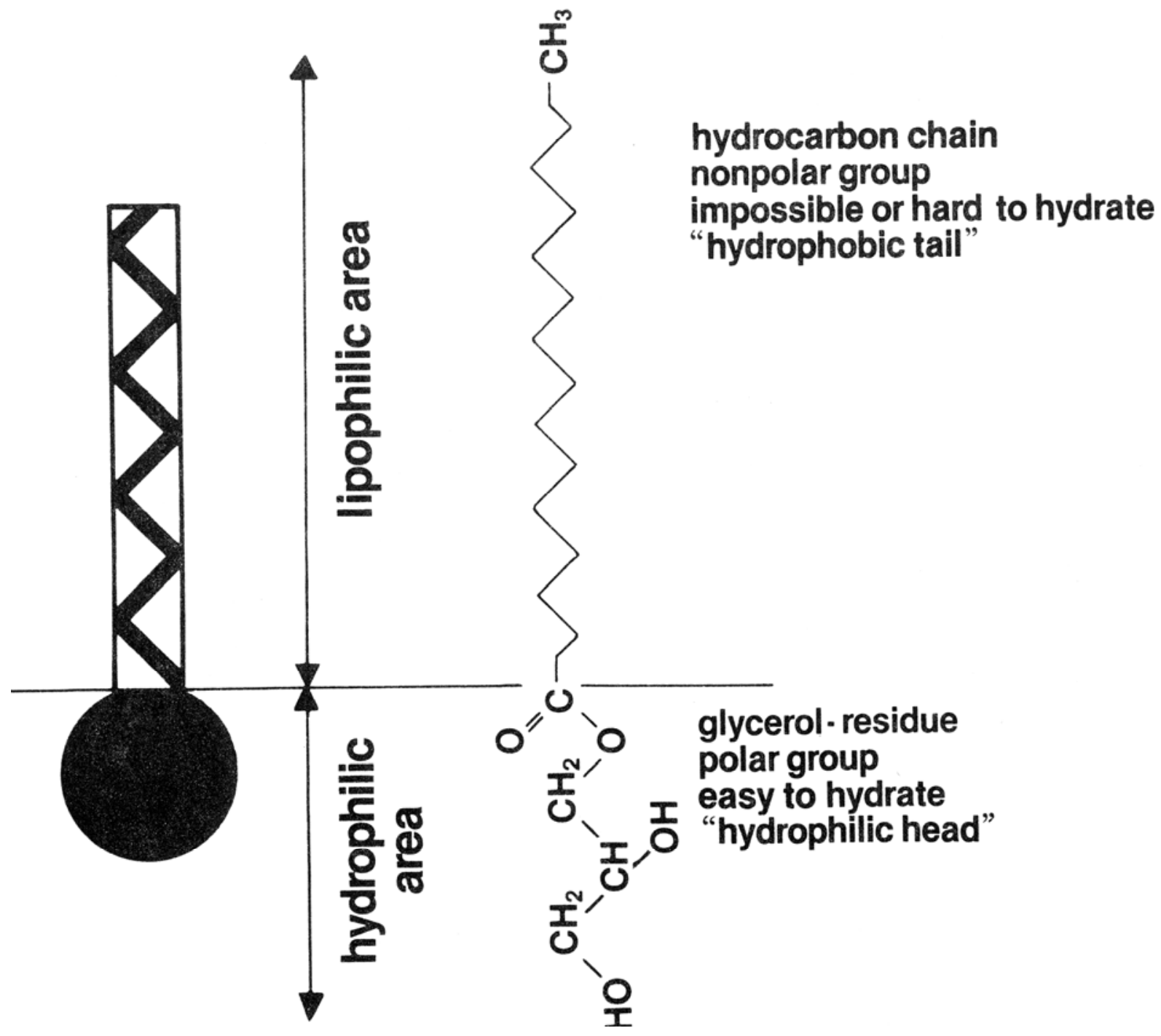

(Adapted from Schuster and Adams, 1984)

\subsubsection{Classification}

There are several methods for classification of emulsifiers, such as the charge of the hydrophilic groups in water, the lipophilic groups, the solubility in various substances, the ratio of hydrophilic to lipophilic groups, the crystal form, and the arrangement of the emulsifier molecule during interaction with water (Del Vecchio, 1975; Schuster and Adams, 1984). One of the best-known criteria is classification by HLB. HLB stands for hydrophilic-lipophilic balance 
and theoretically relates the ratio of the molecular weight of the hydrophilic portion of the surfactant molecule to the total molecular weight. The range set for HLB is 0-20. This scale indicates attraction to either oil or water. Emulsifiers that are predominantly lipophilic will have low HLB values and tend to form water-in-oil emulsions. The neutral point between lipophilic and hydrophilic properties in this HLB scale is 10 . While this system has some drawbacks, HLB does offer a starting point for emulsifier selection in products such as cakes where emulsification is important (Duxbury, 1992a).

\subsubsection{Emulsifier functions}

\section{Emulsification:}

One of the main properties of emulsifiers is the stabilization of emulsions by reducing the surface tension at the interface between immiscible liquids or phases (Schuster and Adams, 1984). Cake batter is an oil-in-water emulsion, with shortening or oil as the dispersed phase and water as the continuous phase (Pohl, 1968). An emulsifier reduces the interfacial tension between oil and water and, therefore, facilitates the disruption of emulsion droplets during homogenization. The emulsifier adsorbs on the surfaces of emulsion droplets to form a protective coating that prevents the droplets from aggregating with each other. The integrity of the foam walls, formed by proteins, determines cake volume and uniform appearance (Brooker, 1993). Shortening is an antifoam agent that tends to disrupt the foam cells. Emulsifiers coat the fat particles' exterior surface, providing protection to the protein film cell walls and eliminating film disruption. Because of this protection, bakers can incorporate shortenings (or vegetable oils) in their formulation (Wootton et al., 1967; Rusch, 1981).

\section{Crumb softening:}

Emulsifiers were first used in bread to extend shelf life, i.e., to retard staling. The mechanisms behind this include the formation of a starch-emulsifier complex on the surface of the starch granule, stabilizing the granule, and retarding water penetration and swelling, as temperature is raised. The complex also reduces the percentage of starch solubilized or dissolved, mainly by retarding recrystallization of the amylose fraction (Matz, 1987; Stauffer, 1990). The amylose in a dough containing an emulsifier coils is like a piece of twine wrapped 
around a nail. The result is that less amylose is free to bind with itself to form the rigid gel (Rusch, 1981). Stauffer (1999) mentioned that starch could form a helical structure, a hollow cylinder that has a hydrophilic outer surface and a hydrophobic inner surface. The straight chain alkyl molecules of emulsifiers such as glycol monostearate (GMS) could fit into the helix and form a starch-emulsifier complex. Some of the practical implications of this behavior follow. Some emulsifiers like GMS, affect starch gelatinization and leavener distribution in a cake system during baking, assuring that rising takes place longer in the outer edges, giving a more symmetrical cake, with homogeneous grain, softer crumb and extended shelf life (Gorton, 1977).

\section{Aeration/foam stability:}

Cake batter is an aerated emulsion. The integrity of the air cells determines cake volume and uniformity. Emulsifiers coat the exterior of the fat particles protecting the integrity of the air cell (Wooten et al., 1967). In addition, emulsifiers increase the amount of air that can be whipped into the batter by decreasing the surface tension of the aqueous phase, thereby increasing the whipping rate of batters (Rusch, 1981). Carbon dioxide gas, a leavener, can not spontaneously create bubbles in cake batters. Rather, it diffuses into and fills the existing air cells, expanding the cake batter. By adding emulsifiers, more uniform sized air cells are generated during mixing and these act as nucleation sites for the dissolved gas. The result is a cake with improved grain, more even cell structure, and increased volume (Handleman, 1961). The emulsifiers adsorb on the surfaces of emulsion droplets to form a protective coating that prevents the droplets from aggregating, and thus stabilize the foam (Sakiyan et al, 2004).

\section{Crystal modification:}

The emulsifiers used in food systems are fat derivatives, because their lipophilic parts are fatty acids. Fats (fatty acid triglycerides) are polymorphic. Emulsifiers exhibit varying degrees of similarity to triglycerides and, thus, varying degrees of polymorphism. The crystal form and crystal size of emulsifiers play important roles in their functionality and improving effect (Wootton et al., 1967; Howard, 1972; Schuster and Adams, 1984). For many applications, the alpha or alpha-tending forms of emulsifiers exhibit particularly advantageous effects, e.g., increased emulsifying activity, easier dispersibility, and improved aerating properties, all because of their crystal modification capabilities. The fat crystal transition (from crystal form $\alpha$ transfer to $\beta$ ' and finally transfer to $\beta$ ) could be retarded by the incorporation of emulsifiers to 
stabilize the crystal form in the more active alpha or beta prime form, resulting in improved functionality (O'Brien, 1998). That result makes it possible for liquid shortenings to be used in cake-making. Richardson et al. (2002) noted that in the cake batter, all the $\alpha$-gel ( $\alpha$-tending emulsifiers melted with water and liquid oil) emulsifiers decreased batter density, thus increasing the incorporation of air and cake volume. The ß-crystalline emulsifier did not have any effect on the density.

\subsubsection{Emulsifier combinations}

Each individual emulsifier has specific properties, but in food systems, emulsifiers may be required to perform several functions at the same time. Therefore, combinations of emulsifiers are very important for development of food formulations, and in fact are commonly used. It is well known that combinations of emulsifiers have synergistic effects, improving on their individual properties (Schuster and Adams 1984; Del Vecchio 1975). Different mechanisms have been proposed to explain the synergistic effects of emulsifier combinations. One is that the fat surface, if it is an oil/water emulsion, is covered better by a combination of various emulsifiers with different structures, forming a better protective layer with fewer gaps (Gonzalez-Juarez 1994). Lee and Hoseney (1982a) studied the single-stage cake mix and found that even though a lot of emulsifiers can form $\alpha$-gels, interfacial viscoelastic properties are often improved by blending two emulsifiers in specific proportions.

Although many types of emulsifiers can function effectively in cakes, several are predominant because of their cost and their excellent performance. In cakes, the most commonly used emulsifier is PGMS at $10-15 \%$ of shortening weight, and incorporated into the shortening (Rusch, 1981). The behavior of cake crumb softening involves retention of moisture, efficiency of shortening action, and starch complexing. The starch-complexing phenomenon in cakes is the same as it is in breads (Rusch, 1981). Distilled monoglyceride (GMS) is the primary antistaling additive used today for baking foods (Stauffer, 1999). It is very common to compound monoglycerides with other $\alpha$-tending surfactants such as PGMS for use in cake making (Birnhaum, 1978).

Lecithin has been used in bread and other baked goods for a long time. It can delay staling and reduce the amount of shortening required. A synergistic effect on baked goods volume and crumb grain occurs between lecithin and monoglycerides (Orthoefer, 2008). A cake 
emulsifier system is usually a blend of two or three emulsifiers such as GMS, PGMS, and Lecithin (Orthoefer, 2008).

The patent WO 03/079802 (Rajiv et al, 2003) discussed a shortening-based emulsifying formulation for the preparation of cakes. The emulsifier combination of distilled glycerol monostearate (GMS), sodium stearoyl-2-lactylate (SSL), sorbitan monostearate (SMS), poly glycerol monostearate (PGMS), and polysorbate (PS-60) was claimed to produce lower specific gravity, higher cake volume, and more uniform cake cells than using individual emulsifiers.

Duxbury (1992b) suggested that combinations of emulsifiers including lecithin, monoand diglycerides, polyglycerol esters, polyoxyethylene sorbitan esters, propylene glycol monoesters, and glycerolacto palmitate might work synergistically to yield a cake with improved eating quality. In his research, four cake mixes were prepared and baked with different shortening/emulsifier systems. One contained a regular commercial shortening, one contained $73 \%$ soybean oil-based powdered vegetable shortening, one contained $73 \%$ shortening with a blend of mono-and diglycerides, and one contained liquid oil with propylene glycol esters and mono- and diglycerides. Results showed that the last combination had the closest, most even texture, and the greatest volume (Duxbury, 1992b). The results also indicated that propylene glycol esters and mono-and diglycerides work synergistically to produce better cakes than does adding them separately. Liquid oil with propylene glycol esters and mono- and diglycerides worked better than did plastic shortening in cakes.

In Lee and Hoseney's (1982b) research, 4.0\% propylene glycol monostearate (PGMS), $3.0 \%$ mono- and diglycerides, and $0.81 \%$ lecithin were used in the formula. More results showed that the combinations were more effective than the single components.

Gonzalez-Juarez (1994) studied several different emulsifiers used in the cakes. He had tested PGMS at 1.0\%, 2.0\% and 3.0\% (flour weight basis) levels and GMS at 1.0\%, 1.5\% and $2.0 \%$ levels. For PGMS, it was found that between $1.0 \%$ to $1.5 \%$ (flour weight basis) was the optimum when combined with PS-60. GMS at 1.0\% produced cakes with highest volume, but when the GMS level increased, cake volume decreased. 


\section{CHAPTER 3 - MATERIALS AND METHODS}

\subsection{Materials}

Flour: Purasnow ${ }^{\circledR}$ Bakers Hi-ratio cake flour from General Mills (Minneapolis, MN). (Protein content $9.12 \%$, ash $0.46 \%$, moisture $13.81 \%$ and $\mathrm{pH} 4.6$ )

Liquid Shortening: NUTEX Z® high ratio liquid cake shortening from ACH Food companies (Memphis, TN). This product was made from soybean oil with Mono- and Diglycerides, Propylene Glycol Mono- and Diesters of Fatty acids, and Glyceryl-Lacto Esters of Fatty acids.

Plastic Cake shortening: HYMO® emulsified vegetable shortening from ACH Food companies (Memphis, TN). This product was made from palm oil, with Mono- and Diglycerides.

Liquid oil: Soybean oil from Cargill (Minneapolis, MS). Citric acid was added to protect freshness.

Baking Powder: AB Mauri Double-acting baking powder from Fleischmann's Yeast Company. (Ingredients: sodium acid pyrophosphate, sodium bicarbonate, corn starch, monocalcium phosphate) (Chesterfield, MO).

Dry Whole Eggs: dried whole eggs from Michael Foods (Minnetonka, MN). It was a spray dried, pasteurized whole egg product.

Salt: Purex ${ }^{\circledR}$ salt from the Hutchinson, KS plant.

Sorbic Acid: from Fleischmann's Yeast company (Chesterfield, MO).

Lecithin: Yelkin ${ }^{\circledR}$ soy lecithin from ADM (Decatur, IL).

Distilled glycerol Monostearate (GMS): DIMODAN® HP K-A from Danisco (Kansas City, KS). Total monoglyceride content was over $90 \%$ and melting point of this monoglyceride was about $64^{\circ} \mathrm{C}$.

Propylene glycol monostearate (PGMS): Stepan ${ }^{\circledR}$ PGMS from Stepan company (Northfield, IL). It contained 45-60\% propylene glycol monosterate and 40-55\% propylene glycol disterate. Propylene glycol content was less than $1.5 \%$.

\subsection{Methods}




\subsubsection{High Ratio Yellow Cake Formulation}

\section{Modification of standard AACC formula}

The basic cake formula was based on AACC method 10-90 (AACC, 1999). In order to meet the requirements for our study, i.e., produce acceptable cakes, we found it necessary to modify the AACC method slightly. This included a series of preliminary experiments to adjust the ingredient ratios and procedures.

Table 1. AACC standard formula

\begin{tabular}{|c|c|}
\hline Ingredients & Flour Weight Basis (\%) \\
\hline Flour & 100 \\
\hline Sugar & 140 \\
\hline Shortening & 50 \\
\hline NFDM & 12 \\
\hline Dried Egg Whites & 9 \\
\hline Salt & 3 \\
\hline Baking Powder & 6 \\
\hline Water & 125,135 or 145 \\
\hline
\end{tabular}

\section{Sugar content}

The standard formula is used for evaluating the cake-baking potential of a flour. Its sugar content is higher than in a common commercial formula. Consequently, it was necessary to try different sugar contents for our flour in order to get high quality cakes. Plastic shortening was used for these tests.

\section{Table 2. Sugar content test}

\begin{tabular}{|c|c|c|c|}
\hline Sugar & $130 \%$ & $130 \%$ & $120 \%$ \\
\hline Cake volume $^{2}$ & 110 & 117 & 123 \\
\hline Cake texture & tender, surface sticky & tender & Slightly dry \\
\hline
\end{tabular}

'Flour weight basis; ${ }^{2}$ Cake volumes were measured by plastic template according to AACC10-91

Comparing cake textures, $130 \%$ was chosen as the sugar content for the subsequent tests. 


\section{Egg}

The AACC standard formula is for a high-ratio white layer cake. However, the high-ratio yellow layer cake formula is more common in the market place and we wanted our study to more closely follow commercial baking practice. Consequently, dried whole eggs were used instead of dried egg whites in the formula. The ratio of whole eggs was increased to $15 \%$ (flour weight) because soluble protein (egg white) is known to be the key aerating ingredient (Howard, 1972) and this change maintains the same amount of egg whites in the formula.

\section{Fat content}

Fat is an important ingredient in this study. The intent was tried to keep fat contents as high as possible in the formula in order to see functional differences in the fats. Plastic shortening was used in this test. Table 3 shows the cake volume and texture that resulted with different fat contents. It was found that reducing fat content by $10 \%$ caused the cakes' surfaces to no longer be sticky and to be easy to handle.

Table 3. Fat content test

\begin{tabular}{|c|c|c|}
\hline Fat $^{1}$ & $50 \%$ & $40 \%$ \\
\hline Cake volume $^{2}$ & 116 & 121 \\
\hline Cake texture & tender, sticky, and fragile & tender \\
\hline
\end{tabular}

${ }^{1}$ Flour weight basis; ${ }^{2}$ Cake volume was measured by plastic template according to AACC10-91

\section{Mixing procedures}

The mixing procedure suggested in AACC method 10-90 is: scale all dry ingredients and sift well; put all the dry ingredients and shortening into the mixing bowl, add $60 \%$ of the water and mix at low speed for 30 seconds and scrape down; mix at medium speed for 4 minutes and scrape down; add 20\% water and mix at low speed for 30 seconds, scrape down; mix at medium speed for two minutes, scrape down; add remaining water, mix at low speed for 30 seconds, scrape down; mix at medium speed for two minutes.

Using this mixing sequence resulted in large air cells in the cake batter and cakes with high volume but tunneling in the crumb. Tests were carried out which reduced mixing time and consequently the amount of air incorporated into the batter. Changing the last mixing step from medium speed to low speed positively affected batter viscosity and dispersed the big air cells in the batter, resulting in cakes with improved crumb grain quality. 
A modified mixing procedure, using a paddle instead of a whip was adopted as follows: scale all dry ingredients and sift well; put all the dry ingredients and shortening or oil into the mixing bowl of a Hobart N-50 mixer, (a) mix at low speed for 2 min; add $60 \%$ of the water; (b) mix at low speed for 30 seconds and scrape down; (c) mix at medium speed for 4 minutes and scrape down; (d) add remaining water and mix at low speed for 30 seconds, scrape down; (e) mix at medium speed for two minutes, scrape down; (f) mix at low speed for one minute.

\section{Water absorption}

A series of water absorption tests were run to select the optimum for the final research tests. In this study, liquid oil, liquid shortening, and plastic shortening were tested in the highratio yellow cake formulas developed previously. Liquid shortening and plastic shortening contain emulsifiers and they have higher solid fat contents at room temperature than does liquid oil. Because liquid and plastic shortening held more water during mixing, it was necessary to test water absorption with different fats.

Liquid shortening:

\section{Table 4. Liquid shortening with different water content}

\begin{tabular}{|c|c|c|c|}
\hline Water $^{1}$ & $125 \%$ & $135 \%$ & $145 \%$ \\
\hline Cake volume $^{2}$ & 131 & 133 & 127 \\
\hline Cake texture & Uniform, tender & Uniform, tender & Gummy \\
\hline
\end{tabular}

${ }^{1}$ Flour weight basis; ${ }^{2}$ Cake volume was measured by plastic template according to AACC 10-91

Plastic shortening:

Table 5. Plastic shortening with different water content

\begin{tabular}{|c|c|c|c|}
\hline Water $^{1}$ & $125 \%$ & $135 \%$ & $145 \%$ \\
\hline Cake volume $^{2}$ & 117 & 123 & 123 \\
\hline Cake texture & Uniform, tender & Uniform, tender & Gummy \\
\hline
\end{tabular}

${ }^{1}$ Flour weight basis; ${ }^{2}$ Cake volume was measured by plastic template according to AACC10-91 
Liquid oil:

Table 6. Liquid oil with different water content

\begin{tabular}{|c|c|c|c|}
\hline Water $^{1}$ & $125 \%$ & $130 \%$ & $135 \%$ \\
\hline Cake volume $^{2}$ & 124 & 116 & 116 \\
\hline Cake texture & Coarse & Coarse, big holes & Coarse, big holes \\
\hline
\end{tabular}

${ }^{1}$ Flour weight basis; ${ }^{2}$ Cake volume was measured by plastic template according to AACC10-91

Based on all these tests, the final water absorptions were chosen as: liquid oil-125\%, liquid shortening-135\%, and plastic shortening-135\%. For the emulsifier combination tests, water absorption was set at $135 \%$ to allow comparison with liquid shortening.

The final cake formula used in this study was as follow:

Table 7. Cake formula

\begin{tabular}{|c|c|}
\hline Ingredients & Flour Weight Basis (\%) \\
\hline Flour & 100 \\
\hline Sugar & 130 \\
\hline Shortening & 40 \\
\hline NFDM & 12 \\
\hline Dried Whole Eggs & 15 \\
\hline Salt & 3 \\
\hline Baking Powder & 6 \\
\hline Water & 135 or 125 \\
\hline
\end{tabular}

\section{Final details}

Because the cakes needed to be stored for a long time to test firmness changes in this study, it was necessary to add sorbic acid $(0.15 \%$ batter wt.) to the batter as a preservative to retard mold growth. Batter temperature was controlled at $72-73^{\circ} \mathrm{F}\left(22.2-22.8^{\circ} \mathrm{C}\right)$ by controlling the water and room temperatures. Eight inch (inside diameters $20.3 \mathrm{~cm}$, depth $3.8 \mathrm{~cm}$ ) layer cake pans with cake bottom liner were used in the baking test. Each pan contained $400 \mathrm{~g}$ of batter. The reel over was used in this study. The oven temperature used was $350^{\circ} \mathrm{F}\left(177^{\circ} \mathrm{C}\right)$ and baking time was $25 \mathrm{~min}$. 
After baking, cakes were cooled for 30 minutes at room temperature, depanned, and dusted with cake flour. After cooling for 1 hour, cakes were packaged in double Ziploc plastic bags and stored at room temperature $\left(22-25^{\circ} \mathrm{C}\right)$.

\subsubsection{Cake analysis}

\section{Batter Specific Gravity}

Cake batter specific gravity was calculated by dividing the weight of the batter by the weight of an equal volume of water.

\section{Cake measurement}

Cake volume, symmetry, and contour were determined by AACC method 10-91 (AACC, 1999). Crumb (internal texture) was graded according to AACC method 10-90. Cells, grain, texture, crumb color, and flavor were scored on the next day after baking.

\section{Moisture content}

The cake moisture content was determined by the single-stage air-oven method (AACC 44-15A). The outer surfaces of the cake were removed and the crumb was used for analysis.

\section{Water activity}

Water activity was measured with a DECAGON (Decagon devices Inc., Pullman, WA) CX-1 water activity meter.

\section{Viscosity}

The cake batter viscosity was measured by using a Bostwick consistometer (Christison Particle Technologies Limited, Gateshead, UK). The batter was poured into the sample reservoir sufficient to reach the top of the product gate, and then released by pressing down on the lever arm. The batter was allowed to run along the trough for 30 seconds before measuring the distance traveled in $\mathrm{cm}$. The results were reported as distance per 30 seconds batter flow. Thus, higher values indicate lower viscosities. 


\section{Texture analysis}

Cake crumb firmness was measured using a Voland-Stevens texture analyzer (Voland Crop., Hawthorne, NY currently sold by Brookfield Engineering Laboratories Inc. Middleboro, MA). The cake was sliced in half across its diameter, and then a $25 \mathrm{~mm}$ wide longitudinal slice was taken from one of the halves. The measurements were taken at three different slice points (left, center, and right) with a one inch $(25.4 \mathrm{~mm})$ diameter cylinder probe. Operating conditions were at a crosshead speed of $2 \mathrm{~mm} / \mathrm{sec}$ and $10 \mathrm{~mm}$ penetration distance ( $40 \%$ compression) based on AACC method 74-09.

\section{C-cell analysis}

A cake was sliced in half across the diameter, and then a $25 \mathrm{~mm}$ wide longitudinal slice was taken from one of the halves. The slices were scanned in a C-cell instrument (Calibre Control Internal Ltd., WARRINGTON, UK) using the standard method for collecting images and the standard C-cell software for data analysis. Average crumb brightness, the number of cells, and cell diameter were calculated and recorded.

\subsection{Experimental design}

\section{Emulsifier combination tests}

Based on previous literature and preliminary tests, three emulsifiers (PGMS, GMS, and Lecithin) were selected for testing as combinations. In order to obtain the maximum information with a minimum number of experimental points, a three-way Response Surface Methodology (RSM) experimental design (Walker and Parkhurst, 1984) was used. Thirteen emulsifier combination tests (table 8) (including two replications) were run which covered the 27 possible combinations presented by utilizing the low, medium, and high levels of each emulsifier (table 9). The control cake used liquid oil without any emulsifiers and a water content of $125 \%$ (flour weight basis). The emulsifiers were scaled and heated with liquid oil and stirred uniformly until all the emulsifiers were melted. These emulsifiers and liquid oil were prepared the day before baking and stored at room temperature.

The results were analyzed and plotted by software, RSM plus (AEW consulting, version date: 1992) using the model, STD 3_VAR. 
Table 8. Response Surface Methodology (RSM) design

\begin{tabular}{|c|c|c|c|}
\hline & $X$ & $Y$ & $Z$ \\
\hline 1 & -1 & -1 & -1 \\
\hline 2 & 0 & -1 & 1 \\
\hline 3 & 1 & -1 & 0 \\
\hline 4 & -1 & 0 & 1 \\
\hline 5 & 0 & 0 & -1 \\
\hline 6 & 0 & 0 & 0 \\
\hline 7 & 0 & 0 & 1 \\
\hline 8 & 1 & 0 & -1 \\
\hline 9 & -1 & 1 & 0 \\
\hline 10 & 0 & 1 & -1 \\
\hline 11 & 1 & 1 & 1 \\
\hline 12 & 0 & 0 & 0 \\
\hline 13 & 0 & 0 & 0 \\
\hline
\end{tabular}

Table 9. Variables and levels

\begin{tabular}{|c|c|c|c|c|}
\hline & & $\mathrm{L}(-1)$ & $\mathrm{M}(0)$ & $\mathrm{H}(1)$ \\
\hline $\mathrm{X}$ & $\mathrm{PGMS}$ & 1 & 2 & 3 \\
\hline $\mathrm{Y}$ & GMS & 0.5 & 1 & 1.5 \\
\hline $\mathrm{Z}$ & Lecithin & 0 & 0.5 & 1 \\
\hline
\end{tabular}

The level is based on the flour weight.

\section{Cake storage tests}

Four groups of cakes were baked. The first group was the control that used plastic shortening. The second group used liquid oil only. The third group used liquid shortening and the fourth group used liquid oil plus combinations of emulsifiers. Eight cakes were baked for each group. Batter specific gravity, batter temperature, and viscosity were measured before baking. Cakes were packaged in double Ziploc bags after baking and stored at room temperature $\left(22-25^{\circ} \mathrm{C}\right)$. The cakes were scored including volume, symmetry, and contour on the second day. Moisture analysis, water activity, c-cell, and texture analysis were analyzed at the same time. Texture analysis (cake firmness) was run after 1 day, 5 days, 12 days, and 21 days storage. Triplicate batter tests were done in this research. One-way ANOVA was used to analyze the data. 


\section{CHAPTER 4 - RESULTS AND DISCUSSION}

\subsection{EMULSIFIER COMBINATION}

The emulsifier combination test was to determine which of the emulsifier combinations produced the best final cakes. The results for the 11 different combination tests are shown in Table 10. Based on comparisons with the plastic shortening, the criteria for the best cake combination were: cake score $80-100$, cake volume $>120$, one day firmness 150-200. Contour maps for two variable combinations were run, keeping the third as a stepping variable, and this was repeated for each variable in turn.

First, GMS was kept as a stepping variable, and three contour maps with PGMS and Lecithin were plotted (Figure 4-1, 4-2, 4-3). Figure 4-4 presents an example of how to determine the optimum point from the contour maps. In the GMS $1.0 \%$ map, the area between the firmness curve means cake first day firmness was 150-200; the area above the score curve means cake score was 80-100; the area under the volume curve means cake volume was over 120 . The intersection of these areas was the optimum area for obtaining acceptable cakes. The center of this area was picked as the optimum point and that optimum combination was: PGMS 1.8\%/GMS 1.0\%/Lecithin 0.78\% (Figure 4-4). In the GMS 1.5\% map, another optimum combination was found as; PGMS 2.85\%/GMS 1.5\%/Lecithin 0.85\% (Appendix A).

Second, PGMS was kept as a stepping variable, and three contour maps with GMS and Lecithin were plotted, for each of the response parameters described above. The optimum combinations shown were: PGMS 2\%/GMS 1.05\%/Lecithin 0.75\% and PGMS 3.0\%/GMS 1.4\%/Lecithin $0.375 \%$ (Appendix A).

Third, Lecithin was kept as the stepping variable, and three contour maps with PGMS and GMS were plotted, for each of the response parameters described above. The optimum combinations shown were: PGMS 2.3\%/GMS 1.2\%/Lecithin 0.5\% and PGMS1.5\%/GMS 1.075\%/Lecithin 1.0\% (Appendix A).

The different stepping variables identified a very similar combination (PGMS 2\%/GMS 1.05\%/Lecithin 0.75\%, PGMS 1.8\%/GMS 1.0\%/Lecithin 0.78\%, and PGMS1.5\%/GMS 1.075\%/Lecithin 1.0\%). So the best emulsifier combination was selected as: PGMS1.8\%/ GMS $1.0 \%$ / Lecithin $0.8 \%$. 
Table 10. Effect of different emulsifier combinations on cake quality

\begin{tabular}{|c|c|c|c|c|c|c|c|c|c|}
\hline & \multirow{2}{*}{$\begin{array}{c}\text { Specific Gravity } \\
(\mathrm{g} / \mathrm{ml})\end{array}$} & \multirow{2}{*}{$\begin{array}{l}\text { Batter temp. } \\
\quad\left({ }^{\circ} \mathrm{F}\right)\end{array}$} & \multirow{2}{*}{ cake volume } & \multirow{2}{*}{ cake score } & \multirow{2}{*}{$\begin{array}{c}\text { moisture content } \\
(\%)\end{array}$} & \multirow{2}{*}{ water activity } & \multicolumn{3}{|c|}{ Firmness } \\
\hline & & & & & & & 1st day & 5th day & 12thday \\
\hline Control & $0.988 \pm 0.009$ & $70.9 \pm 2.8$ & $120.7 \pm 7.2$ & $67 \pm 13.8$ & $28.42 \pm 1.25$ & $0.858 \pm 0.009$ & $323 \pm 28.5$ & $403.7 \pm 28.9$ & $448.3 \pm 18.8$ \\
\hline 1 & $1.025 \pm 0.048$ & $71.3 \pm 0.9$ & $112.3 \pm 1.5$ & $62.7 \pm 12.5$ & $29.67 \pm 0.86$ & $0.876 \pm 0.009$ & $361.7 \pm 89.6$ & $418 \pm 72.5$ & $442.3 \pm 64.8$ \\
\hline 2 & $0.893 \pm 0.01$ & $73.2 \pm 0.3$ & $122.3 \pm 2.5$ & $88 \pm 3$ & $29.79 \pm 1.13$ & $0.873 \pm 0.012$ & $230 \pm 7.5$ & $272 \pm 26.9$ & $312 \pm 38.7$ \\
\hline 3 & $0.789 \pm 0.012$ & $72.7 \pm 0.6$ & $117.3 \pm 3.5$ & $83.3 \pm 4.6$ & $29.94 \pm 0.86$ & $0.878 \pm 0.012$ & $211.3 \pm 32.7$ & $230.7 \pm 5.5$ & $266 \pm 43.5$ \\
\hline 4 & $0.91 \pm 0.085$ & $71.2 \pm 1.5$ & $121.7 \pm 4.0$ & $81 \pm 11.1$ & $29.54 \pm 1.15$ & $0.879 \pm 0.01$ & $228.3 \pm 39.2$ & $262.7 \pm 41.5$ & $299.7 \pm 54.1$ \\
\hline 5 & $0.826 \pm 0.09$ & $71.3 \pm 1.1$ & $120.0 \pm 6.2$ & $86.7 \pm 6.8$ & $31.35 \pm 0.36$ & $0.881 \pm 0.011$ & $185 \pm 39.5$ & $218 \pm 31.6$ & $238.3 \pm 52.5$ \\
\hline 6 & $0.787 \pm 0.012$ & $71.0 \pm 0.6$ & $118.7 \pm 7.4$ & $82.7 \pm 5.5$ & $29.98 \pm 0.82$ & $0.878 \pm 0.008$ & $212.3 \pm 32.7$ & $237.7 \pm 15.6$ & $273.3 \pm 69.4$ \\
\hline 7 & $0.806 \pm 0.023$ & $71.8 \pm 0.7$ & $125.0 \pm 1.4$ & $91.5 \pm 0.7$ & $30.21 \pm 0.71$ & $0.877 \pm 0.008$ & $174.7 \pm 11.5$ & $215.5 \pm 33.2$ & $235.5 \pm 0.7$ \\
\hline 8 & $0.803 \pm 0.022$ & $72.1 \pm 1.0$ & $117.7 \pm 4.7$ & $77.7 \pm 11.6$ & $28.92 \pm 1.56$ & $0.882 \pm 0.006$ & $198.3 \pm 21.6$ & $242.7 \pm 11.9$ & $269.3 \pm 27.5$ \\
\hline 9 & $1.037 \pm 0.046$ & $71.8 \pm 0.8$ & $114.3 \pm 3.1$ & $71.7 \pm 8.1$ & $30.24 \pm 0.64$ & $0.877 \pm 0.01$ & $277.3 \pm 35.0$ & $305 \pm 50.7$ & $359.7 \pm 48.3$ \\
\hline 10 & $0.99 \pm 0.026$ & $72.9 \pm 0.7$ & $117.3 \pm 7.1$ & $73 \pm 1$ & $29.58 \pm 0.96$ & $0.878 \pm 0.012$ & $269.3 \pm 46.9$ & $305.7 \pm 15.4$ & $332.7 \pm 53.2$ \\
\hline 11 & $0.701 \pm 0.021$ & $72.7 \pm 1.1$ & $129.7 \pm 2.5$ & $90 \pm 5.3$ & $30.35 \pm 1.15$ & $0.879 \pm 0.013$ & $153.3 \pm 22.4$ & $172.0 \pm 16.5$ & $198.7 \pm 54.6$ \\
\hline 12 & $0.773 \pm 0.006$ & 72 & $121.3 \pm 4.7$ & $84.3 \pm 4.0$ & $30.31 \pm 0.71$ & $0.881 \pm 0.008$ & $193.3 \pm 33.3$ & $229.3 \pm 11.6$ & $252.1 \pm 43.7$ \\
\hline 13 & $0.784 \pm 0.023$ & $72.3 \pm 0.6$ & $120.3 \pm 3.5$ & $83 \pm 1$ & $30.14 \pm 0.82$ & $0.875 \pm 0.005$ & $201.3 \pm 13.7$ & $232.7 \pm 28.0$ & $259.7 \pm 14.0$ \\
\hline
\end{tabular}

Control: liquid oil without any emulsifier.

Emulsifier combination 1: PGMS 1.0\%/ GMS 0.5\%/ Lecithin 0

2: PGMS 2.0\%/ GMS 0.5\% / Lecithin 1.0\%

3: PGMS 3.0\%/ GMS 0.5\% / Lecithin 0.5\%

4: PGMS 1.0\%/ GMS 1.0\% / Lecithin 1.0\%

5: PGMS 2.0\%/ GMS 1.0\% / Lecithin 0

6: PGMS 2.0\%/ GMS 1.0\%/ Lecithin 0.5\%

7: PGMS 2.0\%/ GMS 1.0\% / Lecithin 1.0\%

8: PGMS 3.0\%/ GMS 1.0\% / Lecithin $0 \%$

9: PGMS 1.0\%/ GMS 1.5\%/ Lecithin 0.5\%

10: PGMS 2.0\%/ GMS 1.5\% / Lecithin 0

11: PGMS 3.0\%/ GMS 1.5\% / Lecithin 1.0\%

12: PGMS 2.0\%/ GMS 1.0\% / Lecithin 0.5\%

13: PGMS 2.0\%/ GMS 1.0\% / Lecithin $0.5 \%$ 


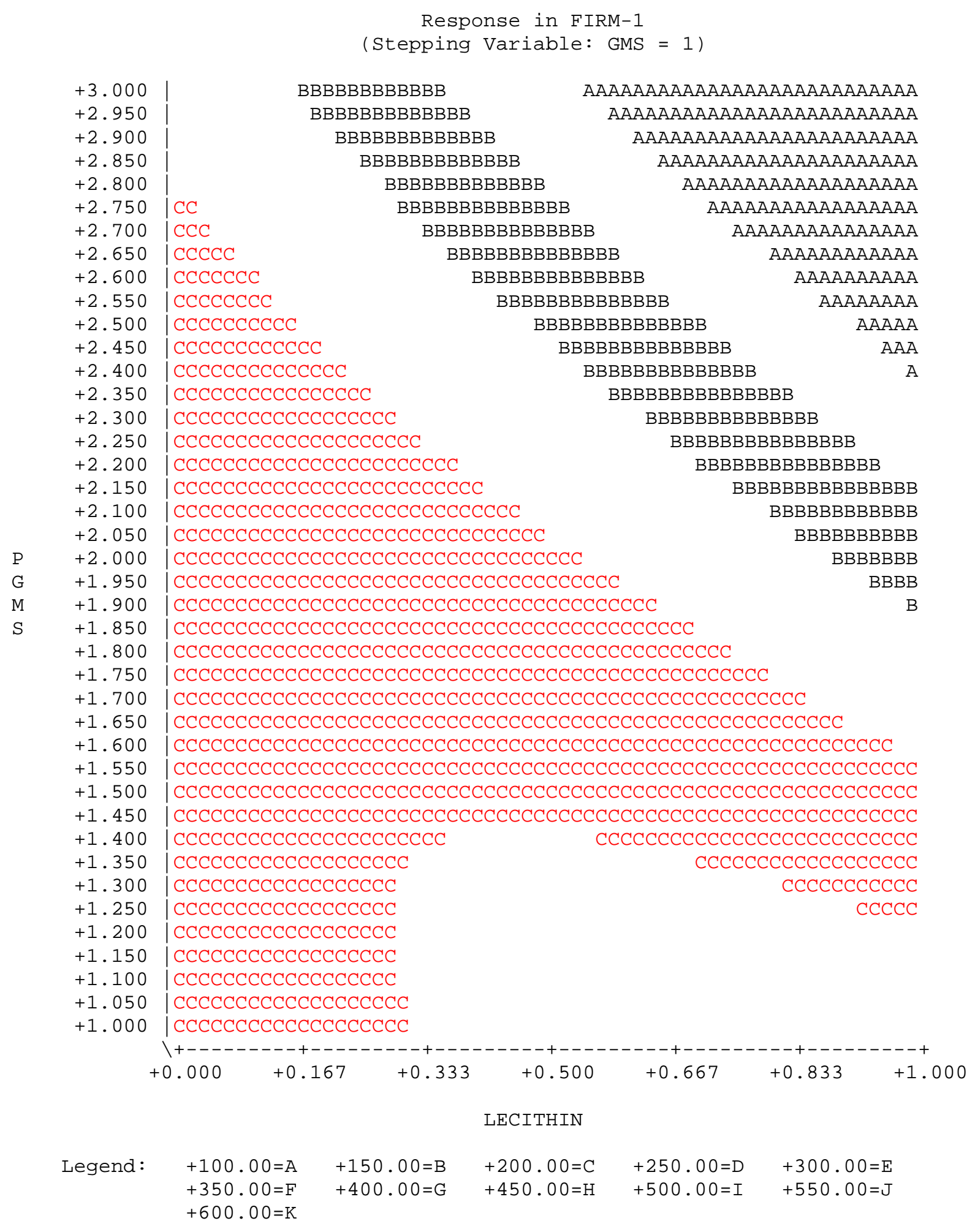

Figure 4-1. RSM plots for first day firmness. GMS= 1.0 


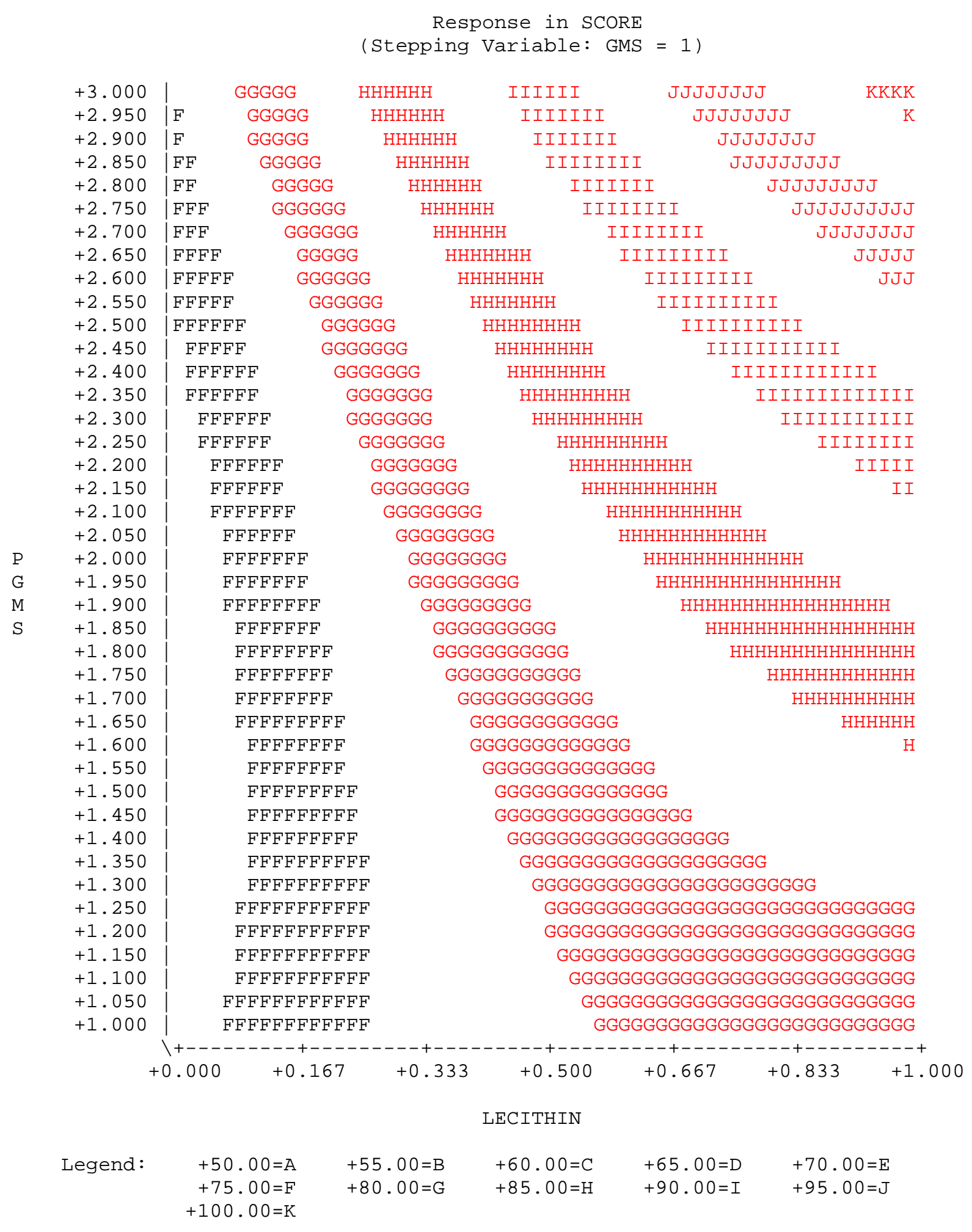

Figure 4-2. RSM plots for cake score. GMS= 1.0 
Response in VOLUME

(Stepping Variable: GMS = 1)

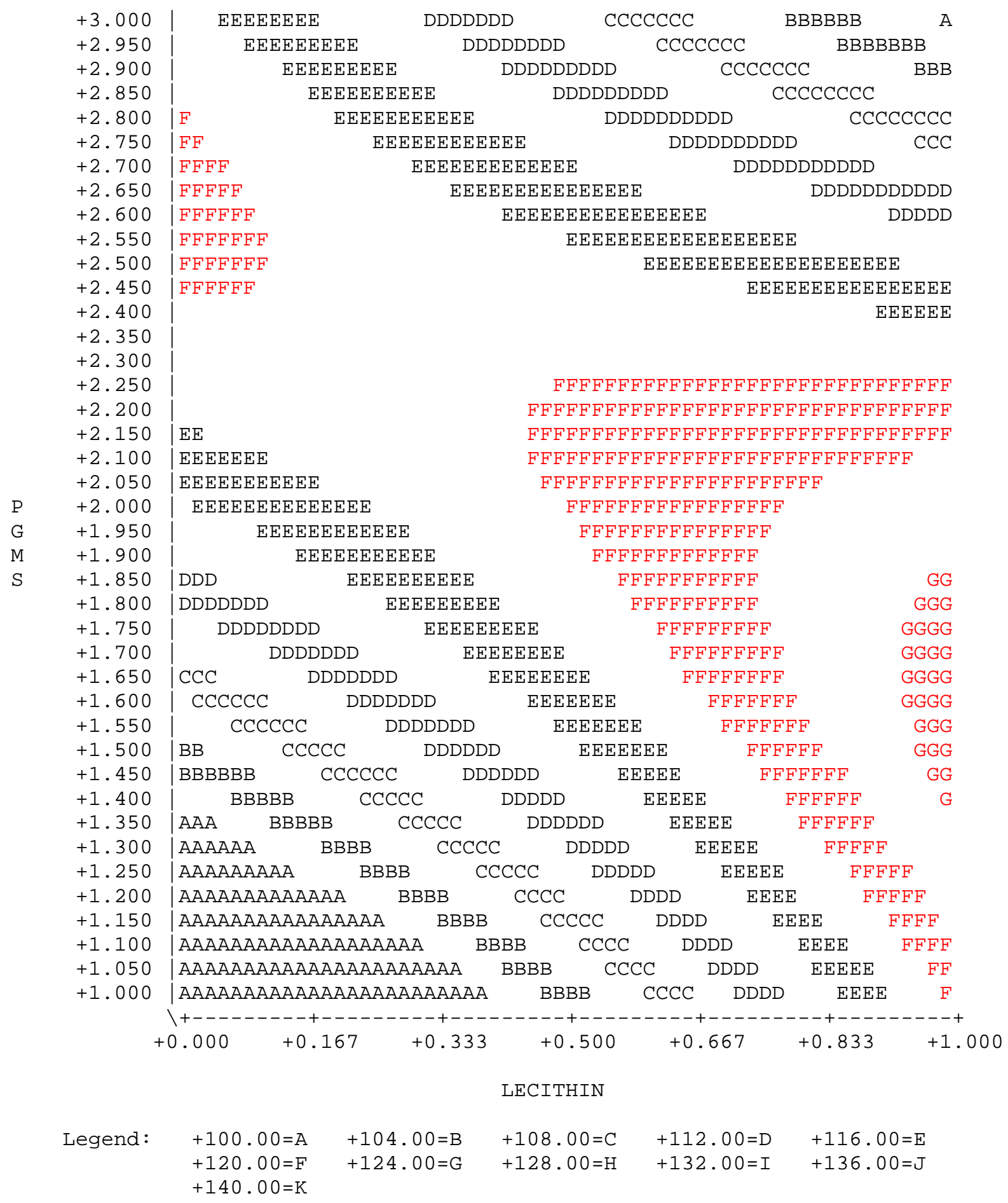

Figure 4-3. RSM plots for cake volume. GMS= 1.0 


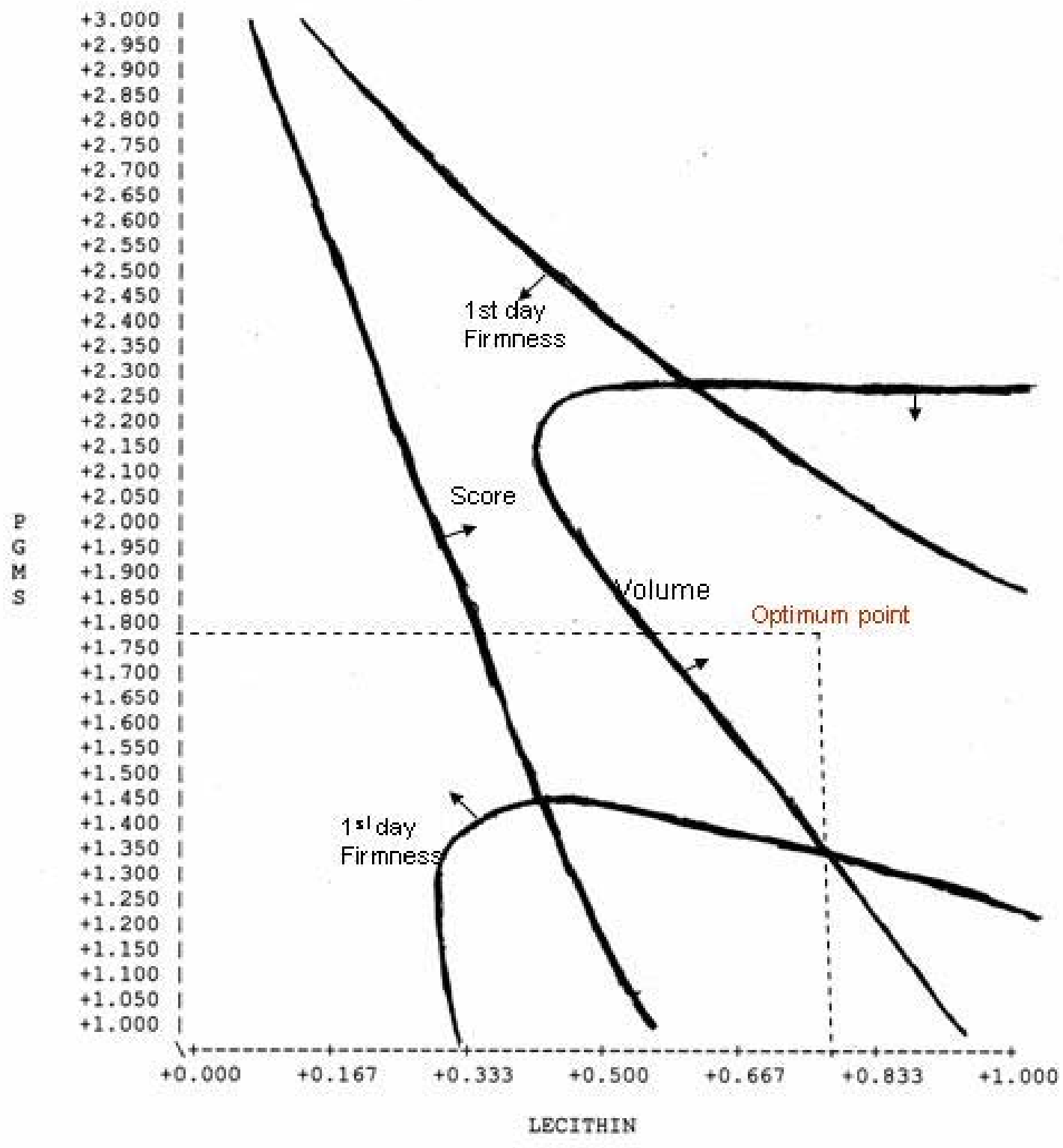

Figure 4-4. RSM plots summary. GMS= 1.0 


\subsubsection{Batters Properties}

\section{Specific gravity}

Figure 4-5 compares the specific gravity of cake batters with different emulsifier combinations. Batter specific gravity is a measurement of total air-holding capacity but gives little information about bubble size or dispersion. Combinations 1 and 9 produce higher batter specific gravities than does the control. This is because the control cake uses $125 \%$ water and the others use $135 \%$ water. When emulsifier content is low and the batter has too much liquid, the batter cannot hold as much air after mixing. Combinations 1, 4, 9 all have $1.0 \%$ PGMS (the low value) and high specific gravity, which indicated that PGMS is important to aerate and increase the incorporation of air of the cake batter. PGMS is an $\alpha$-tending emulsifier and creates a film on the bubble surfaces. The stronger the film, the more air the bubble incorporates (Richardson et al, 2002). The Combination 10 has 2.0\% PGMS but its specific gravity is still very high. That might be because there is no lecithin in that combination and lecithin has a synergistic effect with PGMS in improving aeration (Orthoefer, 2008). Combination 11 which had $3.0 \%$ PGMS and 1.0\% Lecithin in the formula produced the lowest batter specific gravity. This suggests that PGMS increases the air incorporation and that lecithin works synergistically with PGMS to do this. Further, combinations 3 and 6 have the same amount of Lecithin and the higher the PGMS is, the lower the specific gravity.

From the above results, it is possible to conclude first, that as the amount of PGMS in the blend increases, the specific gravity decreases, and secondly, Lecithin helps facilitate or potentates this effect. This study did not test higher emulsifier contents (PGMS $>3.0 \%$ or Lecithin $>1.0 \%$ ), because at those levels, the cake crumb would be too tender and it would collapse after baking. 
Figure 4-5. Cake batter specific gravity for different emulsifier combinations

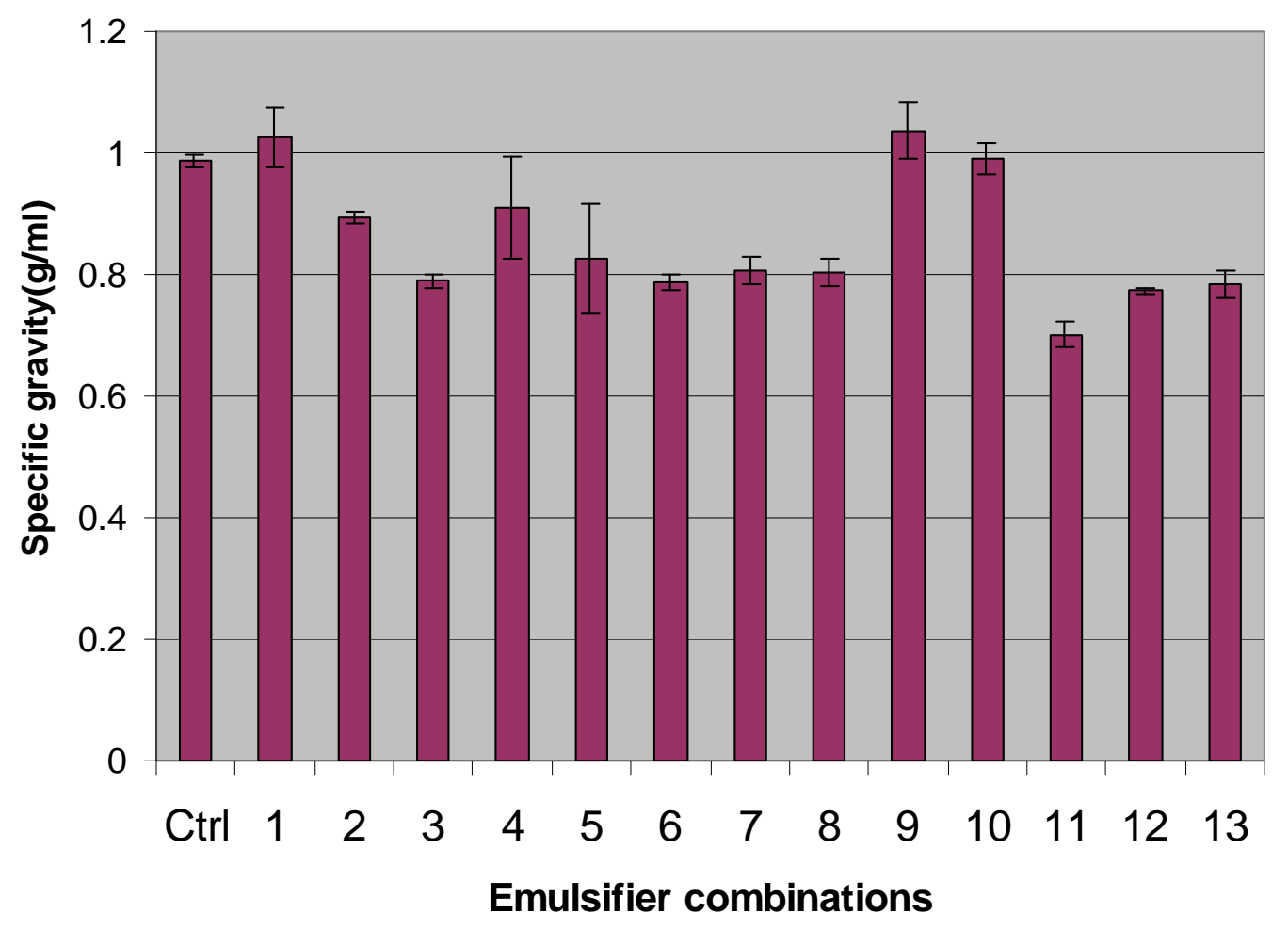

Control: liquid oil without any emulsifier

Emulsifier combination 1: PGMS 1.0\%/ GMS 0.5\%/ Lecithin 0

2: PGMS 2.0\%/ GMS 0.5\% / Lecithin $1.0 \%$

3: PGMS 3.0\%/ GMS 0.5\% / Lecithin 0.5\%

4: PGMS 1.0\%/ GMS 1.0\% / Lecithin 1.0\%

5: PGMS 2.0\%/ GMS 1.0\% / Lecithin 0

6: PGMS $2.0 \%$ / GMS $1.0 \%$ / Lecithin $0.5 \%$

7: PGMS $2.0 \%$ / GMS $1.0 \%$ / Lecithin $1.0 \%$

8: PGMS 3.0\%/ GMS 1.0\% / Lecithin $0 \%$

9: PGMS 1.0\%/ GMS 1.5\% / Lecithin 0.5\%

10: PGMS 2.0\%/ GMS 1.5\% / Lecithin 0

11: PGMS 3.0\%/ GMS 1.5\%/ Lecithin 1.0\%

12: PGMS 2.0\%/ GMS 1.0\% / Lecithin 0.5\%

13: PGMS 2.0\%/ GMS 1.0\%/Lecithin 0.5\% 


\subsubsection{Baking tests}

\subsubsection{Cake Volume}

Cake volume is a measure of cake size and reflects the amount of air entrapped during mixing and $\mathrm{CO}_{2}$ expansion throughout the crumb. These gases may be dispersed in small cells throughout a fine crumb or in larger cells throughout a coarser crumb. Although high volumes do not always indicate a desirable cake, low volumes generally indicate a heavy, less desirable crumb (Brooker, 1993). Figure 4-6 shows the cake volumes (and standard deviations) for each of the combinations plus control. The lowest cake volume resulted from combination 1 . This is likely due to the low emulsifier content coupled with the high water content compared to that of the control cake. Combination 3, 8, 9, and 10 resulted in lower cake volume than that of control cake. The most probable explanation is the fact that they all have low Lecithin content and thus are less able to stabilize the air cells in the cake batter during mixing and baking. Combinations 2, 4, and 7 have higher volumes compared to the control cake, which indicates that Lecithin has a synergistic effect with PGMS on improving batter aeration (Orthoefer, 2008). Combination 11 produced the highest cake volume, probably because it had the highest emulsifier content. However, cakes containing combination 11 were very fragile and very difficult to handle. Consequently, this combination and higher emulsifier content was deemed unsuitable for this research. 
Figure 4-6. Cake volume with different emulsifier combinations

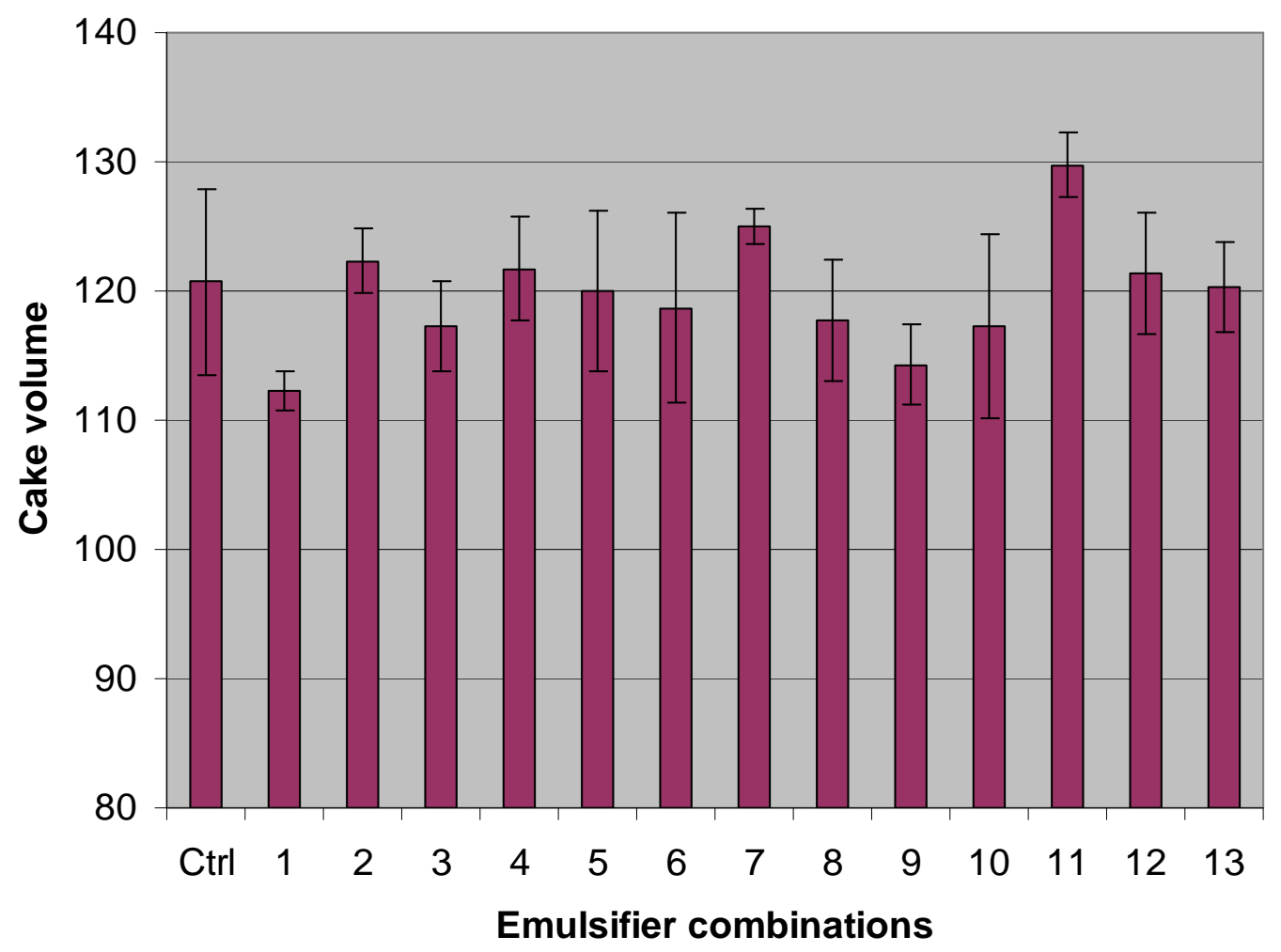

Control: liquid oil without any emulsifier

Emulsifier combination 1: PGMS 1.0\%/ GMS 0.5\%/ Lecithin 0

2: PGMS 2.0\%/ GMS 0.5\% / Lecithin 1.0\%

3: PGMS 3.0\%/ GMS 0.5\% / Lecithin $0.5 \%$

4: PGMS 1.0\%/ GMS 1.0\% / Lecithin 1.0\%

5: PGMS 2.0\%/ GMS 1.0\% / Lecithin 0

6: PGMS 2.0\%/ GMS 1.0\% / Lecithin 0.5\%

7: PGMS 2.0\%/ GMS 1.0\% / Lecithin 1.0\%

8: PGMS 3.0\%/ GMS 1.0\% / Lecithin $0 \%$

9: PGMS 1.0\%/ GMS 1.5\% / Lecithin 0.5\%

10: PGMS 2.0\%/ GMS 1.5\% / Lecithin 0

11: PGMS 3.0\%/ GMS 1.5\%/ Lecithin 1.0\%

12: PGMS 2.0\%/ GMS 1.0\% / Lecithin $0.5 \%$

13: PGMS 2.0\%/ GMS 1.0\% / Lecithin 0.5\% 
Figure 4-7. Cake volume vs. Batter specific gravity

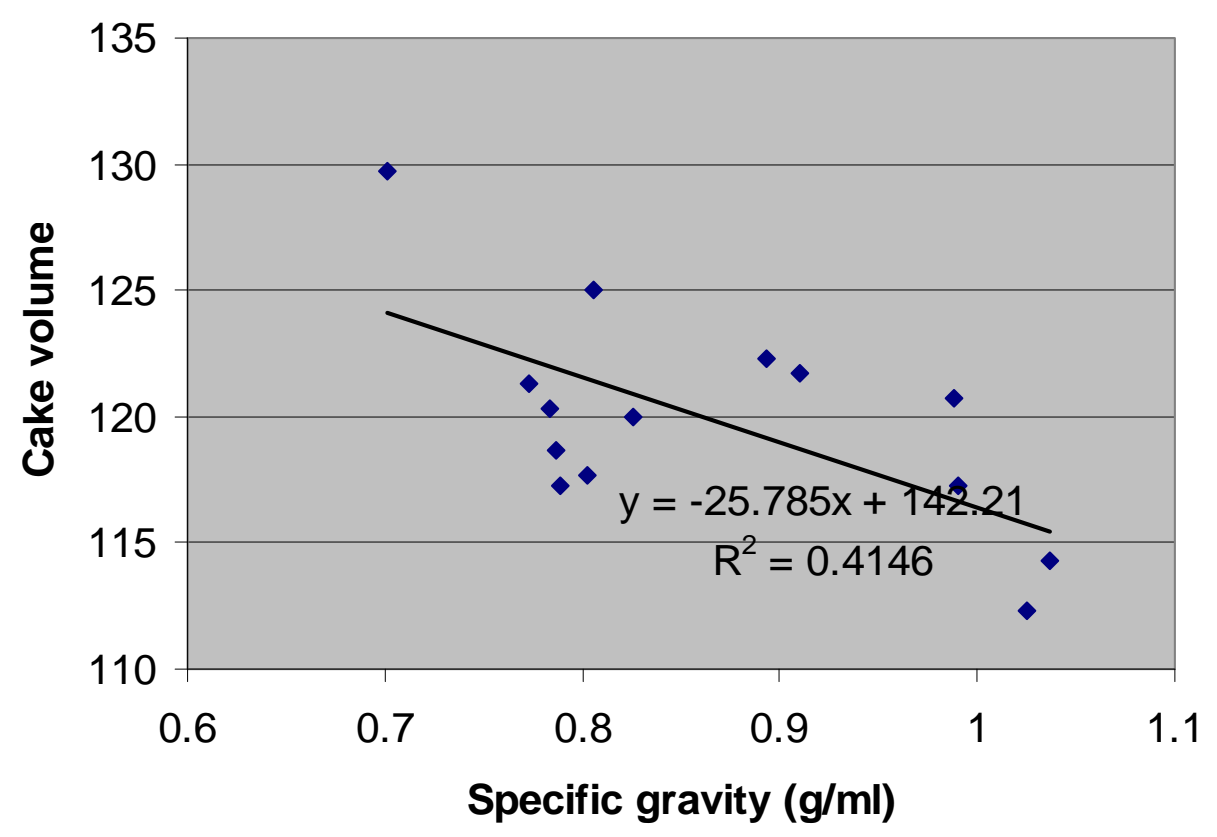

Figure 4-7 plots the relationship between cake volume and batter specific gravity. The trend, as expected, was that specific gravity decreases were associated with volume increases. However, the relationship was not a strong one. The $\mathrm{R}^{2}$ value of 0.41 indicates that less than half the variability in the data can be attributed to variations in batter specific gravity. We can establish that the final volume of cakes was not only dependant on the initial air incorporated in the batter but also on its capacity to retain air during baking. Different emulsifier combinations have different air retaining capabilities. 


\subsubsection{Cake Score}

Cake scores for different emulsifier combinations are shown in Figure 4-8. Cake cells, grain, texture, color, and flavor were graded separately, then summed. Cake score mainly reflects the air cell distribution in the cake crumb. The RSM relationship between the independent emulsifier variables and cake score was high $(\mathrm{r}=0.80366)$. Control cake produced cakes with very open cells and coarse grain. This showed that liquid oil alone is not suitable for cake-making as in the results described by Brooker (1993) in his research. Combinations 7 and 11 produced cakes with higher scores than those of the control. They possessed more uniform texture and finer grain, compared to the control cake. This can be explained as follows: the emulsifiers aid in the transformation of big air cells in the liquid oil batter into small, uniform cells and the crumb in consequence forms finer texture. It was hard to tell an individual

emulsifier's effects on the cake score. The trend was that higher Lecithin produced higher score cakes when the other two emulsifiers are the same. It is indicated that Lecithin helps to produce a better crumb grain as well as loaf volume, which was also reported by Orthoefer (2008). 
Figure 4-8. Cake scores for different emulsifier combinations

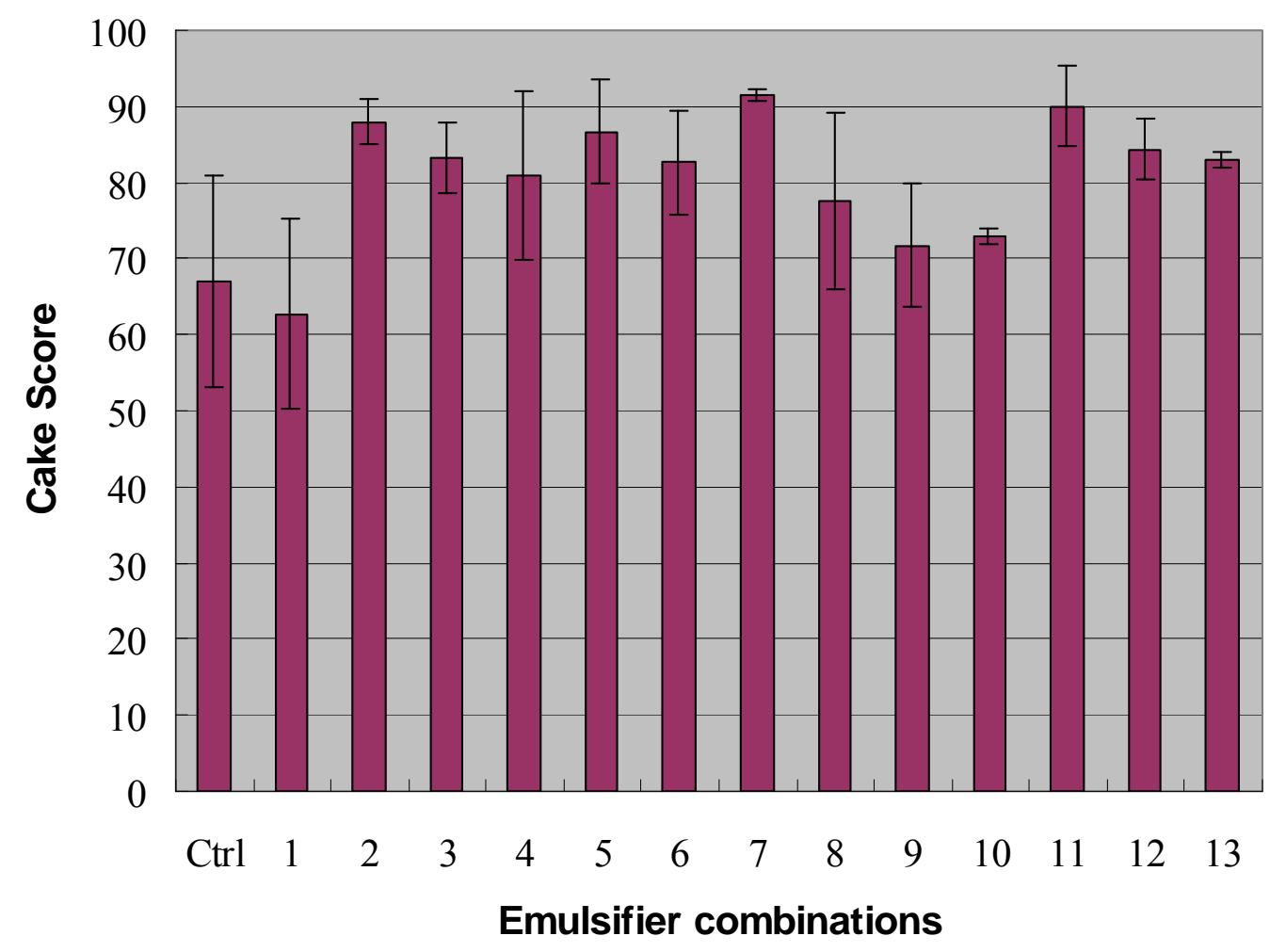

Control: liquid oil without any emulsifier

Emulsifier combination 1: PGMS 1.0\%/ GMS 0.5\%/Lecithin 0

2: PGMS $2.0 \%$ / GMS $0.5 \%$ / Lecithin $1.0 \%$

3: PGMS 3.0\%/ GMS 0.5\% / Lecithin 0.5\%

4: PGMS 1.0\%/ GMS 1.0\% / Lecithin 1.0\%

5: PGMS 2.0\%/ GMS 1.0\% / Lecithin 0

6: PGMS 2.0\%/ GMS 1.0\% / Lecithin 0.5\%

7: PGMS 2.0\%/ GMS 1.0\% / Lecithin 1.0\%

8: PGMS 3.0\%/ GMS 1.0\% / Lecithin $0 \%$

9: PGMS 1.0\%/ GMS 1.5\% / Lecithin 0.5\%

10: PGMS 2.0\%/ GMS 1.5\% / Lecithin 0

11: PGMS 3.0\%/ GMS 1.5\% / Lecithin 1.0\%

12: PGMS 2.0\%/ GMS 1.0\%/ Lecithin 0.5\%

13: PGMS 2.0\%/ GMS 1.0\% / Lecithin $0.5 \%$ 


\subsubsection{Cake firmness}

Cake firmness increased as the storage time increased. Two important physical changes occur in cakes during storage. The first is the migration of water from the moist central crumb to the dry crust, which causes some firming. The second change is due to the intrinsic firming of the crumb caused by the retrogradation of starch. There was no clear relationship between cake water contents and its resulting firmness. The RSM relationship between the independent emulsifier variables and firmness was high $(\mathrm{r}=0.83774)$. Combination 11 produced the most uniform and the softest cakes compared to the control; all the combinations except 1 all produced much softer cakes than the control. One of the reasons might be the increased moisture content of the cake crumb and the increased cake volume. The other possible explanation is that, by adding emulsifiers, the air cells tended to distribute evenly and thus soften the cakes. Figure 4-9 showed that combination 1 produced the firmest cake one day after baking. This might be because of the higher water content and lower emulsifier content of the formula. However, the curve of the combination 1 is flatter than the control curve. This indicates that the emulsifier's function in crumb softening is as an antistaling agent, and makes the firmness change more slowly than in the control cake. The highest GMS and Lecithin contents in combination 11 made the cake firmness change slower than in the other cakes. The highest emulsifier content was not used in the second part of the research, because cakes containing combination 11 were very fragile and very difficult to handle. 
Figure 4-9. Cake firmness with different emulsifier combinations and storage time

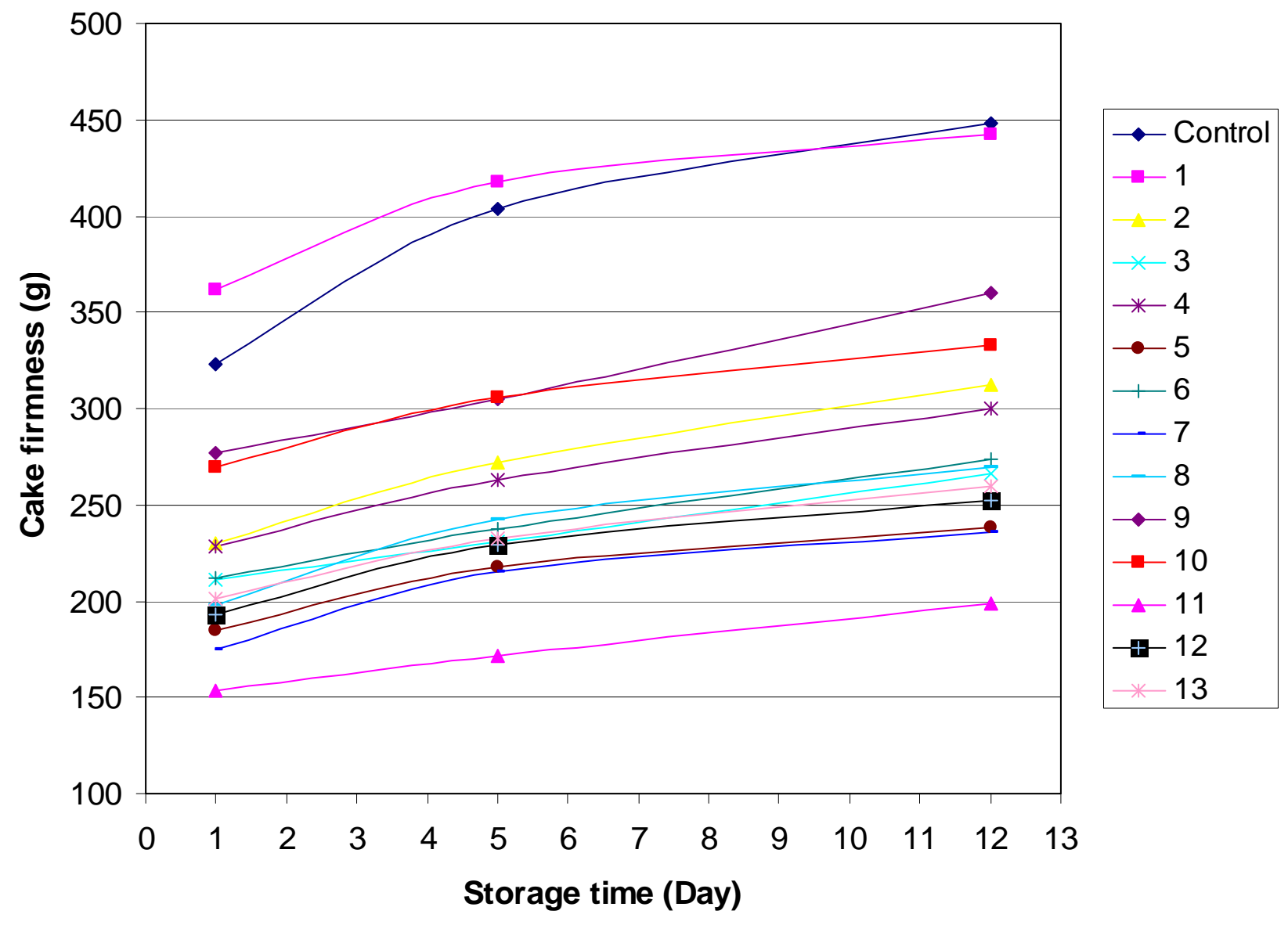

Control: liquid oil without any emulsifier

Emulsifier combination 1: PGMS 1.0\%/ GMS 0.5\%/ Lecithin 0

2: PGMS 2.0\%/ GMS 0.5\% / Lecithin $1.0 \%$

3: PGMS 3.0\%/ GMS 0.5\% / Lecithin 0.5\%

4: PGMS 1.0\%/ GMS 1.0\% / Lecithin 1.0\%

5: PGMS 2.0\%/ GMS 1.0\% / Lecithin 0

6: PGMS 2.0\%/ GMS 1.0\% / Lecithin $0.5 \%$

7: PGMS 2.0\%/ GMS 1.0\% / Lecithin 1.0\%

8: PGMS 3.0\%/ GMS 1.0\% / Lecithin 0\%

9: PGMS 1.0\%/ GMS 1.5\% / Lecithin 0.5\%

10: PGMS 2.0\%/ GMS 1.5\% / Lecithin 0

11: PGMS 3.0\%/ GMS 1.5\% / Lecithin 1.0\%

12: PGMS 2.0\%/ GMS 1.0\% / Lecithin 0.5\%

13: PGMS 2.0\%/ GMS 1.0\% / Lecithin 0.5\% 
Figure 4-10. Cake firmness vs. cake volume

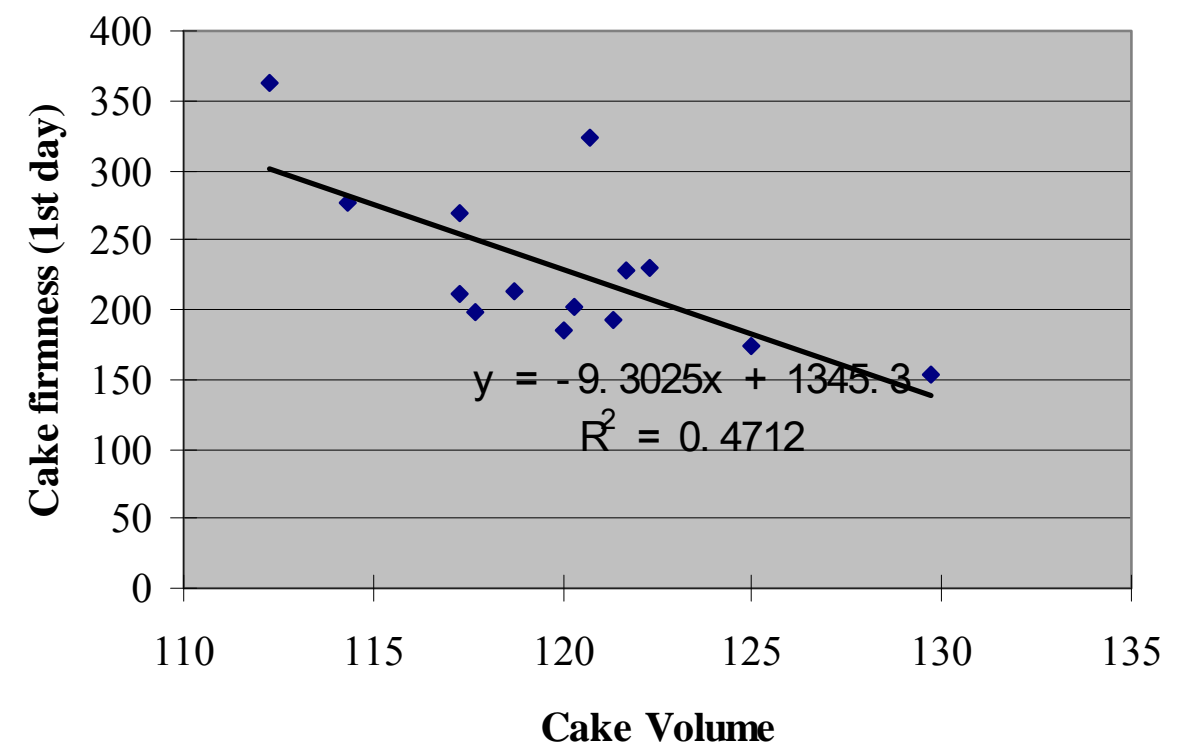

Figure 4-10 plots the relationship between cake volume and cake firmness. As Stauffer discussed (1999) in the case of bread staling, higher specific volume usually results in a lower initial firmness. The trend here was that cake firmness decreases were associated with volume increase. However, the relationship was not a strong one. The $\mathrm{R}^{2}$ value of 0.47 indicates that less than half the variability in the data can be attributed to change in cake volume, which shows that the improvement in the softness was due both to an increase in cake volume and to an antifirming agent. 


\subsection{CAKE STORAGE TEST}

Experiments were conducted to study the different types of fats used in the high-ratio yellow layer cakes for their effects on cake properties, including firming over time. Four types of shortenings were used in this experiment: plastic shortening, liquid oil, liquid shortening, and liquid oil plus the emulsifier combinations identified from the results of part I: PGMS 1.8\%/ GMS 1.0\%/ Lecithin 0.8\% (flour weight basis). Results for cake batter specific gravity, viscosity and cake properties are shown in Table 11. 
Table 11. Cake properties baked with different types of fats

\begin{tabular}{|c|c|c|c|c|}
\hline & Plastic shortening & Liquid oil & Liquid shortening & Liquid oil + emul. \\
\hline Specific gravity(g/ml) & $0.858 \pm 0.012 \mathrm{~b}$ & $0.975 \pm 0.01 \mathrm{c}$ & $0.846 \pm 0.004 \mathrm{~b}$ & $0.782 \pm 0.019 \mathrm{a}$ \\
\hline${\text { Viscosity }(\mathrm{cm} / 30 \mathrm{sec})^{1}}$ & $9.6 \pm 0.35 \mathrm{a}$ & $15.5 \pm 0.3 \mathrm{c}$ & $13 \pm 0.5 \mathrm{~b}$ & $13.3 \pm 0.21 \mathrm{~b}$ \\
\hline Cake volume $^{2}$ & $121.3 \pm 2.52 \mathrm{a}$ & $129.7 \pm 8.39 \mathrm{a}$ & $132.7 \pm 1.53 \mathrm{a}$ & $130.7 \pm 3.51 \mathrm{a}$ \\
\hline Cake score & $85 \pm 3.46 \mathrm{~b}$ & $58.7 \pm 7.37 \mathrm{a}$ & $94 \pm 1.73 \mathrm{~b}$ & $87 \pm 2.65 \mathrm{~b}$ \\
\hline cake firmness 1st day(g) & $211 \pm 32.78 \mathrm{a}$ & $299 \pm 19.47 \mathrm{~b}$ & $173 \pm 16.25 \mathrm{a}$ & $160 \pm 13.12 \mathrm{a}$ \\
\hline 5th day(g) & $247 \pm 12.65 \mathrm{~b}$ & $362 \pm 29.65 \mathrm{c}$ & $200 \pm 20.58 \mathrm{a}$ & $184 \pm 10.39 \mathrm{a}$ \\
\hline 12th day(g) & $270 \pm 38.25 \mathrm{a}$ & $422 \pm 17.33 \mathrm{~b}$ & $219 \pm 18.02 \mathrm{a}$ & $215 \pm 17.5 \mathrm{a}$ \\
\hline 21st day(g) & $296 \pm 12.68 \mathrm{~b}$ & $509 \pm 19.30 \mathrm{c}$ & $249 \pm 6.52 \mathrm{a}$ & $230 \pm 18.39 \mathrm{a}$ \\
\hline Slice brightness & $156.4 \pm 2.51 \mathrm{~b}$ & $145.2 \pm 5.08 \mathrm{a}$ & $156.9 \pm 3.48 \mathrm{~b}$ & $153.75 \pm 2.40 \mathrm{~b}$ \\
\hline Wall thickness(mm) & $0.473 \pm 0.0064 \mathrm{a}$ & $0.469 \pm 0.0018 \mathrm{a}$ & $0.477 \pm 0.0018 \mathrm{a}$ & $0.487 \pm 0.0074 \mathrm{a}$ \\
\hline number of cells & $3674 \pm 233 \mathrm{a}$ & $3859 \pm 218 \mathrm{a}$ & $3844 \pm 340 \mathrm{a}$ & $3637 \pm 201 \mathrm{a}$ \\
\hline cell diameter $(\mathrm{mm})$ & $2.5757 \pm 0.067 \mathrm{a}, \mathrm{b}$ & $2.109 \pm 0.048 \mathrm{a}$ & $2.5265 \pm 0.435 \mathrm{a}, \mathrm{b}$ & $2.9335 \pm 0.218 \mathrm{~b}$ \\
\hline
\end{tabular}

${ }^{1}$ Viscosity was measured by Bostwich consistometer; ${ }^{2}$ Cake volume was measured by plastic template according to AACC 10-91

Mean \pm standard deviation of each analysis $(n=3)$

Means with the same letters within rows are not significantly different $(\mathrm{P}<0.05)$. 


\subsubsection{Batter Properties}

\subsubsection{Specific gravity}

Figure 4-11 shows the cake batter specific gravity resulting from the incorporation of different types of fats. The cakes made with liquid oil had very high specific gravities as expected. Plastic shortening and liquid shortening had similar effects on the specific gravity of the cake batters. Liquid oil plus emulsifier combinations produced significantly lower values than did the others $(\mathrm{p}<0.05)$.

\section{Figure 4-11. Batter specific gravity from different types of fats}

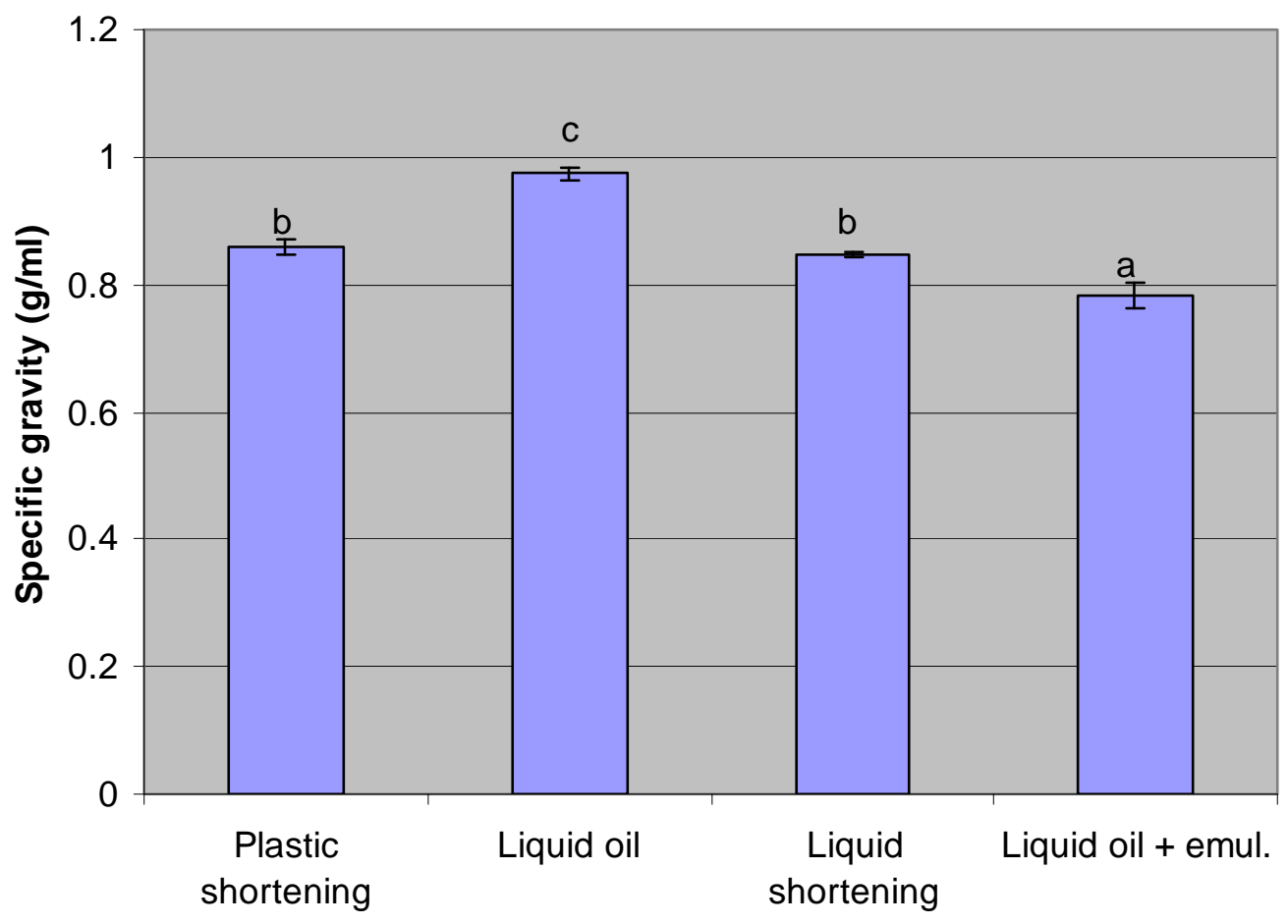

As Brooker (1993) explained, liquid oil cannot hold air bubbles because it has no crystal structure. The small ß' crystals in plastic shortening help stabilize the small bubbles, so the liquid oil had higher specific gravity than plastic shortening. Liquid shortening had high emulsifier content and could incorporate more air into the batter. As more air bubbles are incorporated into the batter, cake batter became aerated and specific gravity decreased. The 
batter's viscous resistance to flow increases as the batter entrapped gas bubbles cause the fluid batter to have increased frictional resistance to moving past each other (Brooker, 1993). These bubbles tend to stay in place without coalescing or migrating out because they can only move slowly in a very viscous batter, and surface forces tend to hold them in place. PGMS is an important $\alpha$-tending emulsifier and in the cake batter it can help increase the incorporation of air and decrease the cake batter specific gravity (Richardson et al, 2002). Liquid oil plus emulsifiers had high PGMS content, so a low specific gravity could be produced.

\subsubsection{Viscosity}

Because the Bostwick consistometer measures how far the batter runs in 30 seconds, the higher the result is, the lower the viscosity of the batter. Liquid oil has no solid structure and could not hold enough air in the batter, so batters made with it had significantly higher results than the others, and the viscosity is lower $(\mathrm{p}<0.05)$ (Figure 4-12). Gas cells in the cake batter made from liquid oil tended to coalesce into larger gas cells and to be lost to the atmosphere. This could result in lower cake volume. Batters incorporating plastic shortening showed significantly less flow $(\mathrm{p}<0.05)$ because the plastic shortening was solid at the room temperature and could not flow very well, and it incorporated more air in bubbles, further increasing viscosity. Kim and Walker (1992) have commented on air bubbles' ability to increase batter viscosity due to stearic hindrance. They also stated that an increase in batter viscosity aids the incorporation of air.

Comparing liquid shortening and liquid oil plus emulsifiers, the latter had significantly higher viscosities than did those with liquid oil only and significantly lower viscosity than batters containing plastic shortening. This can be explained by the fact that liquid shortening and liquid oil plus emulsifier batters had much less solid structure than did those with plastic shortening, but they incorporated much more air than did liquid oil batters. 
Figure 4-12. Batter viscosity from different types of fats

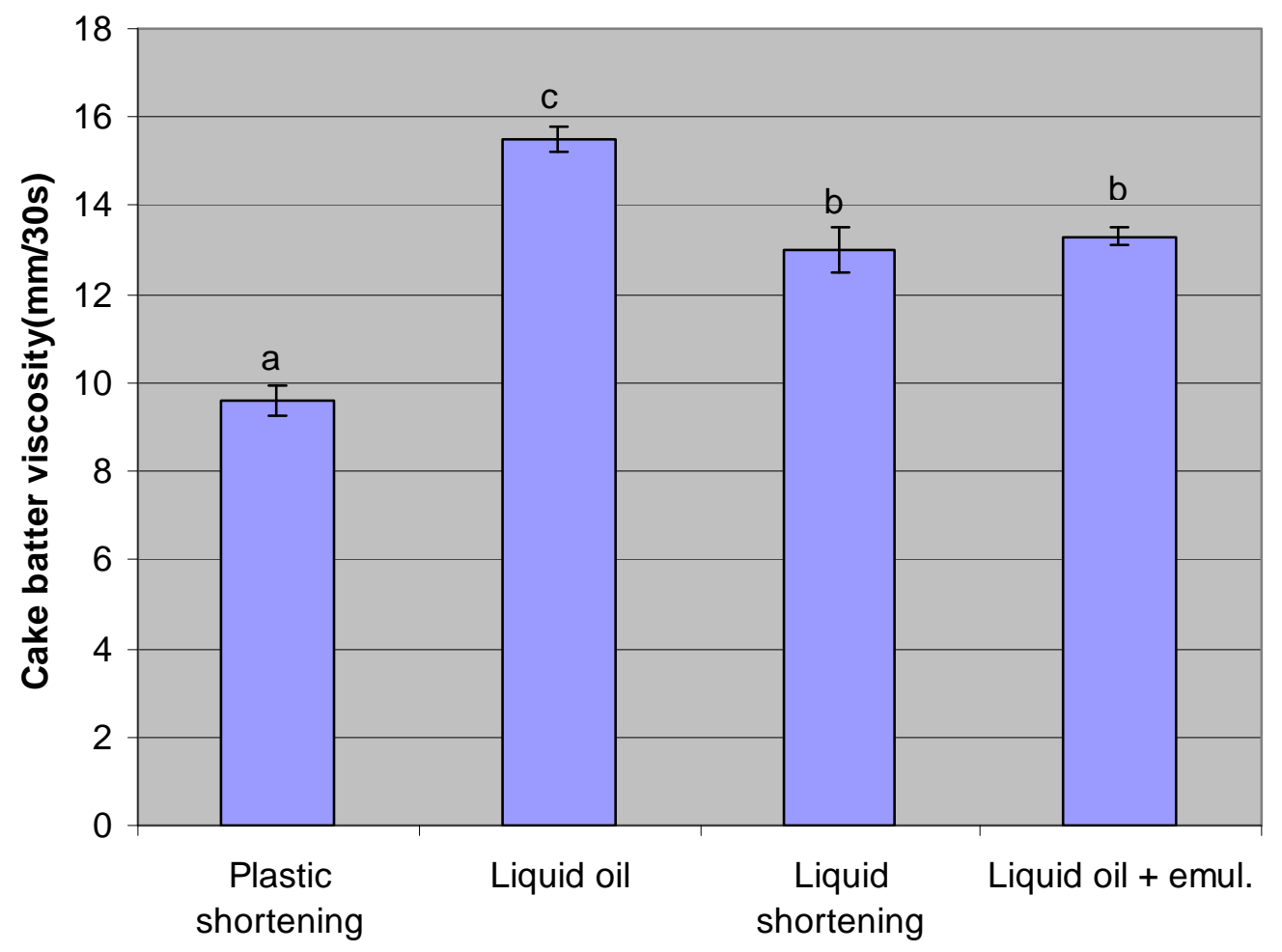

\subsubsection{Baking test}

\subsubsection{Cake volume}

Figure 4-13 shows cake volume as affected by different types of fats in the batters. No significant differences are shown in the results $(p>0.05)$. The cake volumes from liquid shortening and liquid oil plus emulsifiers were similar or higher than those for plastic shortening incorporation. Liquid oil produced cake volumes similar to those of the other fats, even though the batter specific gravity of liquid oil was higher than others. Table 12 compares the cake volume index with different types of fats. A peaked cake would have a high symmetry (2C-B-D) value and a flat cake would have a low value. Liquid oil produced cakes with higher symmetry value than the others. It may be that, during baking, cake batters' viscosity from liquid oil was too low and the dispersed gas cells could move freely to coalesce into big bubbles, and float rapidly to the surface. If the cake surface were to set before the air bubbles dispersed, the big 
bubbles would form tunnels in the baking cake. Such a phenomenon is shown in figure 4-15 (b). Bath et al. (1992) noticed that by adding emulsifiers, the rate of heating would decrease. This may indicate that the cakes made with liquid oil set earlier in the oven than did the other cakes.

Table 12. Cake volume index with different types of fats

\begin{tabular}{|l|c|c|c|c|}
\hline & Plastic shortening & Liquid oil & Liquid shortening & Liquid oil+emul. \\
\hline $\mathrm{B}$ & $39.67 \pm 0.58$ & $41.33 \pm 2.08$ & $43.67 \pm 1.53$ & $42.33 \pm 1.53$ \\
\hline $\mathrm{C}$ & $43.33 \pm 2.08$ & $47.33 \pm 5.51$ & $47.00 \pm 1.0$ & $46.67 \pm 1.53$ \\
\hline $\mathrm{D}$ & $38.33 \pm 0.58$ & $41.00 \pm 1.0$ & $42.00 \pm 1.73$ & $41.67 \pm 0.58$ \\
\hline Volume(B+C+D) & $121.33 \pm 2.52$ & $129.67 \pm 8.33$ & $132.67 \pm 1.53$ & $130.67 \pm 3.51$ \\
\hline Symmetry(2C-B-D) & $8.67 \pm 4.04$ & $12.33 \pm 8.33$ & $8.33 \pm 4.51$ & $9.33 \pm 1.15$ \\
\hline Uniformity(B-D) & $1.33 \pm 0.58$ & $1.0 \pm 0$ & $1.67 \pm 2.08$ & $0.67 \pm 1.15$ \\
\hline
\end{tabular}

\section{Figure 4-13. Cake volumes baked with different types of fats}

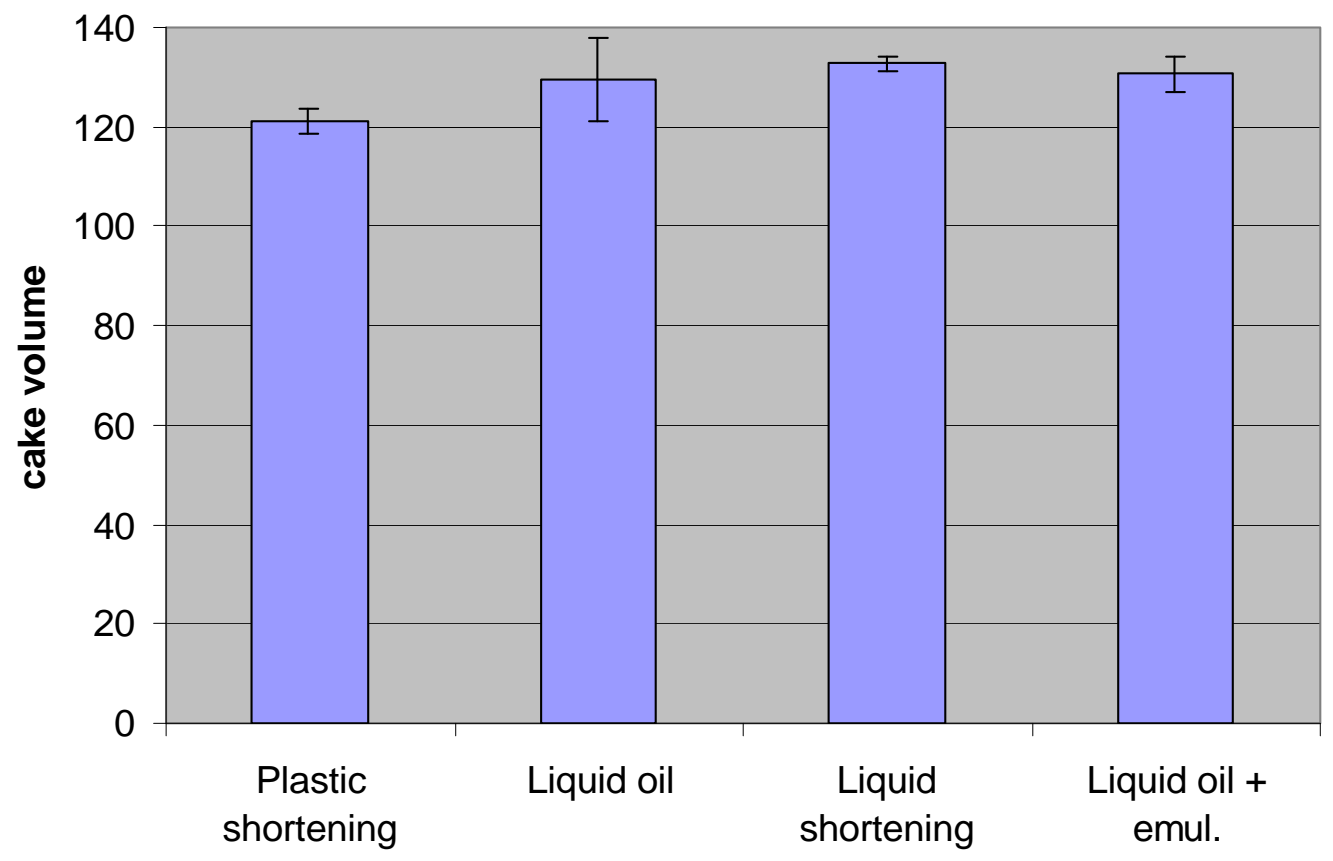

\subsubsection{Cake score}

Cake internal textures were graded according to AACC 10-90; cake cells, grain, texture, crumb color, and flavor were graded separately, then summed (Appendix B Tables16, 17, 18). 
Figure 4-14 shows that liquid oil based cakes have significantly lower scores than do the others $(p<0.05)$. There are no significant differences in cake scores $(p>0.05)$ between plastic shortening, liquid shortening and liquid oil plus emulsifiers based batters.

Figure 4-14. Cake score with different types of fats

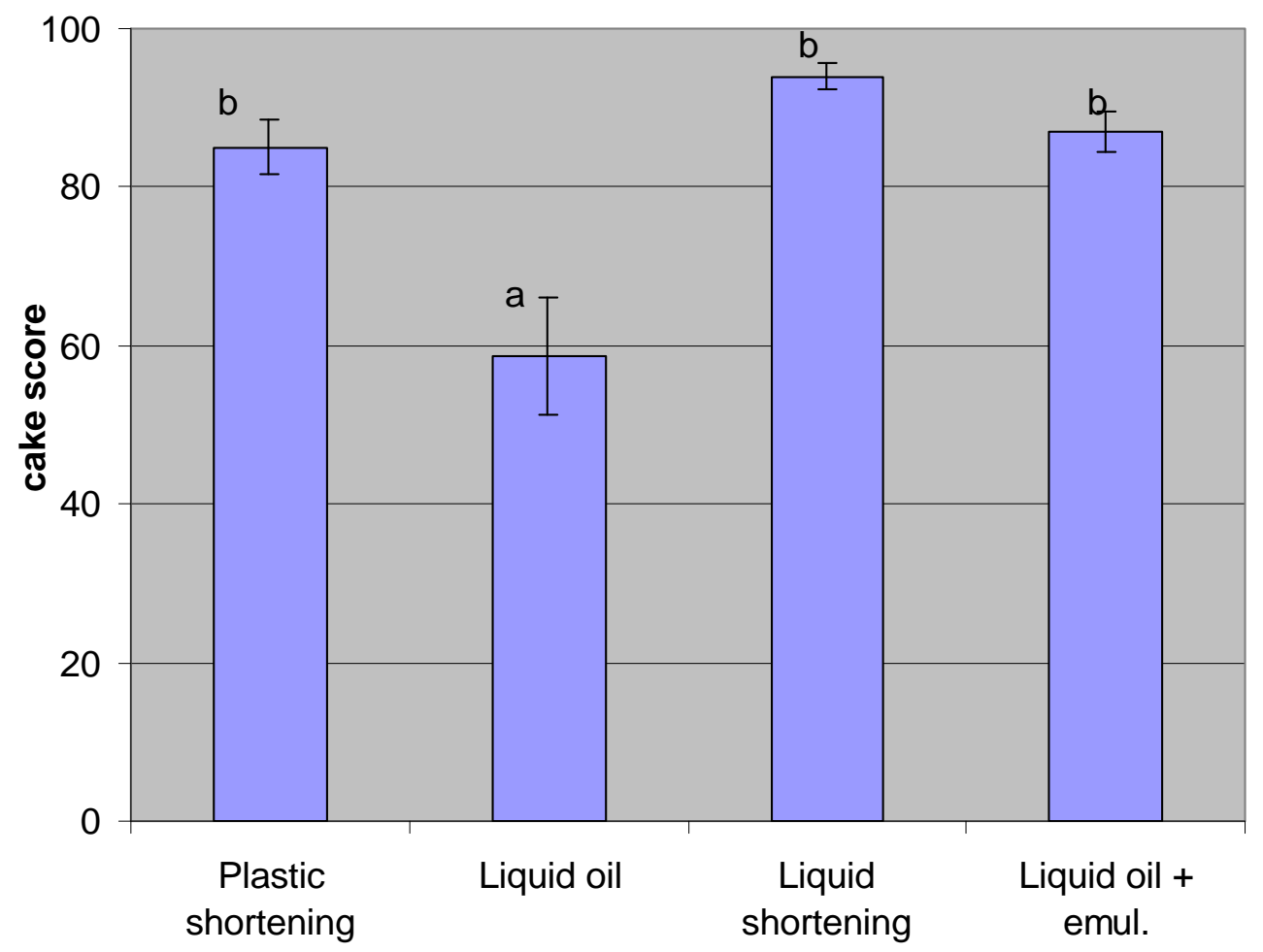

Figure 4-15 presents the crumb portions of cakes made with four different types of fats. Clearly cake b (liquid oil) has some bigger holes than do the other three cakes. That is the tunneling problems caused by less emulsifiers in the formula of the liquid oil cake. Compared to plastic shortening, liquid oil produced cakes with uneven and open cells, very thick cell walls, harsh grain, and a slightly dry, firm texture. One explanation for this is that the liquid oil based batters cannot hold the bubbles because they have no crystal structure. The pressure inside a bubble is inversely proportional to its radius, so during baking large air bubbles can easily coalesce together and form very big and buoyant cells. During baking, as the temperature of the batter rises, the air inside the bubbles begins to expand. In the batters made from plastic shortening, at the same time as the air starts expanding, the absorbed fat crystals approach their melting point. Eventually, all of the fat crystals melt and the resulting oil runs over the inside 
surface of the bubble and forms a uniform layer. The large number of adsorbed crystals create sufficient interface to allow the bubbles to expand without rupturing (Brooker, 1993). With liquid oil, the oil droplets inside the batter are big and thus produce cakes with very open cells. Liquid shortening and liquid oil plus emulsifiers produce cakes with dense cells, thin cell walls, silky grain, and very tender, moist, soft texture. The emulsifiers inside the liquid shortening and liquid oil plus emulsifiers help to decrease the bubble size and stabilize the bubbles. Brooker (1993) explained that the addition of emulsifiers could replace the interfacial properties conferred by adsorbed fat crystals, thereby allowing bubble expansion without rupture during baking. Wootton et al. (1967) noticed that in cake batters made with liquid shortening, the emulsifiers made it possible for the air to be incorporated throughout the aqueous phase of the batter.

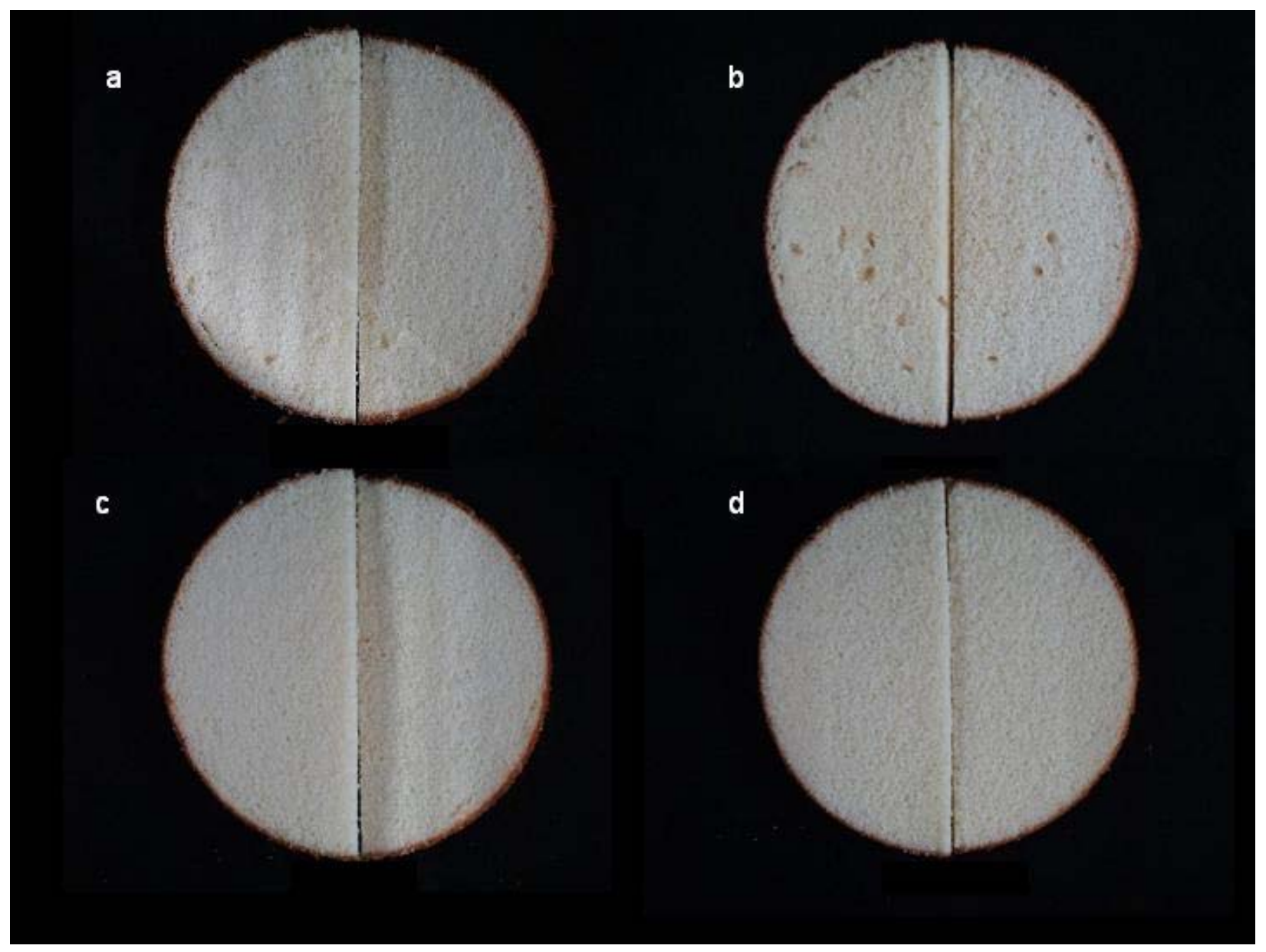

Figure 4-15. Cake crumb (a. plastic shortening; b. liquid oil; c. liquid shortening; d. liquid oil plus emulsifiers) 


\subsubsection{C-cell results:}

\section{Slice brightness}

The slice brightness of the cakes (Figure 4-16) made with liquid oil was significantly lower than that of the others $(\mathrm{p}<0.05)$. There was no significant difference in slice brightness ( $>0.05$ ) among cakes produced with plastic shortening, liquid shortening, or liquid oil plus emulsifiers. This can be explained as that liquid oil cannot form a uniform emulsion and the cake batter had a very high specific gravity. Low air content in the cakes made with liquid oil cause the crumb to look yellowish.

Figure 4-16. Slice brightness made with different types of fats

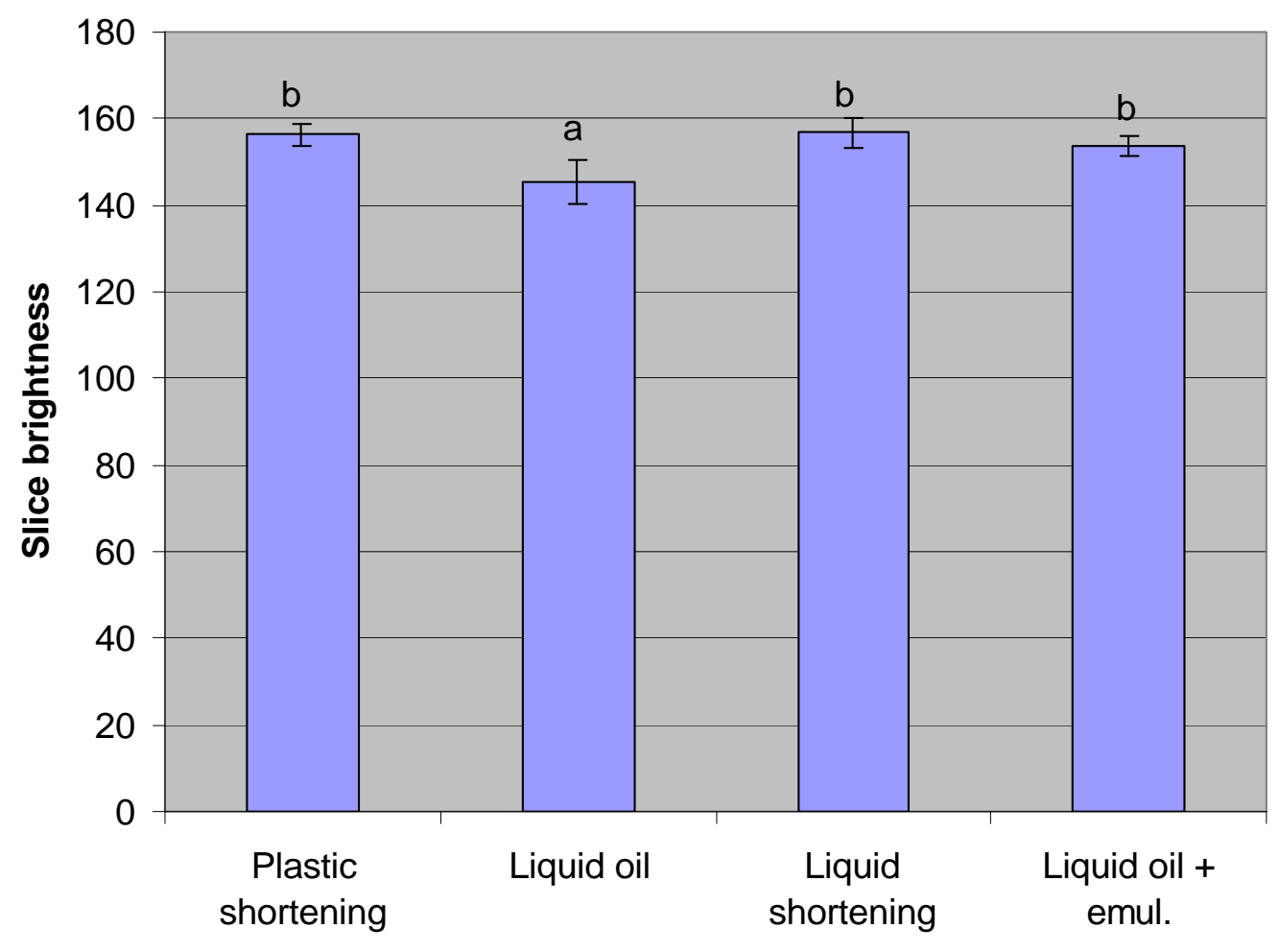




\section{Cell wall thickness}

There were no significant differences in cake cell wall thicknesses (Figure 4-17) among all kinds of fats $(\mathrm{p}>0.05)$. From visual observation, liquid oil produced cakes which appeared to have much thicker cell walls than the others. However, the C-Cell data didn't show the differences. This might be because, in the cakes made with liquid oil, some big cells were considered as "holes" instead of cells (Cauvain, 2003). The results were the averages of all "cells" in the measurement field. When the big holes are removed from the analysis, all the results had no significant difference.

Figure 4-17. Cell wall thickness of cakes made with different types of fats

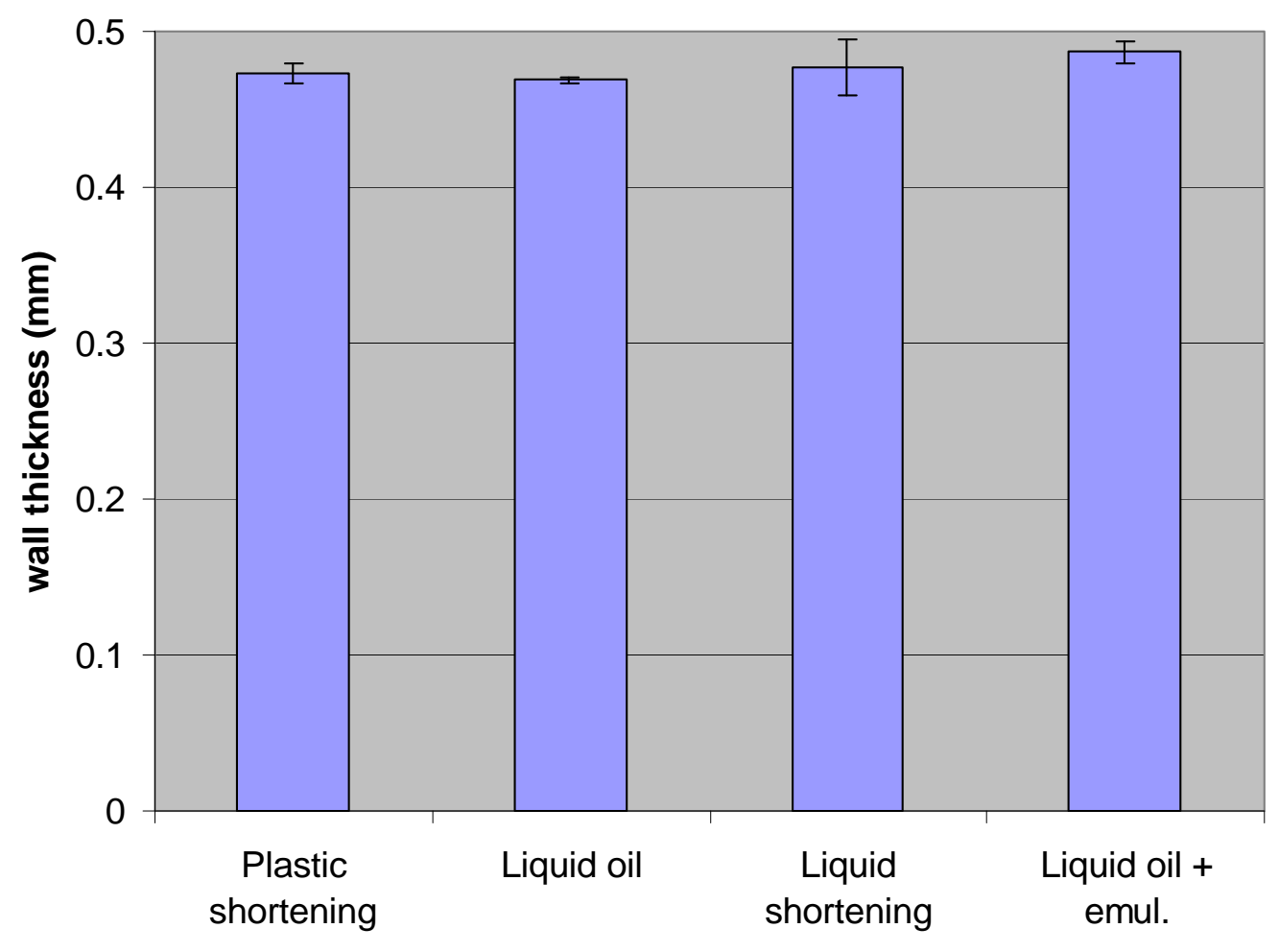




\section{Numbers of cells}

The numbers of cells (Figure 4-18) in the crumbs of cakes made using different fats did not show any significant differences ( $p>0.05$ ). A lower number of cells would indicate either that fewer air bubbles were incorporated into the cake batter or that there was more coalescence in the batter. When the batter viscosity is low, the gas cells would tend to coalesce more readily into large cells. In this study, we expected that cakes made from liquid oil would have fewer cells than the other groups. However, that was not confirmed by the C-cell results. This might be because, when cutting the cakes, cakes made from liquid oil are dryer than others, so the surface of the cake is smooth and it was easier to resolve cells. So those results showed higher values than did the others.

Figure 4-18. Numbers of cells in cakes made with different types of fats

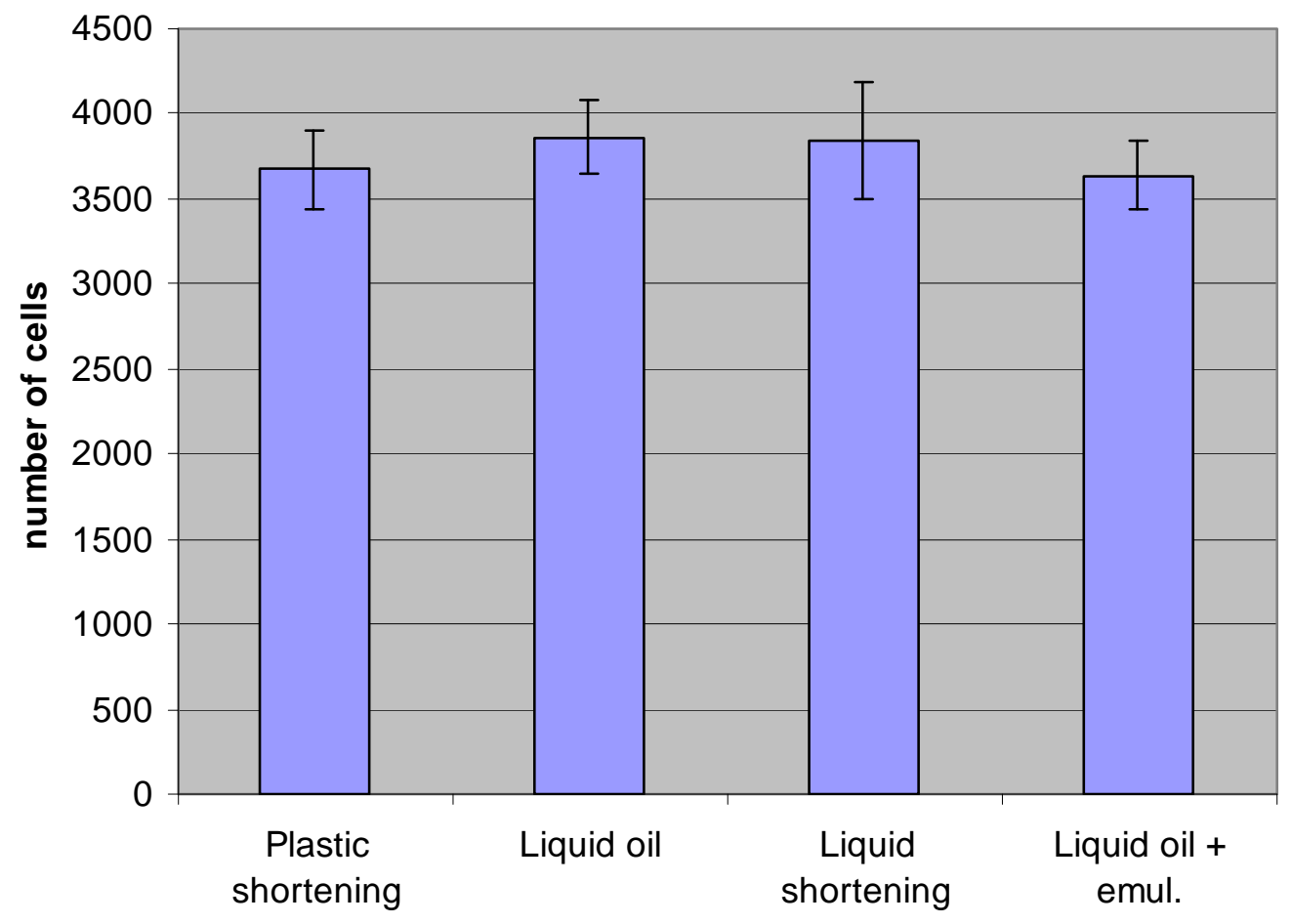




\section{Cell diameters}

Cell diameters (Figure 4-19) in cakes made with liquid oil were significantly lower than for those made with liquid oil plus emulsifiers $(\mathrm{p}<0.05)$. Liquid oil, plastic shortening, and liquid shortening produced cakes did not show significant differences in cell diameter $(\mathrm{p}>0.05)$. Plastic shortening, liquid shortening, and liquid oil plus emulsifiers produced cakes that were not significantly different in cell diameter $(\mathrm{p}>0.05)$. The size of air bubbles is important to cake volume and crumb grain. The small cell diameter in cakes made from liquid oil indicates less expansion of air bubbles during cake baking, which is reflected in the low cake volume. For the liquid oil plus emulsifiers' cakes, the large diameter of cells comprising the cake crumb may reflect the greater expansion of air bubbles, which helped improve the cake volume.

Figure 4-19. Cell diameters in cakes made with different types of fats

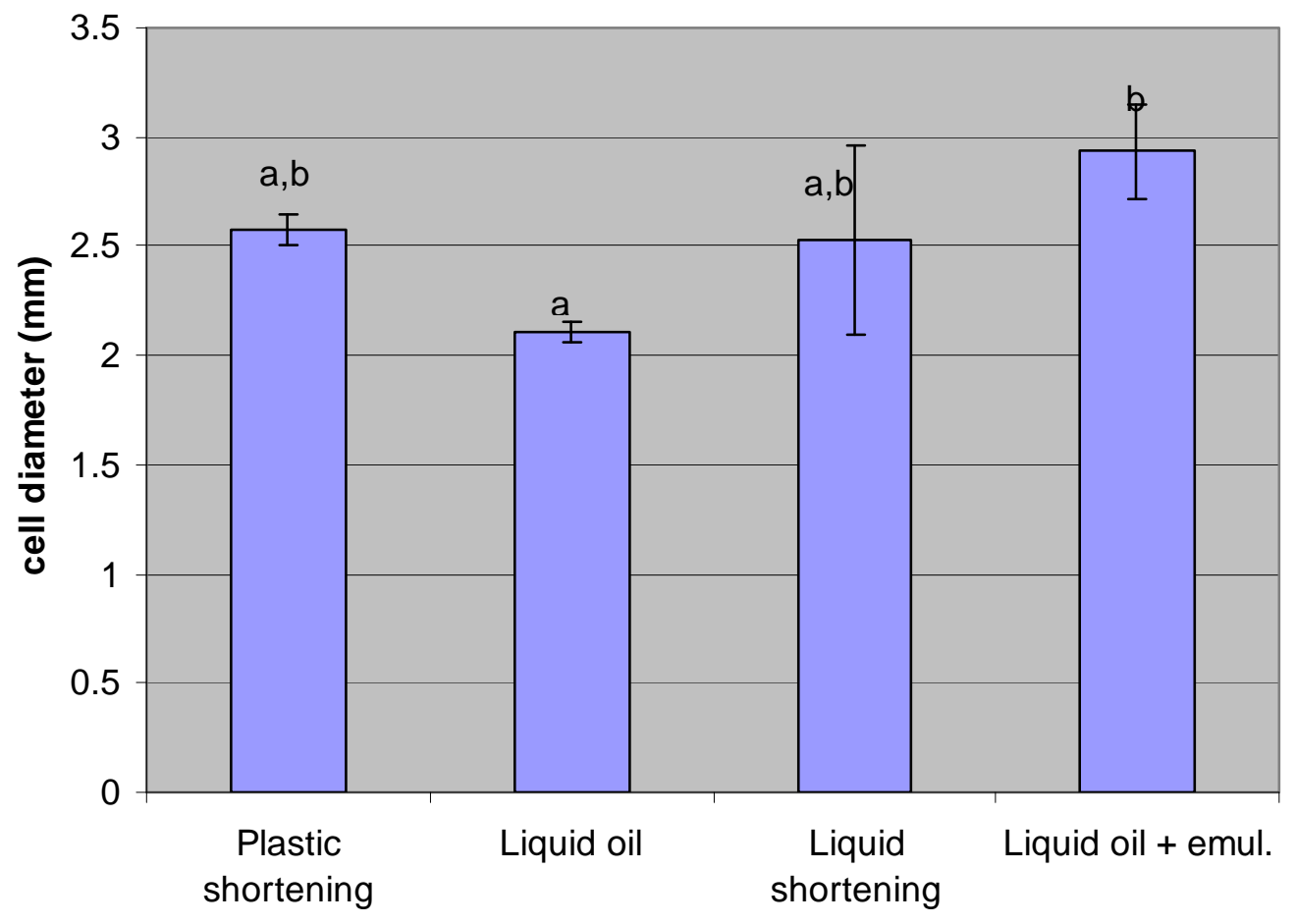




\subsubsection{Cake firmness}

Figure 4-20 shows the changes in firmness of cakes made from different types of fats over extended storage time. Clearly, cakes made with liquid oil have much greater firmness than the cakes made with other types of fats $(p<0.05)$, and the cake firmness change was much more rapid than others. Liquid shortening and liquid oil with emulsifiers produced cakes which were not significantly different in their firmness $(\mathrm{p}>0.05)$. Cakes made from plastic shortening were not significantly firmer than cakes made with liquid shortening or liquid oil plus emulsifiers on the $1^{\text {st }}$ and $12^{\text {th }}$ day ( $\left.>0.05\right)$, but they were significantly more firm than cake containing liquid shortening and liquid oil plus emulsifiers on the $5^{\text {th }}$ and $21^{\text {st }}$ day $(\mathrm{p}<0.05)$. The $12^{\text {th }}$ day's firmness of cakes made from plastic shortening had very high standard deviation. This might be the reason that the difference between plastic shortening and liquid shortening did not show significant statistical differences.

Liquid oil with no emulsifiers produced cakes in which firmness increased rapidly, which indicates that liquid oil alone produces firm cakes but the addition of emulsifiers to that liquid oil softens the cakes, essentially equivalent in firmness to the liquid shortening cakes. This confirms previously published data (Stauffer, 1999; Rusch, 1981).

\section{Figure 4-20. Cake firmness}

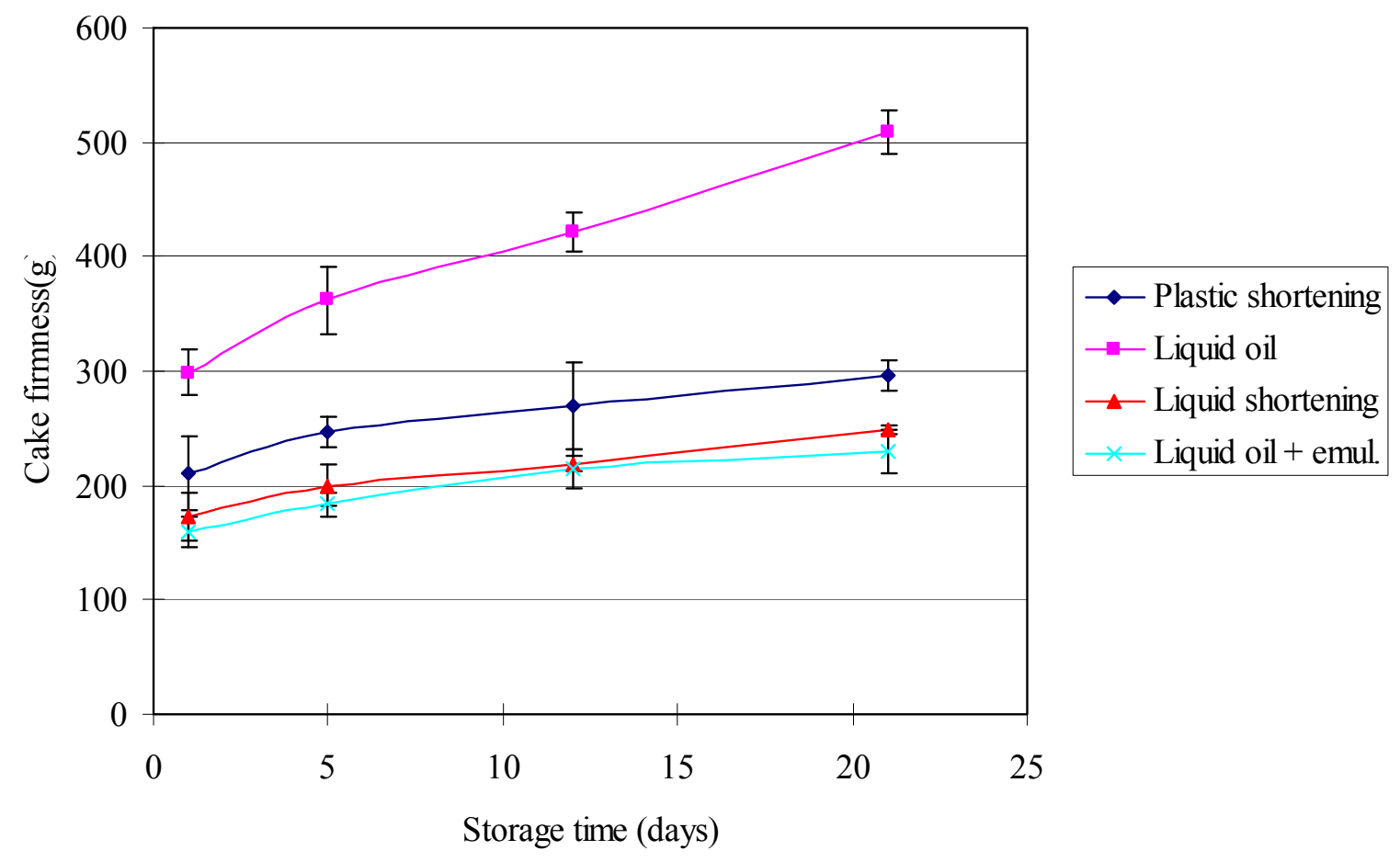


On the first day after baking, cakes baked with plastic shortening showed no significant differences in firmness from those baked with liquid shortening or liquid oil plus emulsifiers, but they showed significant differences later. According to the ingredient statements, Mono- and diglycerides were added to the plastic shortening by the manufacturer. Mono- and diglycerides work the same as monoglycerides in starch antistaling, and may be better than simple monoglycerides in increasing the aeration, depending on the source of the fat and the iodine value (Orthoefer, 2008).

In the liquid shortening formula, Mono- and Diglycerides, Propylene Glycol Mono- and Diesters of Fatty acids, and Glyceryl-Lacto Esters of Fatty acids were used. The differences between liquid shortening and liquid oil plus emulsifiers are:

(1) Fat crystals. In liquid shortening production, $ß$ tending hard fats are used to serve as quick-forming nuclei that cause solids in the base oil to precipitate in small enough crystals to ensure pourablity and prevent separation (O'Brien, 1996).

(2) Special processing. Many different crystallization procedures have been patented for liquid shortening production. The commonality of the procedures including: (a) all are dispersions of solids in liquid fractions; (b) the heat of crystallization must be dissipated before a stable product is achieved; (c) aeration of the liquid shortenings must be avoided at all stages of processing; (d) storage temperature is critical. It should be stored between $18-35^{\circ} \mathrm{C}(\mathrm{O}$ 'Brien, 1996).

(3) Emulsifier's formula and content. It is difficult to determine the exact formula for the commercial liquid shortening, but from the ingredient statement, it appears that the difference is just the Glyceryl-Lacto Esters of Fatty acids and lecithin, and these results presented above show similar cake firmness changes.

As discussed above, the processing and storage costs of liquid shortening are very high. The liquid oil plus emulsifiers is less costly in processing, and doesn't require storage at a critical temperature, so it is much easier to handle. It is less expensive and more convenient for large companies to use liquid oil plus emulsifiers instead of liquid shortening. Still, the emulsifier formula and content are critical to success. Using this blend requires a special tank for heating and blending the emulsifiers. More equipment investment will be needed when using the liquid oil plus emulsifiers. 


\section{CHAPTER 5 - SUMMARY}

Liquid shortening provided the best fresh cake characteristics with a cake volume 132.7, cake score 94 , and $1^{\text {st }}$ day firmness of $173 \mathrm{~g}$. Liquid oil provided the worst fresh cake characteristics with a cake volume 129.7, cake score 58.7, and $1^{\text {st }}$ day firmness of $299 \mathrm{~g}$. Plastic shortening cakes were intermediate with a cake volume 121.3 , cake score 85 , and $1^{\text {st }}$ day firmness of $211 \mathrm{~g}$.

Cake firmness changed slowly during storage for cakes made with liquid shortening. It was $200 \mathrm{~g}\left(5^{\text {th }}\right.$ day), $219 \mathrm{~g}\left(12^{\text {th }}\right.$ day $)$, and $249 \mathrm{~g}\left(21^{\text {st }}\right.$ day $)$. For cakes made with liquid oil, firmness increased rapidly. It was $362 \mathrm{~g}\left(5^{\text {th }}\right.$ day $), 422 \mathrm{~g}\left(12^{\text {th }}\right.$ day $)$, and $509 \mathrm{~g}\left(21^{\text {st }}\right.$ day $)$. Plastic

shortening cake firmness change was intermediate in rate with $247 \mathrm{~g}\left(5^{\text {th }}\right.$ day $), 270 \mathrm{~g}\left(12^{\text {th }}\right.$ day $)$, and $296 \mathrm{~g}\left(21^{\text {st }}\right.$ day). It may be concluded that liquid shortening was better for use in cake making than was plastic shortening. Cakes made from liquid shortening showed more uniform grain, finer texture, and higher volume. Cake firming shelf-life for cakes made from liquid shortening is longer than for cakes made from plastic shortening.

Liquid oil alone is not suitable for use in cake making, but the incorporation of the blend: PGMS 1.8\%/GMS $1.0 \% /$ Lecithin $0.8 \%$ produced layer cakes with characteristics: cake volume 130.7, cake score 87 . Cake firmness change was $160 \mathrm{~g}\left(1^{\text {st }}\right.$ day $), 184 \mathrm{~g}\left(5^{\text {th }}\right.$ day $), 215 \mathrm{~g}\left(12^{\text {th }}\right.$ day $)$, and $230 \mathrm{~g}\left(21^{\text {st }}\right.$ day). It was comparable in cake volume, cake score, and cake firmness to those produced with liquid shortening.

For baking companies, liquid oil plus an emulsifier combination blend would be easy to handle and they can combine different emulsifiers as their requirements change. But more investment for equipment would be needed. 
Future work of this project may include more baking tests of different emulsifiers and emulsifier combinations and cake shelf-life tests using vacuum packaging.

\section{References}

Anon. 2006. Food fats \& oils. Published by Institute of Shortening and Edible Oils. Washington, DC.

Anon. 2007. Trans-free pumpable shortening. Prepared foods. 176 (2): 69-69.

American Association of Cereal Chemists International. 1999. Approved Methods of the AACC. The Association. St. Paul, MN.

Bath, D. E., Shelke, K., and Hoseney, R. C. 1992. Fat Replacers in High-Ratio Layer Cakes. Cereal Foods World. 37 (7): 495-500.

Berger, K. G., Jewll, G. G., and Pollitt, R. 1979. Oils and Fats. In: Food Microscopy. Vaughan, J. G. edit. Academic press, London. Pp: 445-497.

Birnbaum, H. 1978. Surfactants and shortenings in cakemaking. The Bakers Digest. 52(1): 2838.

Bhattacharya, A., Banu, J., Rahman, M., Causey, J., and Fernandes, G. 2006. Biological effects of conjugated linoleic acids in health and disease. Journal of Nutritional Biochemistry. 17 (12): 789-810.

Brooker, B.E. 1993. The Stabilisation of air in cake batters- the role of fat. Food Structure. 12. 285-296

Cauvain, S.P. 2003. Inside the cell structures of bakery products. The world of food ingredients. 2: $24,26,28$ 
Del Vecchio, A. J. 1975. Emulsifiers and their use in soft wheat products. Bakers Dig. 49(4): 2835,52 .

Donelson, J. R., Gaines, C.S. and Finney, P. L. 2000. Baking Formula Innovation to Eliminate Chlorine Treatment of Cake Flour. Cereal Chem. 77(1): 53-57

Duxbury, D. D. 1992a. Emulsifiers alter fat functionalities. Food Processing. 53(5): 86-87.

Duxbury, D. D. 1992b. Emulsifier blends enhance cake qualities. Food Processing. 53 (11): 5960.

Gelinas, P., Roy, G., and Guillet, M. 1999. Relative effects of ingredients on cake staling based on an accelerated shelf-life test. Journal of Food Science. 64(5): 937-940.

Gonzalez-Juarez, N.A. 1994. Use of Emulsifiers in cakes made from chlorinated hard white winter wheat flour streams. Master Thesis. Kansas State University.

Gorton, L.A. 1977. Hydrate emulsifiers both shortening-type and sponge cake batters. Baking Industry. 144: 18-19.

Gunstone, F. D. 1999. Composition and properties of edible oils in: Edible Oil Processing. Ed: Hamm, W. and Hamilton, R. J. CRC Press LLC. Boca Raton. FL. Pp: 1-33

Handleman, A.R. 1961. Bubble mechanics in thick foams and their effects on cake quality. Cereal Chem. 38(3): 294.

Heertje, I. and Leunis, M. 1997. Measurement of shape and size of fat crystals by electron microscopy. Lebensmittel-Wissenschaft und-Technologie. 30(2): 141-146.

Hodge, D. 1977. A fresh look at cake staling. Baking Industries Journal. 9(10): 14-19. 
Howard, N.B. 1972. The role of some essential ingredients in the formulation of layer cake structures. Bakers Digest 46(5): 28-37.

Johnson, A. C. and Hosensy, R. C. 1979. Chlorine treatment of cake flour. II. Effect of certain ingredients in the cake formula. Cereal Chem. 56(4): 336-338

Juttelstad, A. 2004. Trans Fats: Status and Solutions. Food Technology 58(1): 20-22

Kim, C. S. and Walker, C. E. 1992. Interactions between starches, sugars and emulsifiers in high-ratio cake model systems. Cereal Chem. 69(2): 206-212

Kissell, L. T. and Yamazaki, W. T. 1979. Cake-baking dynamics: relation of flour-chlorination rate to batter expansion and layer volume. Cereal Chem. 56(4): 324-327

Lahtinen, S., Levola, M., Jouppila, K., and Salovaara, H. 1998. Factors affecting cake firmness and cake moisture content as evaluated by Response Surface Methodology. Cereal Chem. 75(4): 547-550.

Lee, C. C. and Hoseney, R. C. 1982a. Development of a laboratory-scale single-stage cake mix. Cereal Chem. 59(5): 389-392.

Lee, C. C. and Hoseney, R. C. 1982b. Optimization of the fat-emulsifiers system and the gumegg white-water system for a laboratory-scale single-stage cake mix. Cereal Chem. 59(5): 392395.

List, G.R. 2004. Decreasing trans and saturated fatty acid content in food oils. Food Technology. 58(1): 23-31

Matz, S. A. 1987. Ingredients for Bakers. Pan-Tech International: Mc Allen, TX.

McGill, E.A. 1973. Oils and fats in baking. I. Pumpable shortening - advantages and 
savings. Baking Industries Journal. 5(11): 19, 22, 24

Mizukoshi, M. 1985. Model studies of cake caking. VI. Effects of cake ingredients and cake formula on shear modulus of cake. Cereal Chem. 62(4): 247-251

Moon, H., Lee, H., Seo, J., Chung, C., Kim, T., Chai, Y., and Cho, C. 2009. Antiobesity effect of PEGylated conjugated linoleic acid on high-fat diet-induced obese C57BL/6J (ob/ob) mice: attenuation of insulin resistance and enhancement of antioxidant defenses. Journal of Nutritional Biochemistry. 20(3): 187-194.

O’Brien, R.D. 1996. Shortening: types and formulations, in: Bailey's Industrial Oil \& Fat Products (Fifth Edition). John Wiley \& sons, Inc. New York, NY. Volume III. Pp: 161-192

O’Brien, R.D. 1998. Fats and oils: formulating and processing for applications. Technomic Publishing Company, Inc. PA. Pp: 251-383

Orthoefer, F. 2008. Applications of emulsifiers in baked foods. In: Food Emulsifiers and Their Applications (Second edition). Springer. Ed: Hasenhuettl, G. and Hartel, R. Page: 263-283.

Pohl, P.A. 1968. Freeze-drying cake batter for microscopic study. Journal of Food Sci. 33: 318.

Pyler, E.J. 1988. Baking Science \& Technology (Third Edition). Sosland Publishing Company. Kansas City. MO.

Ramli, M.R., Lin, S. W., Yoo, C.K., Idris, N.A., and Sahri, M.M. 2008. Physico-chemical properties and performance of high oleic and palm-based shortenings. Journal of Oleo Science. 57(11): 605-612

Rajiv, J., Prabhasankar, P., Indrani, D., and Rao, G. V. 2003. Shortening based emulsifying formulation for the preparation of cakes and its method. World Patent. WO 03/079802. 
Richardson, G., Langton, M., Faldt, P., and Hermansson, A.-M. 2002. Microstructure of acrystalline emulsifiers and their influence on air incorporation in cake batter. Cereal Chem. 79(4): 546-552.

Rusch, D. T. 1981. Emulsifiers: Uses in cereal and bakery foods. Cereal Foods World. 26(3): 111-115

Sakiyan, O., Sumnu, G., Sahin, S., and Bayram, G. 2004. Influence of fat content and emulsifier type on the rheological properties of cake batter. Eur Food Res Technol. 219: 635-638

Schuster, G., and Adams, W.F. 1984. Emulsifiers as additives in bread and fine baked products. P139 in: Advances in Cereal Sci. and Tech. Y. Pomeranz, ed. Am. Assoc. of Cereal Chem.: St. Paul, MN.

Stauffer, C. E. 1990. Functional additives for bakery foods. Van Nostrand Reinhold, New York.

Stauffer, C.E. 1999. Bakery products P47-66 in: Emulsifiers (Eagan Press Handbook Series). Published by AACC, St. Paul, MN.

Walker, C. E. and Parkhurst, A. M. 1984. Response surface analysis of bake-lab data with a personal computer. Cereal foods world. 29 (10): 662-666.

Walker, C. E., West, D. I., Pierce, M. M., and Buck, J. S. 1988. Cake firmness measurement by the Universal Testing Machine. Cereal Chem. 65(4): 302-307.

Wootton, J.C., Howard, N.B., Martin, J.B., McOsker, D.E., and Holme, J. 1967. The role of emulsifiers in the incorporation of air into layer cake batter systems. Cereal Chem. 44(3): 333-343

Zelch, Ronald. 2001. Batter Cakes. American Institute of Baking Technical Bulletin. XXIII (3): $1-10$ 


\section{Appendix A - RSM}

Analysis of Data File: $1^{\text {st }}$ Cake firmness. RSM

Using Model: STD 3_VAR | C 1223122313112233

Coefficient of Determination $\left(R^{\wedge} 2\right)=0.70180$

Coefficient of Multiple Correlation $=0.83774$

Standard Error of Estimate 37.40268

EQUATION :

FIRM-1

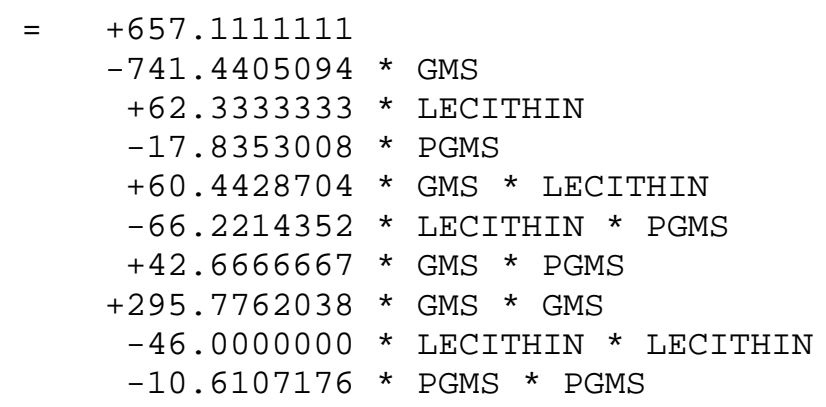


Response in FIRM-1

(Stepping Variable: GMS $=.5$ )

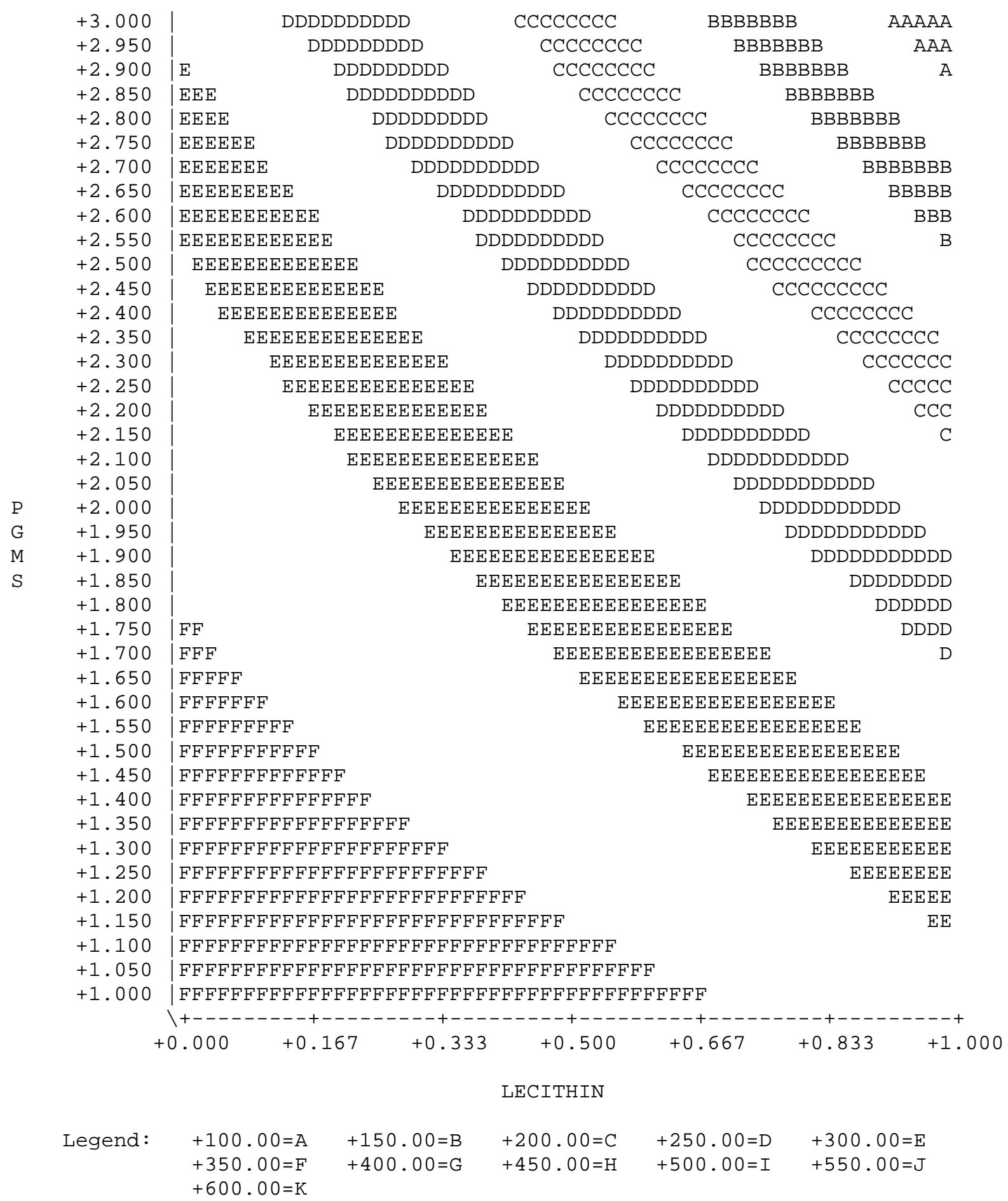


Response in FIRM-1

(Stepping Variable: GMS $=1.5$ )

$+3.00 \odot$ |DDDDD

+2.950 |DDDDDDD

+2.900 DDDDDDDDD

+2.850 DDDDDDDDDDD

+2.800 DDDDDDDDDDDDD

+2.750 DDDDDDDDDDDDDDDD

+2.700 DDDDDDDDDDDDDDDDDD

+2.650 |DDDDDDDDDDDDDDDDDDDDD

+2.600 |DDDDDDDDDDDDDDDDDDDDDDDD

+2.550 DDDDDDDDDDDDDDDDDDDDDDDDDD

+2.500 DDDDDDDDDDDDDDDDDDDDDDDDDDDDD

+2.450 |DDDDDDDDDDDDDDDDDDDDDDDDDDDDDDDDD

+2.400 DDDDDDDDDDDDDDDDDDDDDDDDDDDDDDDDDDDD

$+2.350$

$+2.300$

$+2.250$

$+2.200$

$+2.150$

$+2.100$

$+2.050$

$+2.000$

$+1.950$

$+1.900$

$+1.850$

$+1.800$

$+1.750$

$+1.700$

$+1.650$

$+1.600$

$+1.550$

$+1.500$

$+1.450$

$+1.400$

$+1.350$

$+1.300$

$+1.250$

$+1.200$

$+1.150$

$+1.100$

$+1.050$

$+1.000$ DDDDDDDDDDDDDDDDDDDDDDDDDDDDDDDDDDDDDDD

DDDDDDDDDDDDDDDDDDDDDDDDDDDDDDDDDDDDDDDDDDD | DDDDDDDDDDDDDDDDDDDDDDDDDDDDDD

DDDDDDDDDDDDDDDDDDDDDDDDDDDD

DDDDDDDDDDDDDDDDDDDDDDDDDDD

|DDDDDDDDDDDDDDDDDDDDDDDDDD

DDDDDDDDDDDDDDDDDDDDDDDDD DDDDDDDDDDDDDDDDDDDDDDD DDDDDDDDDDDDDDDDDDDDDD DDDDDDDDDDDDDDDDDDDDD DDDDDDDDDDDDDDDDDDDDD DDDDDDDDDDDDDDDDDDDD DDDDDDDDDDDDDDDDDDD DDDDDDDDDDDDDDDDDDD

$\operatorname{ccc} \operatorname{coc} \operatorname{coc} c \operatorname{ccc}$

CCCCCCCCCCCCCCC

$\operatorname{ccc} \operatorname{ccc} \operatorname{cCC} C \operatorname{CCC}$

$\operatorname{ccc} \operatorname{ccC} C \operatorname{CCCCCC}$ $\operatorname{cccccccccccccccc}$

$\operatorname{ccc} \operatorname{coc} \operatorname{ccc} C \operatorname{ccc} C$ cCCCCCCCCCCCCCCC $\operatorname{coc} \operatorname{coc} \operatorname{ccc} c \mathrm{CCCC}$ $\operatorname{ccccccccccccc}$ $\operatorname{cccccccccC}$ $\operatorname{ccCCCCC}$ $\operatorname{CCCC}$

|DDDDDDDDDDDDDDDDDDDDDDDDDDDDDDDDDDDDDDDDDDDDDD DDDDDDDDDDDDDDDDDDDDDDDDDDDDDDDDDDDDDDDDDDDDDDDDDD DDDDDDDDDDDDDDDDDDDDDDDDDDDDDDDDDDDDDDDDDDDDDDDDDDDDDD

DDDDDDDDDDDDDDDDDDDDDDDDDDDDDDDDDDDDDDDDDDDDDDDDDDDDDDDDDD |DDDDDDDDDDDDDDDDDDDDDDDDDDDDDDDDDDDDDDDDDDDDDDDDDDDDDDDDDDDD | DDDDDDDDDDDDDDDDDDDDDDDDDDDDDDDDDDDDDDDDDDDDDDDDDDDDDDDDDDDD |DDDDDDDDDDDDDDDDDDDDDDDDDDDDDDDDDDDDDDDDDDDDDDDDDDDDDDDDDDDD DDDDDDDDDDDDDDDDDDDDDDDDDDDDDDDDDDDDDDDDDDDDDDDDDDDDDDDDDDDD DDDDDDDDDDDDDDDDDDDDDDDDDDDDDDDDDDDDDDDDDDDDDDDDDDDDDDDDDDDD DDDDDDDDDDDDDDDDDDDDDDDDDDDDDDDDDDDDDDDDDDDDDDDDDDDDDDDDDDDD DDDDDDDDDDDDDDDDD DDDDDDDDDDDDDDDD DDDDDDDDDDDDDDDD EEEEEEEE DDDDDDDDDDDDDDD EEEEEEEEE

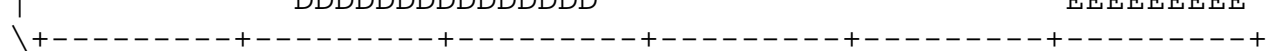
$\begin{array}{llllll}+0.000+0.167 & +0.333+0.500 \quad+0.667 & +0.833 & +1.000\end{array}$

LECITHIN

$\begin{array}{llllll}\text { Legend: } & +100.00=\mathrm{A} & +150.00=\mathrm{B} & +200.00=\mathrm{C} & +250.00=\mathrm{D} & +300.00=\mathrm{E} \\ & +350.00 \mathrm{~F} & +400.00=\mathrm{G} & +450.00=\mathrm{H} & +500.00=\mathrm{I} & +550.00=\mathrm{J} \\ & +600.00=\mathrm{K} & & & & \end{array}$


Analysis of Data File: CAKVOLM3.RSM

Using Model: STD 3_VAR | C C $122312 \quad 2313112233$

Coefficient of Determination $\left(R^{\wedge} 2\right)=0.51182$

Coefficient of Multiple Correlation $=0.71542$

Standard Error of Estimate 4.40101

EQUATION :

VOLUME

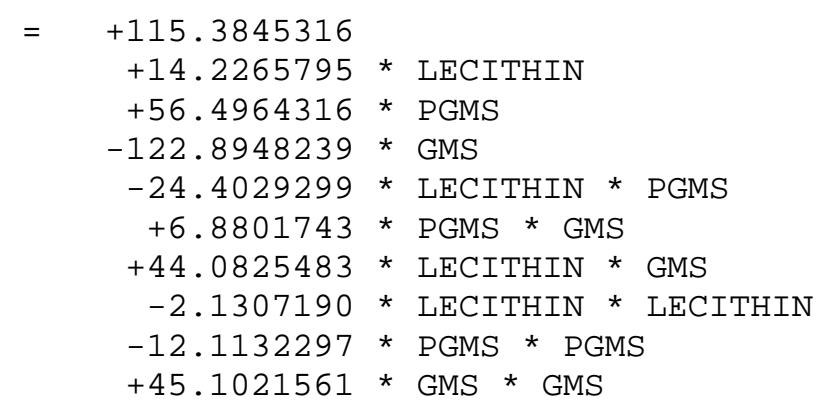


Response in VOLUME

(Stepping Variable: GMS $=.5$ )

$+3.000 \mid \mathrm{J}$ III HHH GGG FFF EEE DDD CCC BBB AAAAAAA +2.950 JJ III HHHH GGG FFFF EEE DDD CCC BBB AAAA $+2.900 \mathrm{JJJ}$ III HHH GG FFF EEE DDD CCC BBB AA +2.850 |JJJ IIII HHHH GGG FFF EEE DDDD CCC BBBB +2.800 JJJ IIII HHHH GGG FFF EEE DDDD CCCC BBB +2.750 JJJJ IIII HHH GGG FFFF EEE DDD CCC +2.700 JJJJ IIII HHHH GGG FFFF EEE DDDD CCCC +2.650 JJJJ IIII HHHH GGGG FFFF EEE DDDD CC +2.600 JJJJ IIII HHHH GGG FFFF EEEE DDD

$+2.550$

$+2.500$

$+2.450$

$+2.400$

$+2.350$

$+2.300$

$+2.250$

$+2.200$

$+2.150$

$+2.100$

$+2.050$

$\mathrm{AJJJJ}$

JJJJJ

JJJJנ

JuJju

azaju

AJJJJJ

נבנבנבנת

JuJJuJu

IJjJJjJ

|JJנJנJJ

IJJJJjo

$P \quad+2.000 \mid \mathrm{JJJJ}$

$\mathrm{G} \quad+1.950 \mid \mathrm{J}$

$M \quad+1.900$

$+1.650$

$+1.600$

$+1.550$

$+1.500$

$+1.450$

$+1.400$

$+1.350$

$+1.300$

$+1.250$

$+1.200$

$+1.150$

$+1.100$

$+1.050$

$+1.000$

J

IIIIIIIIIIII

IIIIIIIIIIIII

IIIIIIII

II

|

НHНHНHНHНHНHНHНHНHНHН

HНHНHНHНHНHHHH

FFFFF EEEE DDDD

IIIII HHHHH GGGG FFFFF EEEE DDD

IIIII HHHH GGGG FFFFF EEEE

IIIIII HHHHH GGGG FFFFF EEEEE

IIIII HHHHH GGGG FFFFF EEEE

IIIIII HHHHHH GGGGG FFFFF EE

IIIIII HHHHHH GGGG FFFFF

IIIIIII HHHHHH GGGGGG FFFFF

IIIIIII HHHHHH GGGGG

IIIIIII HHHHHHH GGGGGG FFFF

IIIIIIII HHHHHHH GGGGGG FF

IIIIIIII

$\mathrm{HHHHHHHH}$

$\mathrm{HHHHHHHHH}$

$\mathrm{HHHHHHHHHH}$

$\mathrm{HHHHHHHHHH}$

GGGGGGG

GGGGGGGG

GGGGGGGGG

GGGGGGGGGG

GGGGGGGGGG

GGGGGGGGG

GGGGGGGG

HHHHHHHHHHHHHHHHHHHHHHHHH

I

GGGGGGG

GGGGGGG

GGGGGGG

GGGGGGGG

GGGGGGGGGGGG

| GGGGGGGGGGGGGGGGGGGGGGGGGGGGGGGGGGGGGGGGGGGGGGGGGGGGGGGGGG

| GGGGGGGGGGGGGGGGGGGGGGGGGGGGGGGGGGGGGGGGGGGGGGGGGGGGGGGGG

FFFFFFFFF

GGGGGGGGGGGGGGGGGGGGGGGGGGGGGGGGGGGGGG

FFFFFFFFFFFFFFFFFFFF

GGGGGGGGGGGGGGGGGGGGGG

FFFFFFFFFFFFFFFFFFF

GGGGGGGGGG

|EEEEEEEEEEE

FFFFFFFFFFFFFFFFF

EEEEEEEEEEEEE

FFFFFFFFFFFFFFFF

DDDDD

EEEEEEEEEEEE

FFFFFFFFFFFFFF

$+\odot .000+\odot .167+\odot .333+0.500+0.667+0.833+1.000$

LECITHIN

$\begin{array}{llllll}\text { Legend: } & +100.00=\mathrm{A} & +104.00=\mathrm{B} & +108.00=\mathrm{C} & +112.00=\mathrm{D} & +116.00=\mathrm{E} \\ & +120.00=\mathrm{F} & +124.00=\mathrm{G} & +128.00=\mathrm{H} & +132.00=\mathrm{I} & +136.00=\mathrm{J}\end{array}$


Response in VOLUME

(Stepping Variable: GMS $=1.5$ )

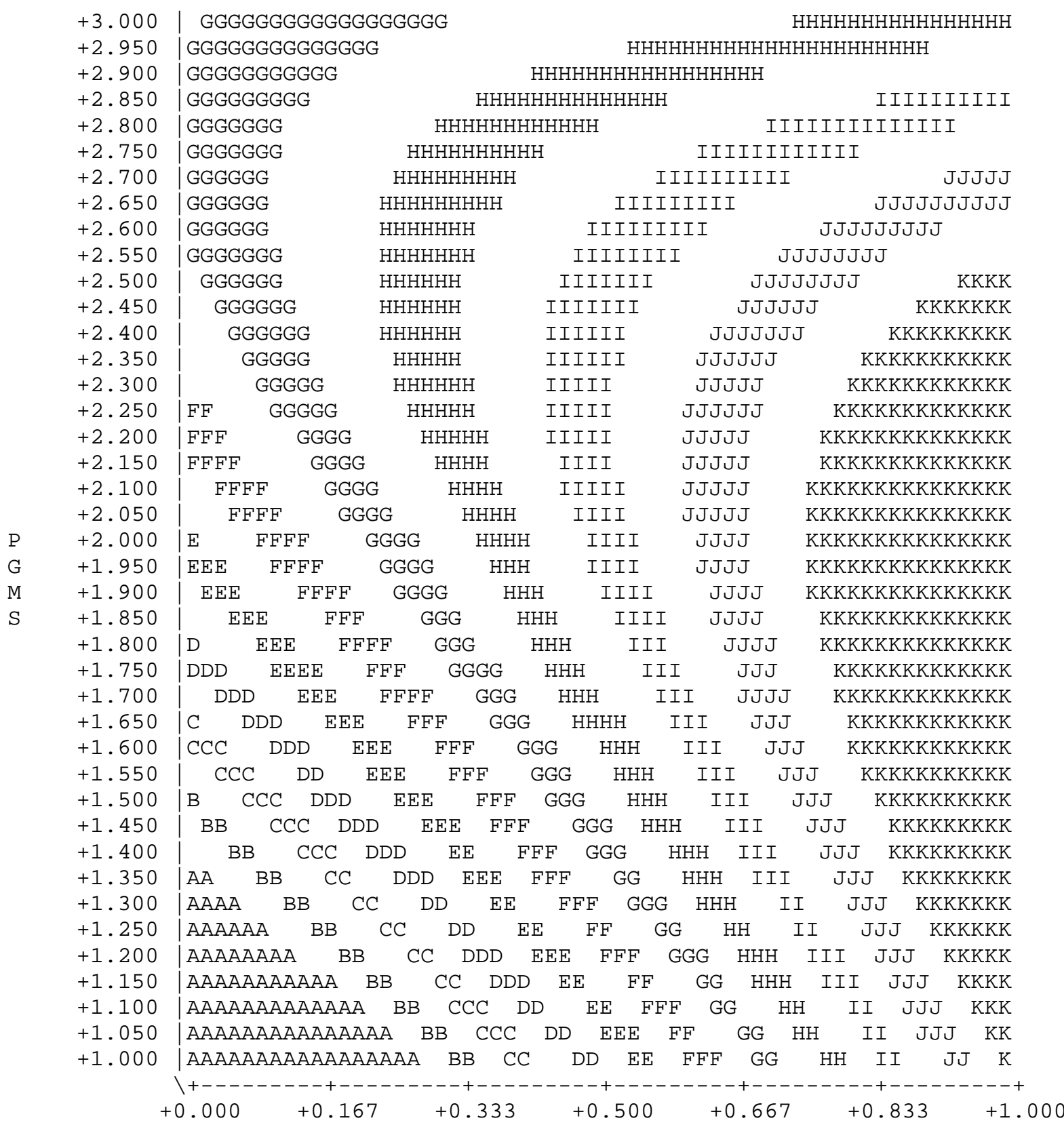

LECITHIN

\begin{tabular}{|c|c|c|c|c|c|}
\hline Legend: & $\begin{array}{l}+100 \cdot 00=\mathrm{A} \\
+120 \cdot 00=\mathrm{F}\end{array}$ & $\begin{array}{l}+104.00=\mathrm{B} \\
+124.00=\mathrm{G}\end{array}$ & $\begin{array}{l}+108.00=C \\
+128.00=H\end{array}$ & $\begin{array}{l}+112.00=D \\
+132.00=I\end{array}$ & $\begin{array}{l}+116 \cdot 00=E \\
+136 \cdot 00=J\end{array}$ \\
\hline
\end{tabular}


Analysis of Data File: CAKSCOR3.RSM

Using Model: STD 3_VAR | C $12231223 \quad 13112233$

Coefficient of Determination $\left(R^{\wedge} 2\right)=0.64586$

Coefficient of Multiple Correlation $=0.80366$

Standard Error of Estimate 6.47671

EQUATION :

SCORE

\begin{tabular}{|c|c|c|}
\hline +45. 5882353 & & \\
\hline+30.6339869 & * LECITHIN & \\
\hline - 9.9198587 & * PGMS & \\
\hline+60.3822011 & * GMS & \\
\hline+8.3117343 & * LECITHIN * & PGMS \\
\hline+2.7320261 & * PGMS * GMS & \\
\hline-23.8652988 & * LECITHIN * & GMS \\
\hline-8.3529412 & * LECITHIN * & LECITHIN \\
\hline+2.2441025 & * PGMS * PGMS & \\
\hline-26.845 & * GMS * GMS & \\
\hline
\end{tabular}


Response in SCORE

(Stepping Variable: GMS $=.5$ )

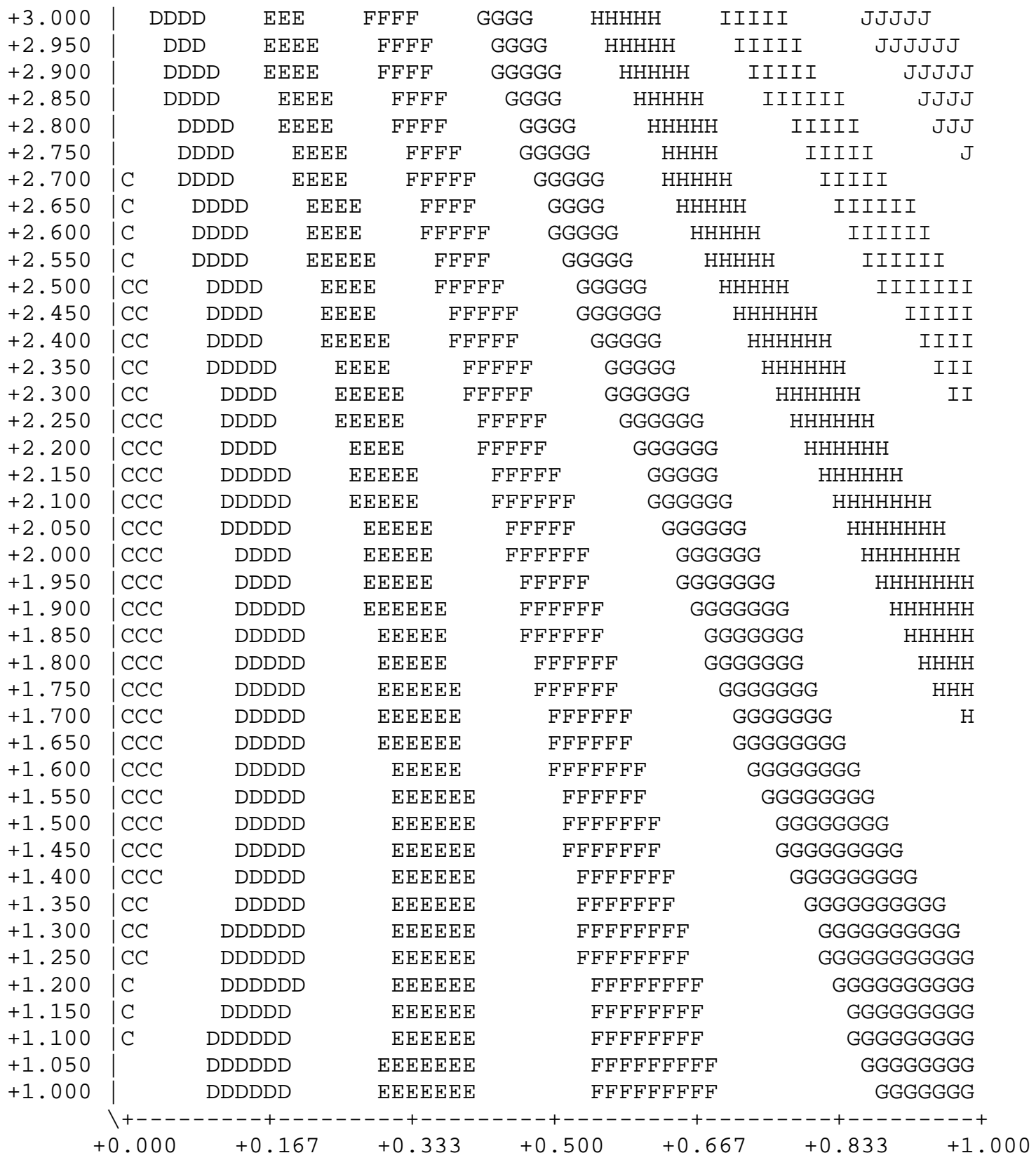

\section{LECITHIN}

$\begin{array}{llllll}\text { Legend: } \quad & +50.00=\mathrm{A} & +55.00=\mathrm{B} & +60.00=\mathrm{C} & +65.00=\mathrm{D} & +70.00=\mathrm{E} \\ & +75.00=\mathrm{F} & +80.00=\mathrm{G} & +85.00=\mathrm{H} & +90.00=\mathrm{I} & +95.00=\mathrm{J} \\ +100.00 \mathrm{~K} & & & & & \end{array}$


Response in SCORE

(Stepping Variable: GMS $=1.5$ )

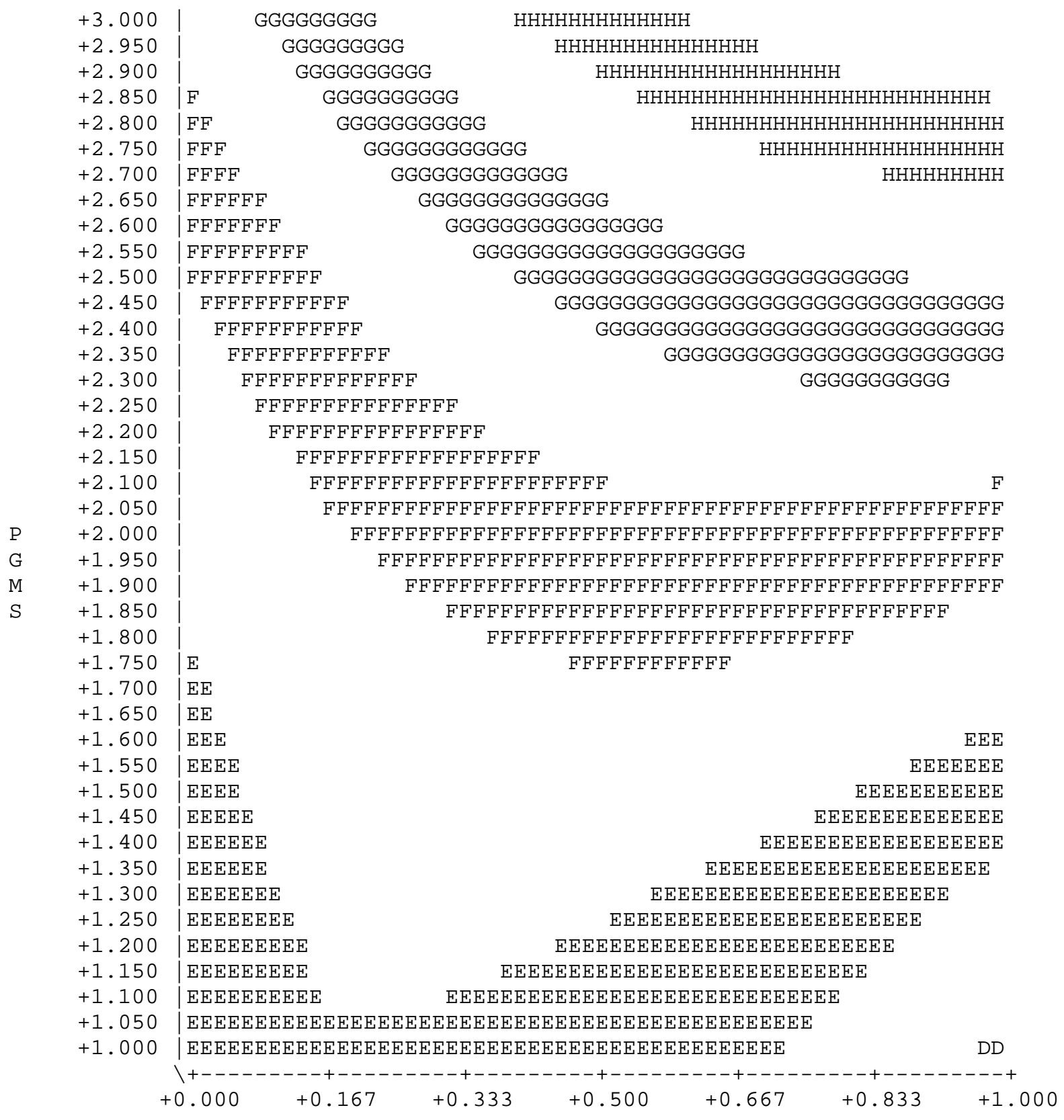

LECITHIN

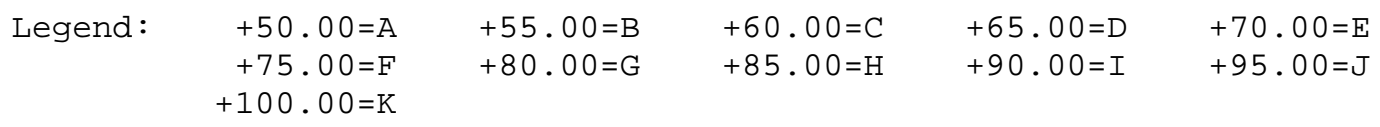


Analysis of Data File: CAKF-01.RSM

Using Model: STD 3_VAR | C 1223122313112233

Coefficient of Determination $\left(R^{\wedge} 2\right)=0.70180$

Coefficient of Multiple Correlation $=0.83774$

Standard Error of Estimate 37.40268

EQUATION :

FIRM-1

$=\quad+657.1111111$

-741.4405094 * GMS

+62.3333333 * LECITHIN

-17.8353008 * PGMS

+60.4428704 * GMS * LECITHIN

-66.2214352 * LECITHIN * PGMS

+42.6666667 * GMS * PGMS

+295.7762038 * GMS * GMS

-46.0000000 * LECITHIN * LECITHIN

-10.6107176 * PGMS * PGMS 
Response in FIRM-1

(Stepping Variable: PGMS = 1)

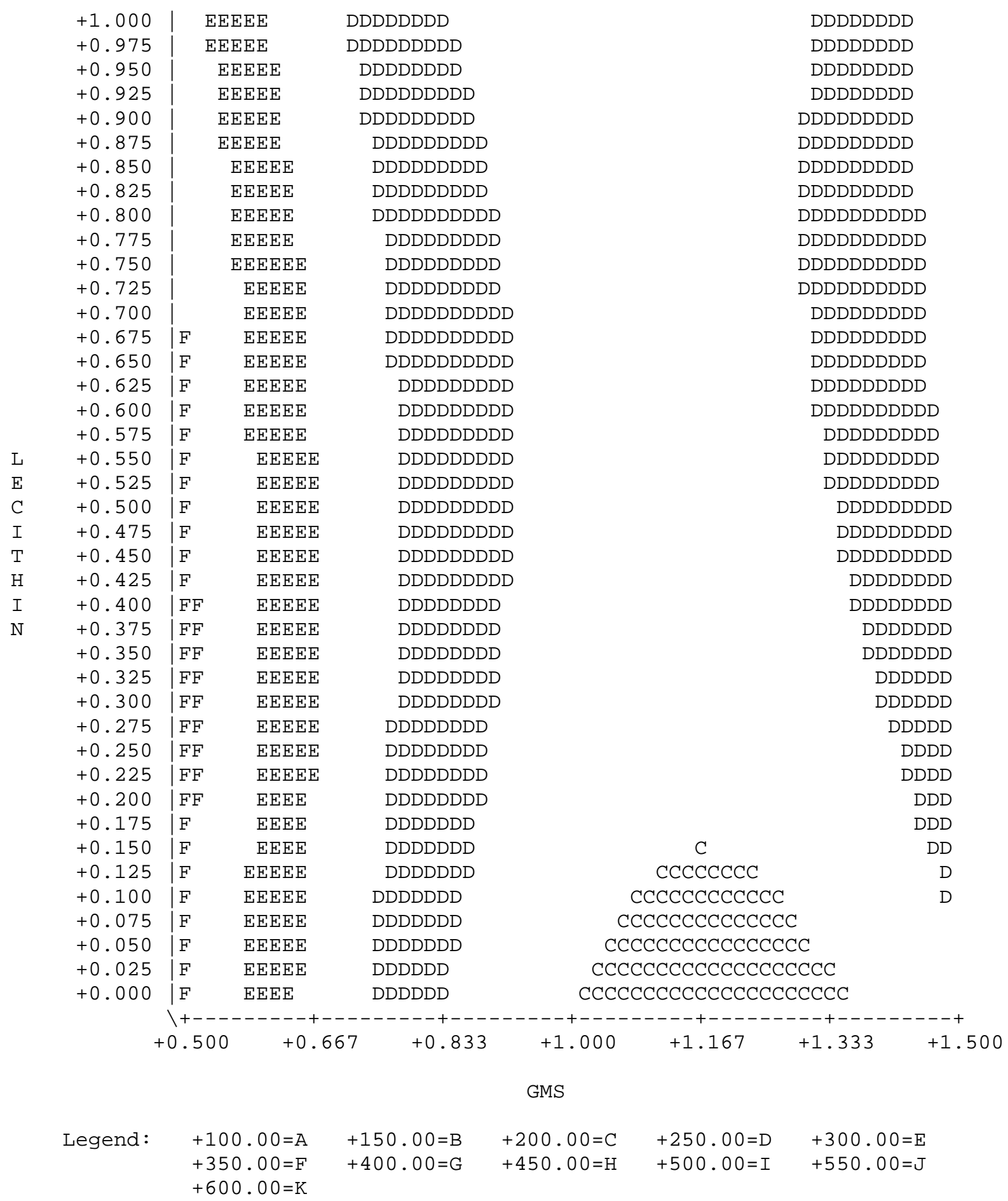


Response in FIRM-1

(Stepping Variable: PGMS $=1.5$ )

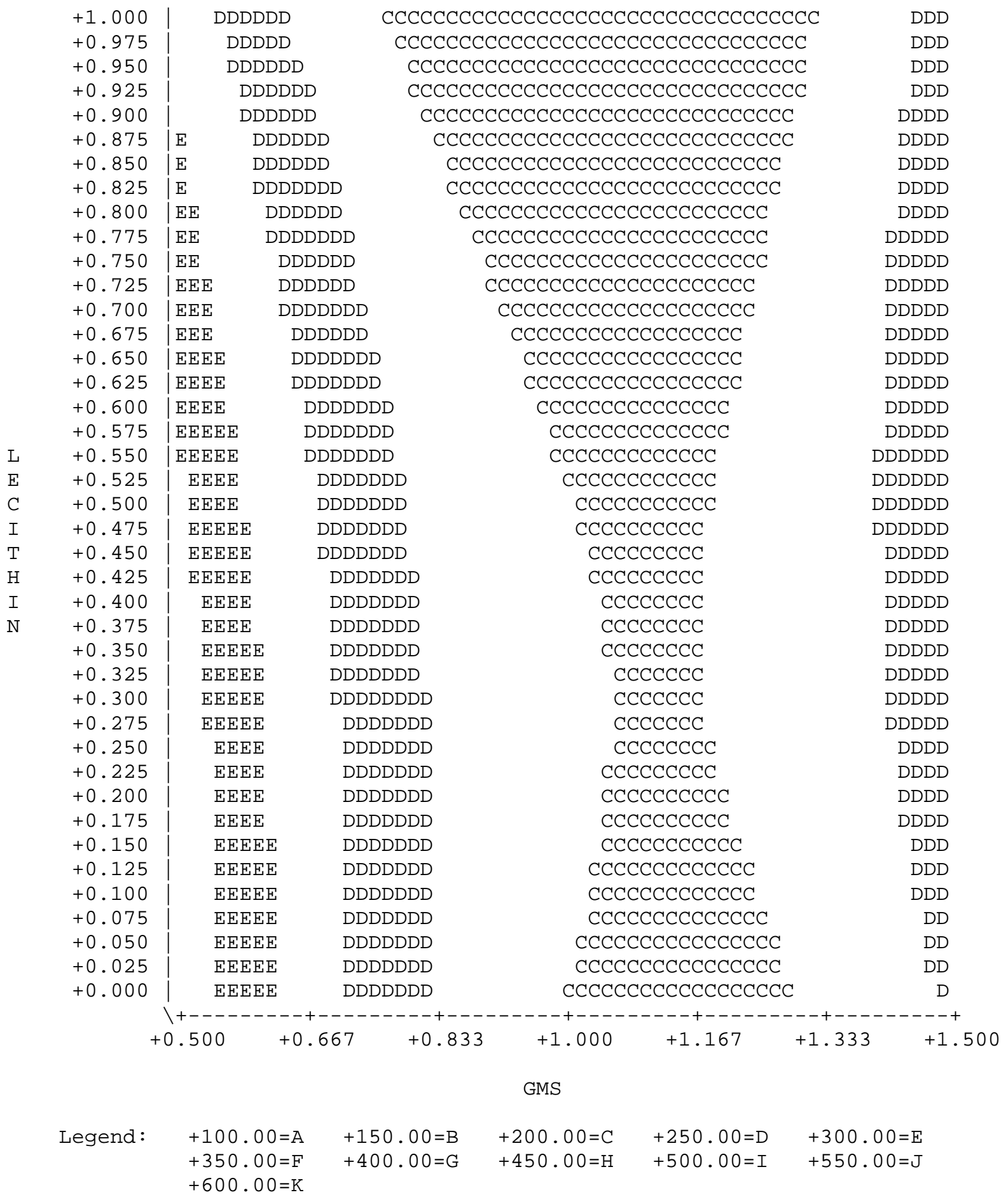


Response in FIRM-1

(Stepping Variable: PGMS = 2)

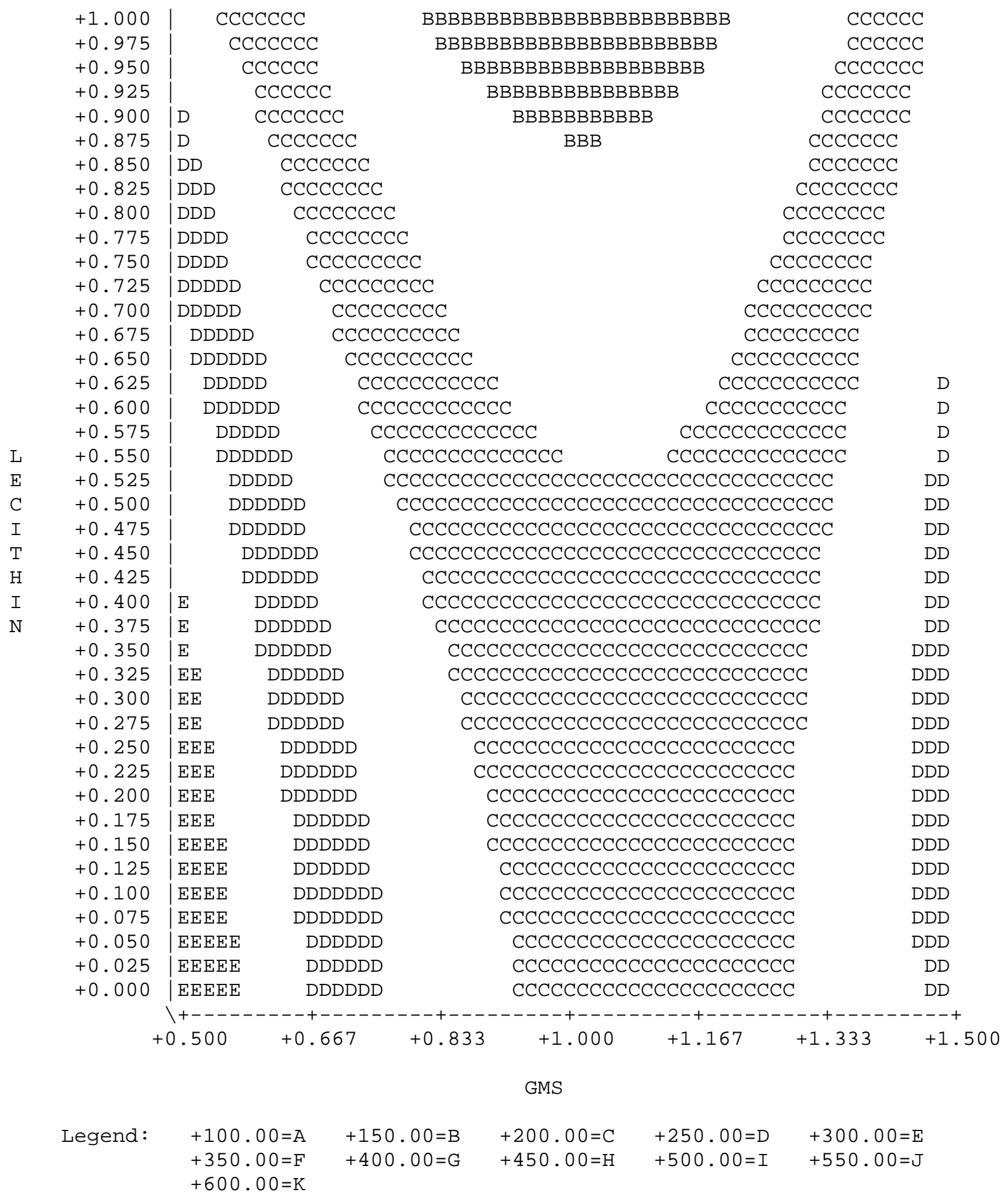


Analysis of Data File: CAKVOLM2.RSM

Using Model: STD 3_VAR | C $12231223 \quad 13112233$

Coefficient of Determination $\left(R^{\wedge} 2\right)=0.51182$

Coefficient of Multiple Correlation $=0.71542$

Standard Error of Estimate 4.40101

EQUATION :

VOLUME

$$
\begin{aligned}
= & +115.3845316 \\
& -82.0127623 * \text { GMS } \\
+ & 14.2265795 * \text { LECITHIN } \\
+ & 36.0554007 \text { * PGMS } \\
+ & 27.7297236 \text { * GMS * LECITHIN } \\
& -16.2265176 \text { * LECITHIN * PGMS } \\
& +6.8801743 \text { * GMS * PGMS } \\
+ & 28.7493315 * \text { GMS * GMS } \\
& -2.1307190 * \text { LECITHIN * LECITHIN } \\
& -8.0250235 * \text { PGMS * PGMS }
\end{aligned}
$$


Response in VOLUME

(Stepping Variable: PGMS $=1$ )

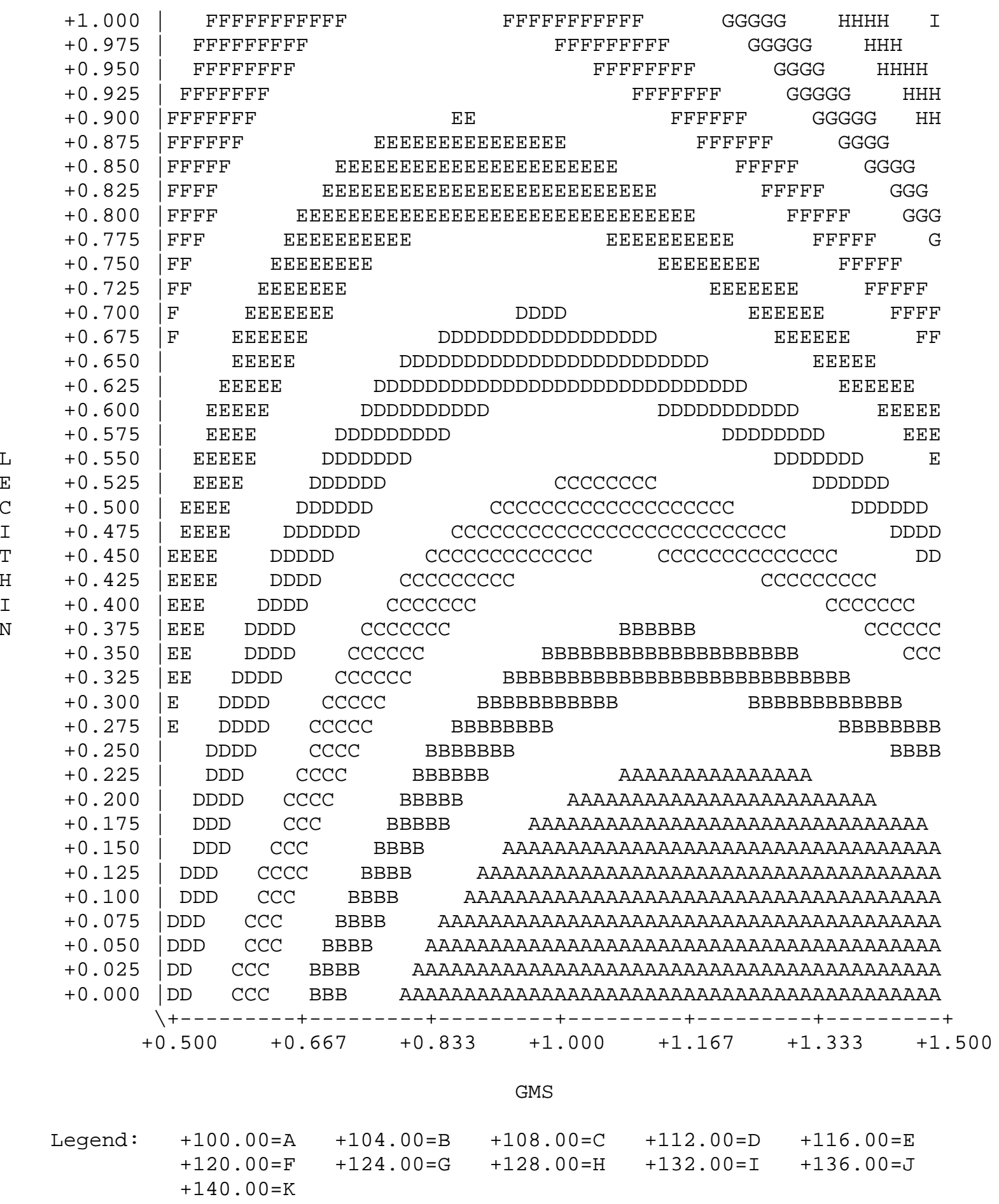


Response in VOLUME

(Stepping Variable: PGMS $=2$ )

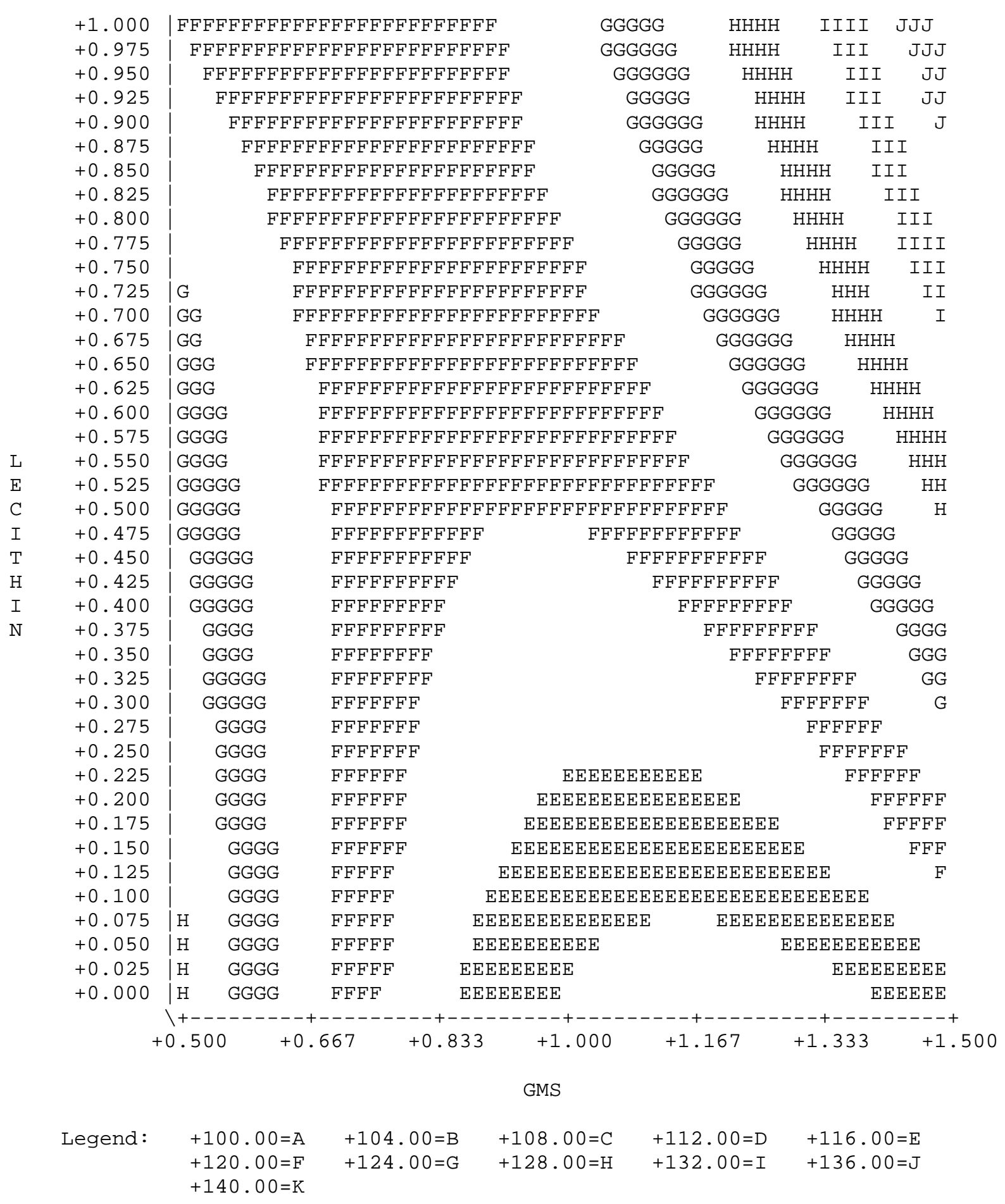


Response in VOLUME

(Stepping Variable: PGMS = 3)

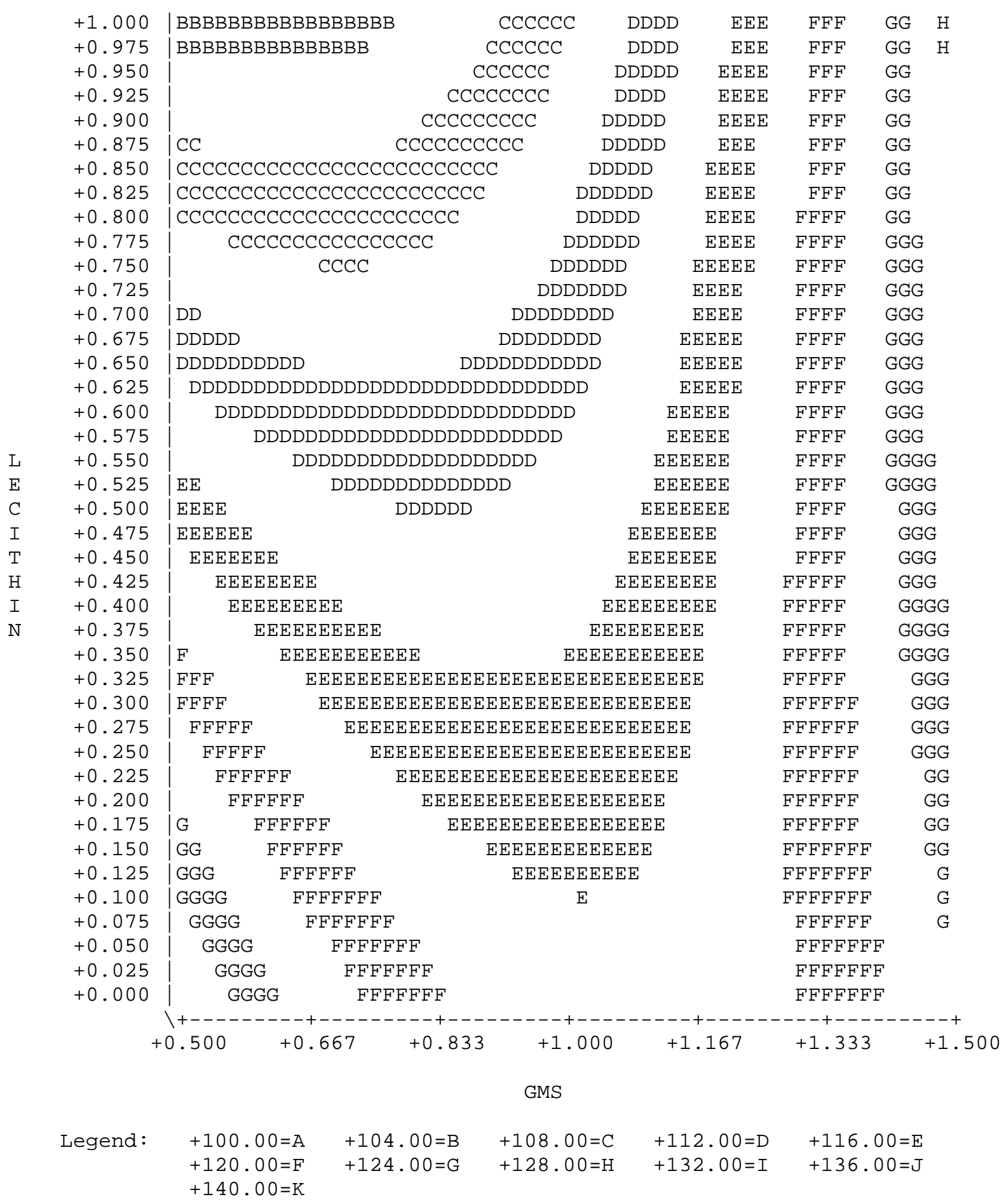


Analysis of Data File: CAKESCORE.RSM

Using Model: STD 3_VAR | C $12231223 \quad 13112233$

Coefficient of Determination $\left(R^{\wedge} 2\right)=0.64586$

Coefficient of Multiple Correlation $=0.80366$

Standard Error of Estimate 6.47671

EQUATION :

SCORE

$\begin{aligned}= & +45.5882353 \\ + & 45.5438092 * \text { GMS } \\ + & 30.6339869 * \text { LECITHIN } \\ & -2.5006628 * \text { PGMS } \\ & -17.9299420 * \text { GMS * LECITHIN } \\ & +5.3440560 * \text { LECITHIN * PGMS } \\ & +2.7320261 * \text { GMS * PGMS } \\ & -20.9103341 * \text { GMS * GMS } \\ & -8.3529412 * \text { LECITHIN * LECITHIN } \\ & +0.7602633 * \text { PGMS * PGMS }\end{aligned}$


Response in SCORE

(Stepping Variable: PGMS = 1)

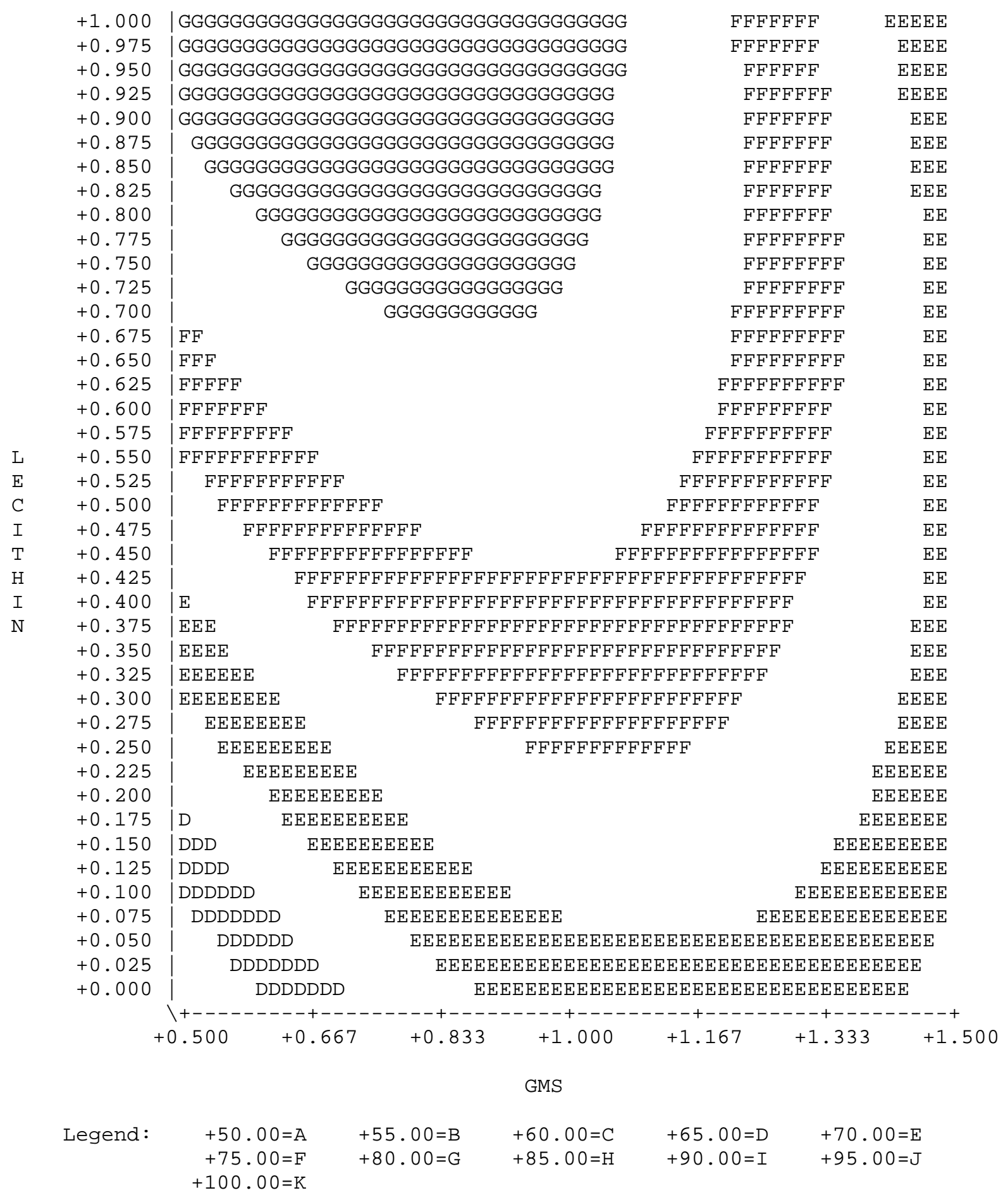


Response in SCORE

(Stepping Variable: PGMS = 2)

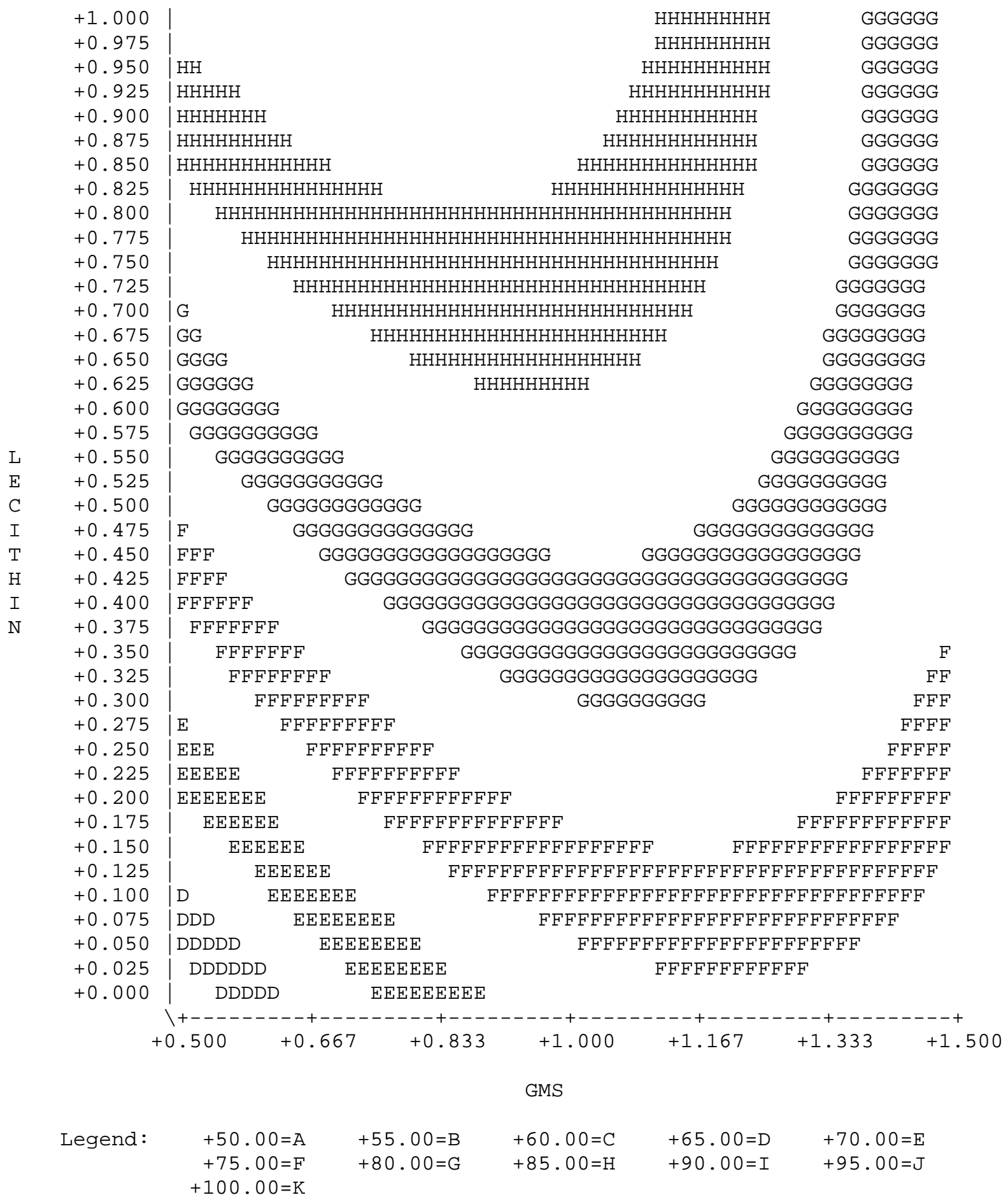


Response in SCORE

(Stepping Variable: PGMS = 3)

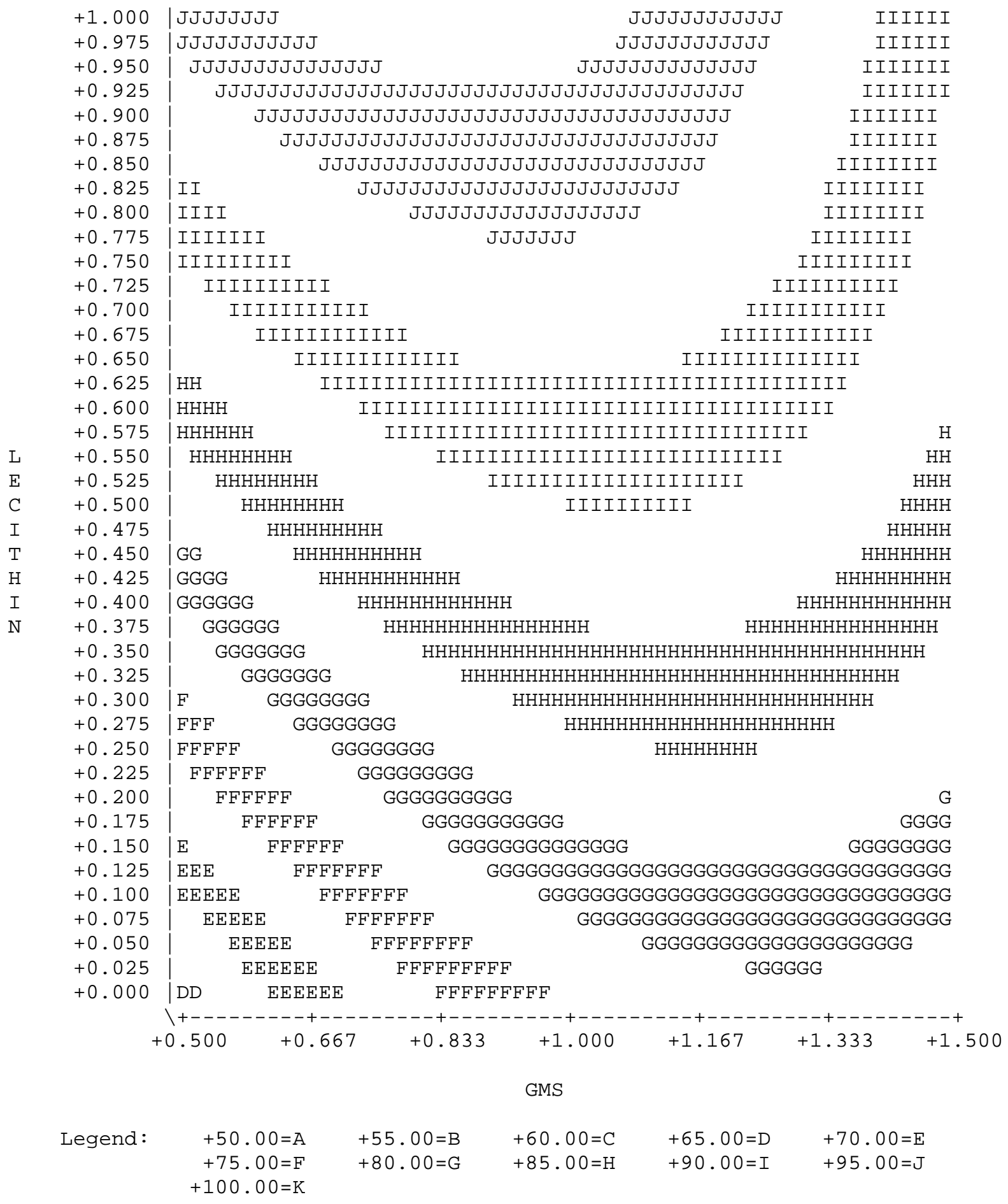


Analysis of Data File: CAKE0109.RSM

Using Model: STD 3_VAR | C $12231223 \quad 13112233$

Coefficient of Determination $\left(R^{\wedge} 2\right)=0.70180$

Coefficient of Multiple Correlation $=0.83774$

Standard Error of Estimate 37.40268

EQUATION :

FIRM-1

$=\quad+657.1111111$

-36.8087927 * PGMS

-703.4935258 * GMS

$+62.3333333 *$ LECITHIN

+42.6666667 * PGMS * GMS

+45.2640770 * GMS * LECITHIN

-58.6320385 * PGMS * LECITHIN

-6.8160192 * PGMS * PGMS

+280.5974103 * GMS * GMS

-46.0000000 * LECITHIN * LECITHIN 
Response in FIRM-1

(Stepping Variable: LECITHIN = 0 )

+1.500 |DDDDDDDDDDDDDDDDDDDDDDDDDDDDDDDDDDDDDDDDDDDDDDDDDDDDDDDDDDDD

$+1.475$

$+1.450$

$+1.425$

$+1.400$

$+1.375$

$+1.350$

$+1.325$

$+1.300$

$+1.275$

$+1.250$

$+1.225$

$+1.200$

$+1.175$

$+1.150$

$+1.125$

$+1.100$

$+1.075$

$+1.050$

$+1.025$

$+1.000$

$+0.975$

$+0.950$

$+0.925$

$+0.900$

$+0.875$

$+0.850$

$+0.825$

$+0.800$

$+0.775$

$+0.750$

$+0.725$

$+0.700$

$+0.675$

$+0.650$

$+0.625$

$+0.600$

$+0.575$

$+0.550$

$+0.525$

$+0.500$ DDDDDDDDDDDDDDDDDDDDDDDDDDDDDDDDDDDDDDDDDDDDDDDDDDDD DDDD

$\operatorname{cccccccc}$

$\operatorname{cccccccccccccccc}$

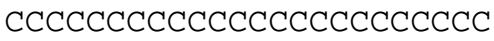

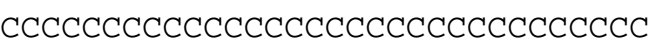

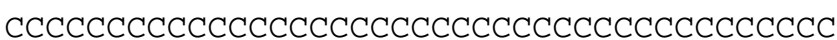

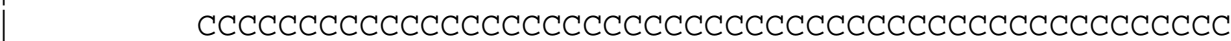

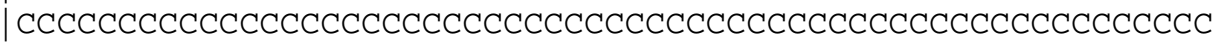



|







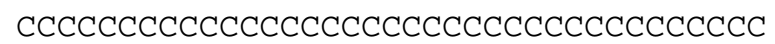



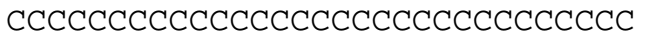

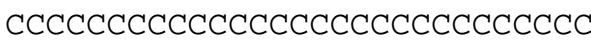

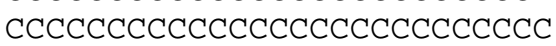

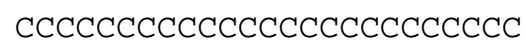

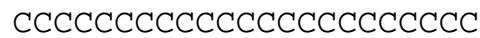

D

сCCCCCCCCCCCCCCCCCCCCC

DDDDDDDDD

DDDDDDDDDDDDDDD

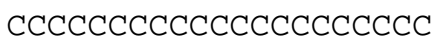

DDDDDDDDDDDDDDDDDDDDD

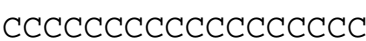

DDDDDDDDDDDDDDDDDDDDDDDDDD

DDDDDDDDDDDDDDDDDDDDDDDDDDDDD

$\operatorname{cccccccccccccc}$

$\operatorname{cccccccccccC}$

DDDDDDDDDDDDDDDDDDDDDDDDD

DDDDDDDDDDDDDDDDDDDDDDD

$\operatorname{ccccccccc}$

|

|EEEE

DDDDDDDDDDDDDDDDDDDDD

$\operatorname{cccccC}$

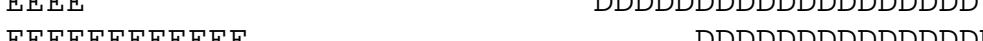

EEEEEEEEEEEEEEEEEEE

DDDDDDDDDDDDDDDDD

EEEEEEEEEEEEEEEEEEEEEEE

EEEEEEEEEEEEEEEEEEEE

DDDDDDDDDDDDDDDD

|

IFFFF

EEEEEEEEEEEEEEEEEEE

DDDDDDDDDDDDDDD

$1+\ldots$. EEEEEEEEEEEEEEEEE

DDDDDDDDDDDD

DDDDDDDD

$\begin{array}{llllll}+1.000 & +1.333+1.667+2.000 & +2.333 & +2.667 & +3.000\end{array}$

PGMS

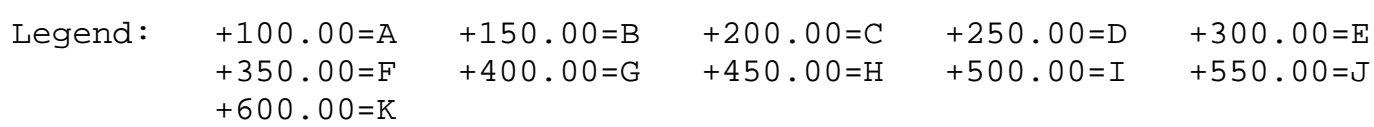


Response in FIRM-1

(Stepping Variable: LECITHIN $=.5$ )

$+1.500$

$+1.475$

$+1.450$

$+1.425$

$+1.400$

$+1.375$

$+1.350$

$+1.325$

$+1.300$

$+1.275$

$+1.250$

$+1.225$

$+1.200$

$+1.175$

$+1.150$

$+1.125$

$+1.100$

$+1.075$

$+1.050$

$+1.025$

$+1.00 \odot$

$+0.975$

$+0.950$

$+\odot .925$

$+0.900$

$+0.875$

$+0.850$

$+\odot .825$

$+0.800$

$+0.775$

$+\odot .750$

$+0.725$

$+0.700$

$+0.675$

$+0.650$

$+\odot .625$

$+0.600$

$+0.575$

$+0.550$

$+\odot .525$

$+\odot .500$
DDDDDDDDDDDDDDDDDDDDDDDDDDDDDDD
| DDDDDDDDDDDDDDDDDDDDDDDDDDDDDD
| DDDDDDDDDDDDDDDDDDDDDDDD
DDDDDDDDDDDDDDDDDDDD

DDDDDDDDDDDDDD

DDDDDDDDD

DDDDD

DD

1

I

1

|

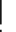

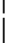

|

1

1

I

ID

DDD

|DDDDD

DDDDDDD

DDDDDDDDDDD

DDDDDDDDDDDD

DDDDDDDDDDDDDDD

DDDDDDDDDDDDDDD

DDDDDDDDDDDDDDD

DDDDDDDDDDDDD

DDDDDDDDDDDDD

E DDDDDDDDDDDD

EEEEE

| EEEEEEEE

| EEEEEEEEEEEE

I EEEEEEEEEEEEE

I EEEEEEEEEEEE

EEEEEEEEEEEE

DDDDDDDDDDDD

DDDDDDDDDDDD

|FFF EEEEEEEEEEE
DDDDDDDDDDD

DDDDDDDDDDD

DDDDDDDDDDD

DDDDDDDDDD

\section{CCCCCCCCCCCCCCCCCC}

$\operatorname{CCCC}$

$\operatorname{ccccccccc}$

ССССССССССС

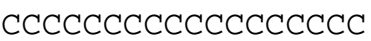

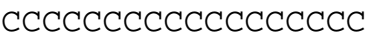

ССССССССССССССССС

СССССССССССССССС

СССССССССССССССС

ССССССССССССССССС

BBB

BBBBBB

BBBBBBBB

BBBBBBBBB

BBBBBBBBBBB

BBBBBBBBBBBB

BBBBBBBBBBBBB

BBBBBBBBBBBBBB

BBBBBBBBBBBBB

BBBBBBBBBBBBB

BBBBBBBBBBBB

BBBBBBBBBBBB

BВBВBВBBBBBB

BBBBBBBBBBBB

BBBBBBBBBBBB

BBBBBBBBBBB

BBBBBBBBBBBB

BBBBBBBBBBB

BBBBBBBBB

BBBBBBBB

BBBBBBB

BBBBBB

BBBB

СटCССССССCC

ССССССССC

СCСССССCC

CCCCCCCCCC

$\operatorname{cccccccccc}$

$\operatorname{cCCCCCCCC~}$

CCCCCCCCCC

ССССССССС DDDDDDDDDD

ССССС $\mathrm{CCCCC}$

$\begin{array}{llllll}+1.000+1.333+1.667+2.000 & +2.333+2.667 & +3.000\end{array}$

PGMS

$\begin{array}{llllll}\text { Legend: } & +100.00=\mathrm{A} & +150.00=\mathrm{B} & +200.00=\mathrm{C} & +250.00=\mathrm{D} & +300.00=\mathrm{E} \\ & +350.00=\mathrm{F} & +400.00=\mathrm{G} & +450.00=\mathrm{H} & +500.00=\mathrm{I} & +550.00=\mathrm{J} \\ & +600.00=\mathrm{K} & & & \end{array}$


Response in FIRM-1

(Stepping Variable: LECITHIN = 1)

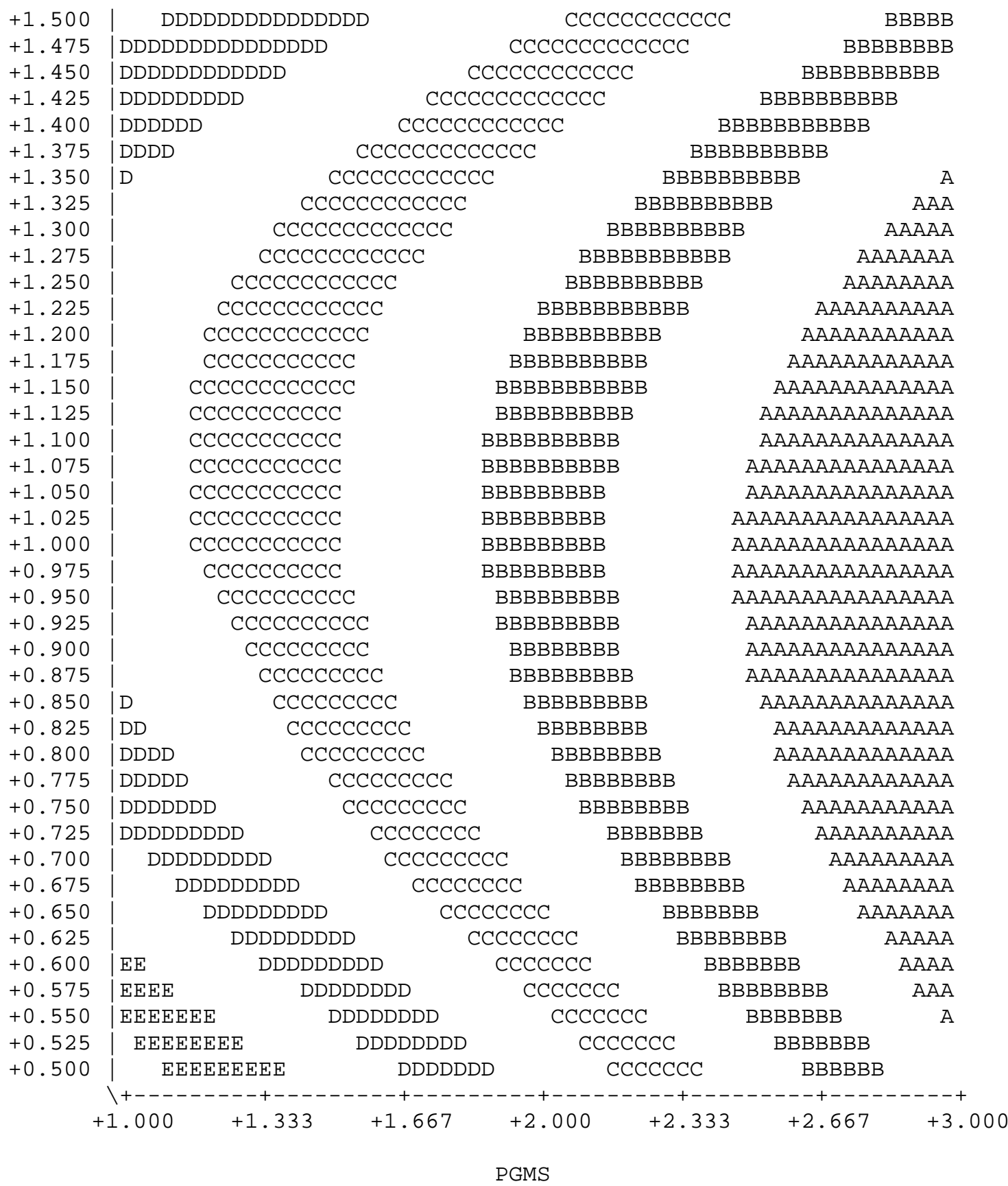

\begin{tabular}{|c|c|c|c|c|c|}
\hline Legend: & $\begin{array}{l}+100 \cdot 00=A \\
+350 \cdot 00=F \\
+600 \cdot 00=K\end{array}$ & $\begin{array}{l}+150 \cdot 0 \odot=B \\
+400 \cdot 0 \odot=G\end{array}$ & $\begin{array}{l}+2 \odot \odot \cdot \odot \odot=C \\
+450 \cdot \odot \odot=H\end{array}$ & $\begin{array}{l}+250 . \odot \odot=D \\
+50 \odot \cdot \odot \odot=I\end{array}$ & $\begin{array}{l}+300 \cdot 0 \odot=E \\
+550 \cdot 0 \odot=J\end{array}$ \\
\hline
\end{tabular}


Analysis of Data File: CAKVOL01.RSM

Using Model: STD 3_VAR | C $12231223 \quad 13112233$

Coefficient of Determination $\left(R^{\wedge} 2\right)=0.51182$

Coefficient of Multiple Correlation $=0.71542$

Standard Error of Estimate 4.40101

EQUATION :

VOLUME

$$
\begin{aligned}
= & +115.3845316 \\
+ & 31.7003734 \text { * PGMS } \\
& -73.3027076 \text { * GMS } \\
+ & 14.2265795 * \text { LECITHIN } \\
& +6.8801743 \text { * PGMS * GMS } \\
+ & 24.2457018 \text { * GMS * LECITHIN } \\
& -14.4845067 \text { * PGMS * LECITHIN } \\
& -7.1540180 * \text { PGMS * PGMS } \\
+ & 25.2653096 \text { * GMS * GMS } \\
& -2.1307190 * \text { LECITHIN * LECITHIN }
\end{aligned}
$$


Response in VOLUME

(Stepping Variable: LECITHIN $=0$ )

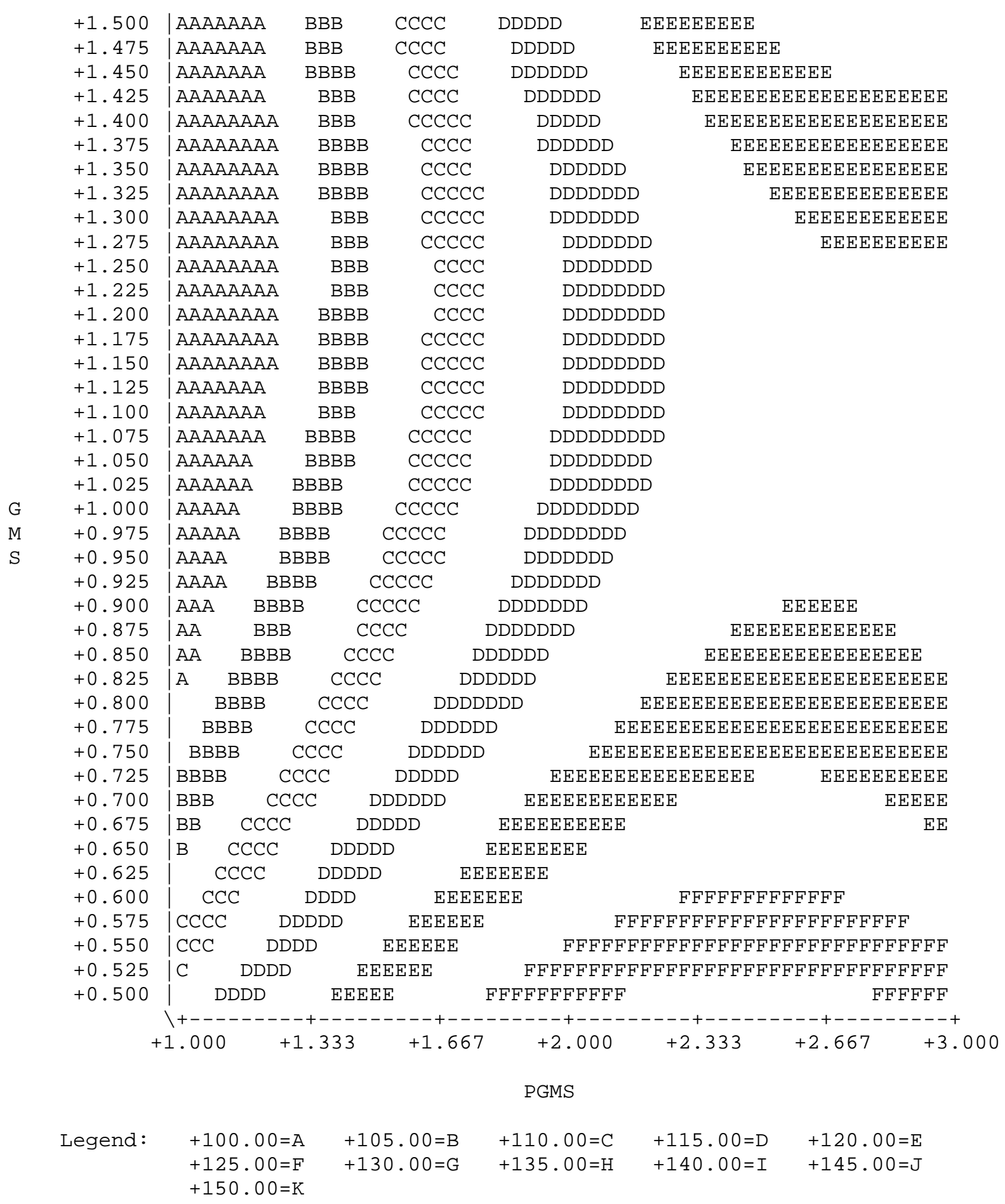


Response in VOLUME

(Stepping Variable: LECITHIN $=.5$ )

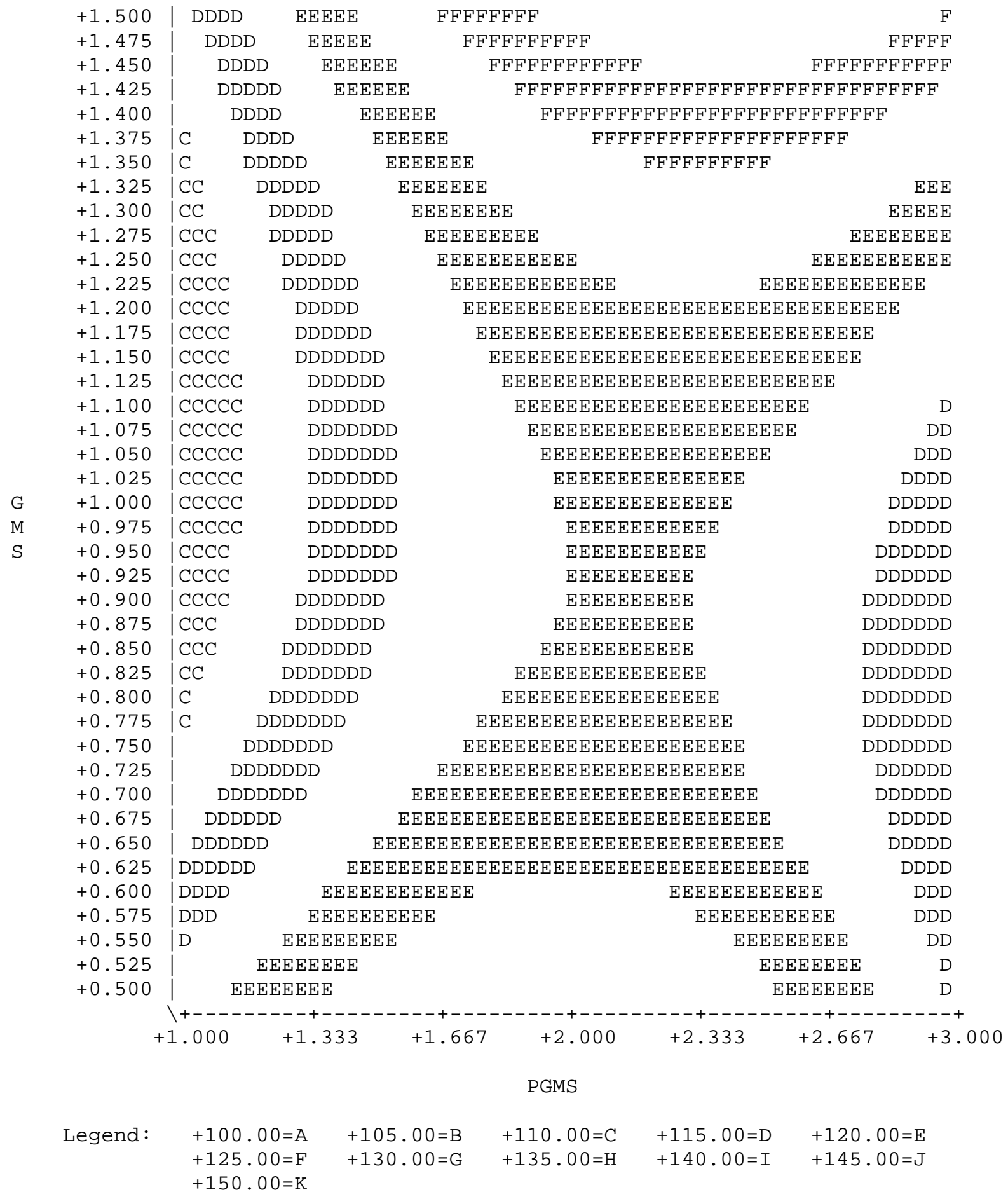




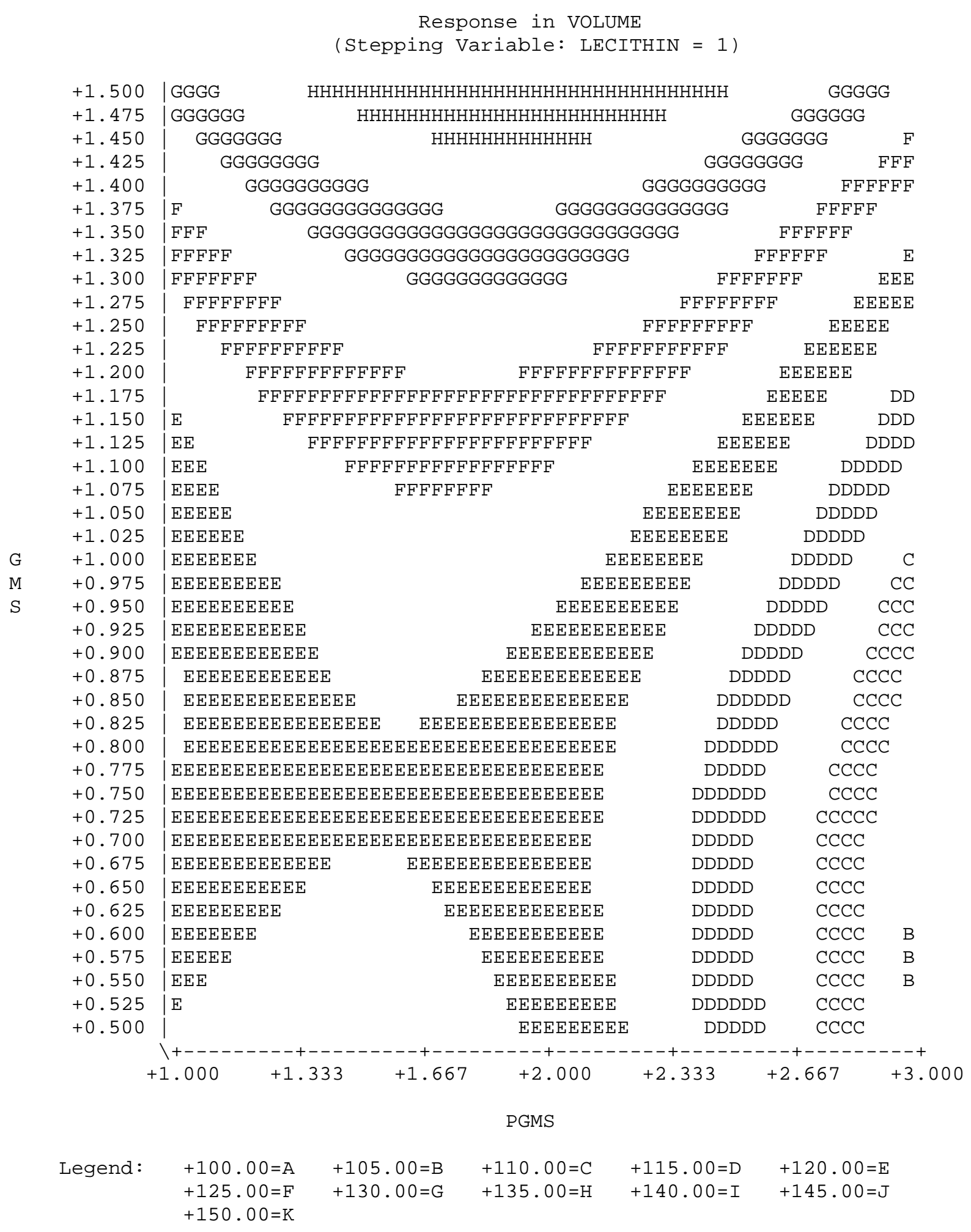


Analysis of Data File: CAKSCORE.RSM

Using Model: STD 3_VAR | C $12231223 \quad 13112233$

Coefficient of Determination $\left(R^{\wedge} 2\right)=0.64586$

Coefficient of Multiple Correlation $=0.80366$

Standard Error of Estimate 6.47671

EQUATION :

SCORE

$=\quad+45.5882353$

-2.0951846 * PGMS

+44.7328528 * GMS

$+30.6339869 *$ LECITHIN

+2.7320261 * PGMS * GMS

-17.6055594 * GMS * LECITHIN

+5.1818647 * PGMS * LECITHIN

+0.6791676 * PGMS * PGMS

-20.5859516 * GMS * GMS

-8.3529412 * LECITHIN * LECITHIN 
Response in SCORE

(Stepping Variable: LECITHIN = 0 )

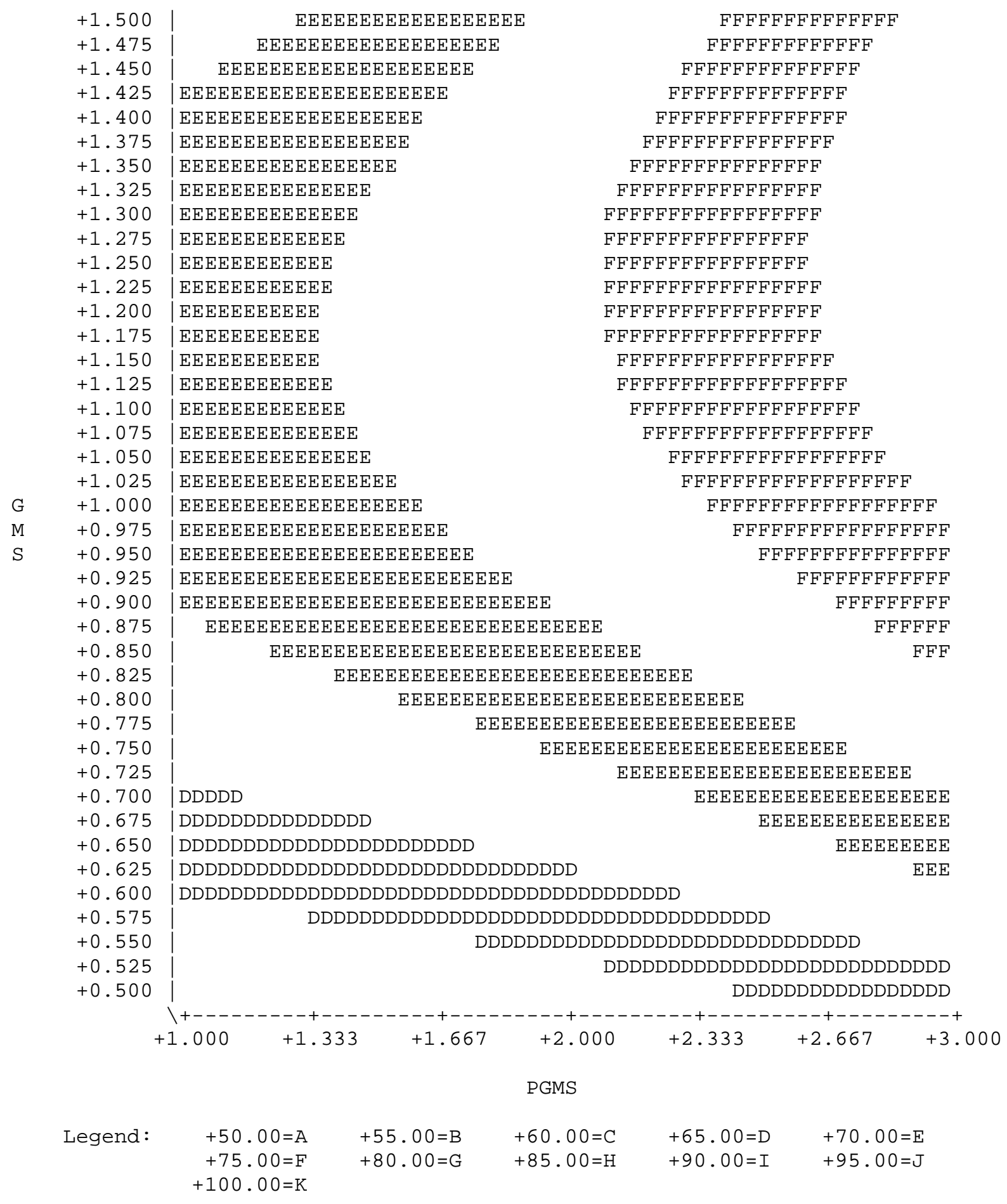


Response in SCORE

(Stepping Variable: LECITHIN $=.5$ )

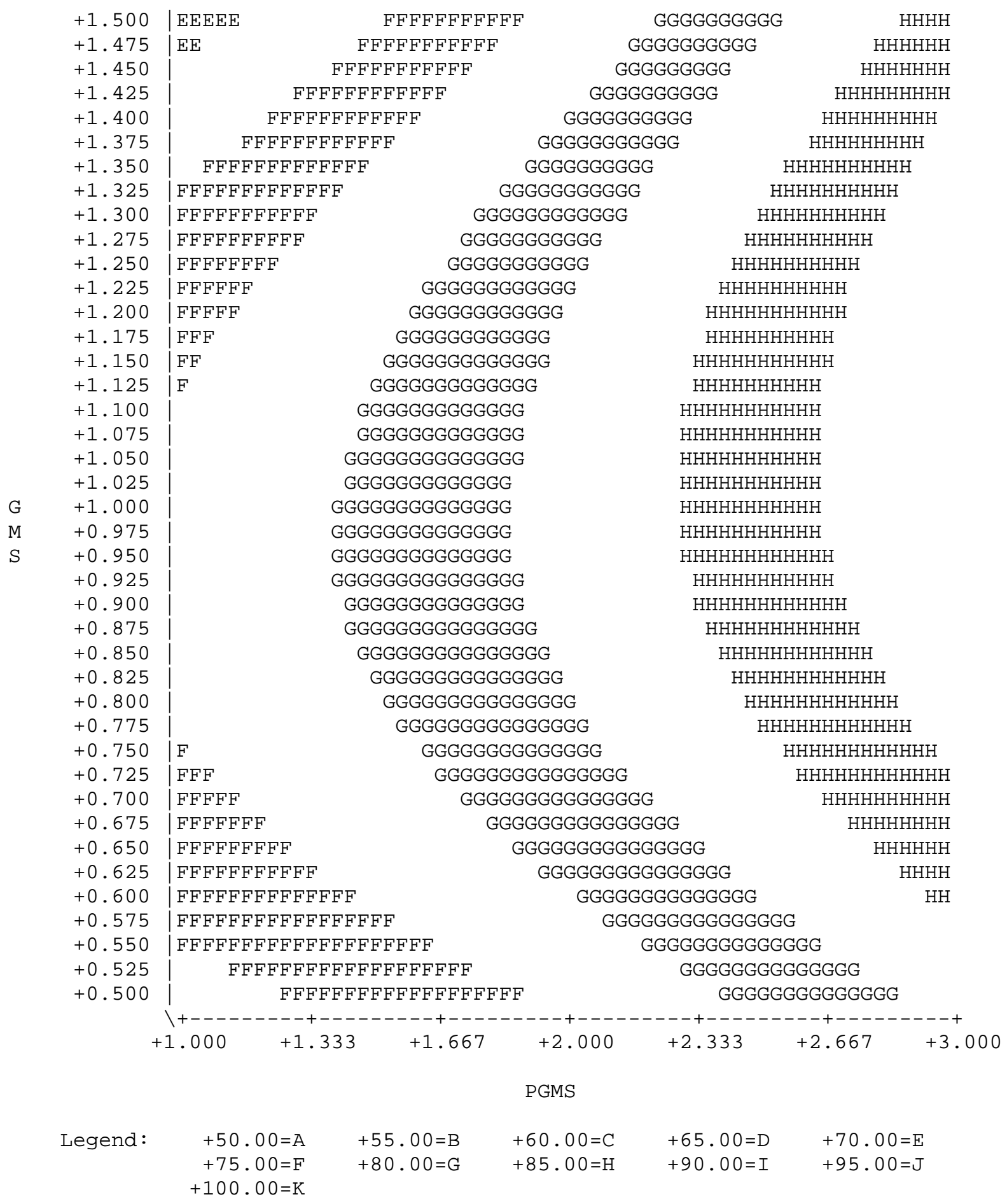


Response in SCORE

(Stepping Variable: LECITHIN = 1)

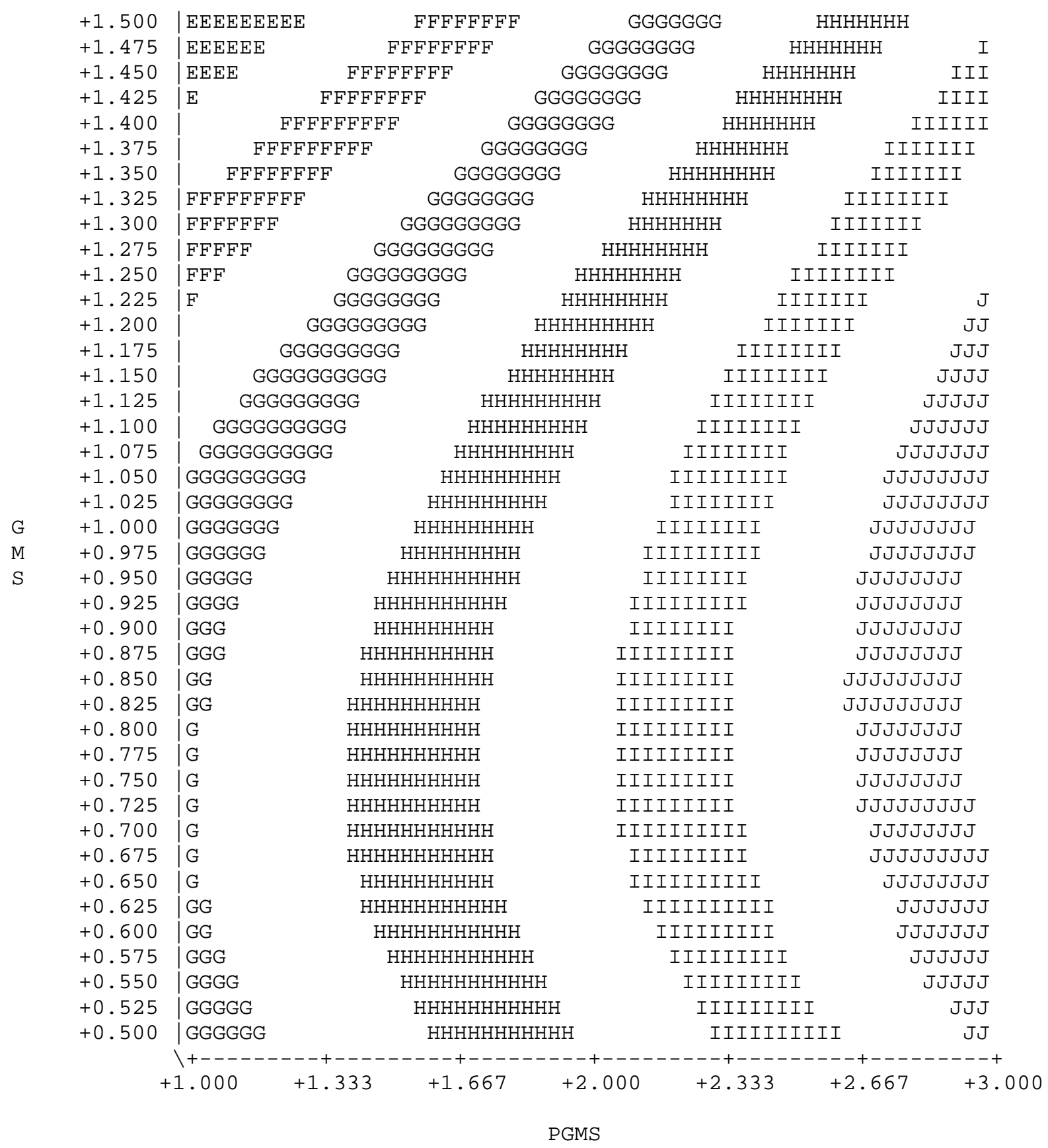

$\begin{array}{llllll}\text { Legend: } \quad & +50.00=\mathrm{A} & +55.0 \odot=\mathrm{B} & +60.00=\mathrm{C} & +65.0 \odot=\mathrm{D} & +70.00=\mathrm{E} \\ & +75.00=\mathrm{F} & +80.0 \odot=\mathrm{G} & +85.00=\mathrm{H} & +90.00=\mathrm{I} & +95.00=\mathrm{J} \\ & +100.00=\mathrm{K}\end{array}$




\section{Appendix B - RAW DATA}

\section{Table 13. Cake firmness (The first set test)}

First Round test

Firmness: Plastic shortening

\begin{tabular}{|c|c|c|c|c|c|c|c|c|}
\hline & $\mathrm{L}$ & C & $\mathrm{R}$ & $\mathrm{L}$ & C & $\mathrm{R}$ & average & S.D \\
\hline 1st day & 175 & 198 & 165 & 149 & 180 & 176 & 173.8 & 14.85 \\
\hline 5th day & 253 & 229 & 232 & 225 & 229 & 239 & 234.5 & 9.31 \\
\hline 12th day & 220 & 254 & 217 & 223 & 261 & 231 & 234.3 & 17.05 \\
\hline 21th day & 238 & 344 & 255 & 269 & 328 & 254 & 281.3 & 39.95 \\
\hline
\end{tabular}

Firmness: liquid shortening

\begin{tabular}{|c|r|r|r|r|r|r|r|r|}
\hline 1st day & 145 & 168 & 162 & 170 & 160 & 135 & 156.7 & 12.59 \\
\hline 5th day & 204 & 189 & 188 & 195 & 198 & 197 & 195.2 & 5.46 \\
\hline 12th day & 193 & 193 & 206 & 208 & 203 & 189 & 198.7 & 7.27 \\
\hline 21th day & 225 & 257 & 238 & 245 & 252 & 228 & 240.8 & 11.74 \\
\hline
\end{tabular}

Firmness: liquid oil

\begin{tabular}{|c|r|r|r|r|r|r|r|r|}
\hline & \multicolumn{1}{|c|}{ L } & \multicolumn{1}{c|}{ C } & \multicolumn{1}{l|}{ R } & \multicolumn{1}{c|}{ L } & \multicolumn{1}{c|}{ C } & \multicolumn{1}{c|}{ R } & average & \multicolumn{1}{c|}{ S.D } \\
\hline 1st day & 267 & 341 & 229 & 298 & 332 & 258 & 287.5 & 40.14 \\
\hline 5th day & 359 & 472 & 362 & 327 & 500 & 356 & 396.0 & 65.16 \\
\hline 12th day & 323 & 531 & 327 & 345 & 522 & 366 & 402.3 & 88.93 \\
\hline 21th day & 464 & 567 & 485 & 450 & 568 & 485 & 503.2 & 47.08 \\
\hline
\end{tabular}

Firmness: liquid oil+emul.

\begin{tabular}{|c|r|r|r|r|r|r|r|r|}
\hline & \multicolumn{1}{|c|}{$\mathrm{L}$} & \multicolumn{1}{l|}{$\mathrm{C}$} & \multicolumn{1}{l|}{$\mathrm{R}$} & $\mathrm{L}$ & \multicolumn{1}{l|}{$\mathrm{C}$} & \multicolumn{1}{c|}{$\mathrm{R}$} & \multicolumn{1}{c|}{ average } & \multicolumn{1}{c|}{ S.D } \\
\hline 1st day & 155 & 146 & 124 & 138 & 163 & 144 & 145.0 & 12.36 \\
\hline 5th day & 165 & 187 & 163 & 169 & 178 & 175 & 172.8 & 8.21 \\
\hline 12th day & 187 & 242 & 199 & 197 & 245 & 184 & 209.0 & 24.96 \\
\hline 21th day & 203 & 217 & 214 & 221 & 221 & 203 & 213.2 & 7.58 \\
\hline
\end{tabular}


Table 14. Cake firmness (The second set test)

Firmness: Plastic shortening

\begin{tabular}{|c|r|r|r|r|r|r|r|r|}
\hline & \multicolumn{1}{|c|}{$\mathrm{L}$} & \multicolumn{1}{c|}{$\mathrm{C}$} & \multicolumn{1}{l|}{$\mathrm{R}$} & \multicolumn{1}{l|}{$\mathrm{L}$} & \multicolumn{1}{c|}{$\mathrm{C}$} & $\mathrm{R}$ & average & \multicolumn{1}{c|}{ S.D } \\
\hline 1st day & 234 & 257 & 263 & 211 & 209 & 239 & 235.5 & 20.56 \\
\hline 5th day & 232 & 233 & 263 & 239 & 266 & 247 & 246.7 & 13.55 \\
\hline 12th day & 261 & 281 & 267 & 272 & 257 & 261 & 266.5 & 8.08 \\
\hline 21th day & 294 & 303 & 336 & 313 & 297 & 270 & 302.2 & 19.96 \\
\hline
\end{tabular}

Firmness: liquid shortening

\begin{tabular}{|c|r|r|r|r|r|r|r|r|}
\hline 1st day & 201 & 200 & 180 & 189 & 187 & 178 & 189.2 & 8.86 \\
\hline 5th day & 192 & 193 & 192 & 209 & 215 & 203 & 200.7 & 9.03 \\
\hline 12th day & 229 & 242 & 219 & 240 & 239 & 234 & 233.8 & 7.90 \\
\hline 21th day & 261 & 272 & 238 & 229 & 267 & 240 & 251.2 & 16.18 \\
\hline
\end{tabular}

Firmness: liquid oil

\begin{tabular}{|c|r|r|r|r|r|r|r|r|}
\hline & \multicolumn{1}{|c|}{$\mathrm{L}$} & \multicolumn{1}{l|}{ C } & \multicolumn{1}{l|}{ R } & \multicolumn{1}{l|}{ L } & \multicolumn{1}{l|}{ C } & R & average & \multicolumn{1}{c|}{ S.D } \\
\hline 1st day & 302 & 318 & 327 & 302 & 379 & 303 & 321.8 & 27.24 \\
\hline 5th day & 352 & 404 & 312 & 291 & 361 & 390 & 351.7 & 39.89 \\
\hline 12th day & 395 & 538 & 405 & 401 & 507 & 358 & 434.0 & 65.03 \\
\hline 21th day & 595 & 625 & 439 & 419 & 640 & 466 & 530.7 & 91.33 \\
\hline
\end{tabular}

Firmness: liquid oil+emul.

\begin{tabular}{|c|r|r|r|r|r|r|r|r|}
\hline & \multicolumn{1}{|c|}{$\mathrm{L}$} & \multicolumn{1}{l|}{$\mathrm{C}$} & \multicolumn{1}{l|}{$\mathrm{R}$} & $\mathrm{L}$ & \multicolumn{1}{l|}{$\mathrm{C}$} & \multicolumn{1}{c|}{$\mathrm{R}$} & \multicolumn{1}{c|}{ average } & \multicolumn{1}{c|}{ S.D } \\
\hline 1st day & 170 & 183 & 165 & 161 & 176 & 154 & 168.2 & 9.55 \\
\hline 5th day & 188 & 194 & 205 & 201 & 184 & 189 & 193.5 & 7.41 \\
\hline 12th day & 203 & 206 & 208 & 194 & 202 & 197 & 201.7 & 4.85 \\
\hline 21th day & 258 & 253 & 226 & 227 & 269 & 266 & 249.8 & 17.30 \\
\hline
\end{tabular}


Table 15. Cake firmness (The third set test)

Firmness: Plastic shortening

\begin{tabular}{|c|r|r|r|r|r|r|r|r|}
\hline & \multicolumn{1}{|c|}{$\mathrm{L}$} & \multicolumn{1}{c|}{$\mathrm{C}$} & \multicolumn{1}{l|}{$\mathrm{R}$} & \multicolumn{1}{l|}{$\mathrm{L}$} & \multicolumn{1}{c|}{$\mathrm{C}$} & $\mathrm{R}$ & average & \multicolumn{1}{c|}{ S.D } \\
\hline 1st day & 240 & 219 & 223 & 211 & 227 & 223 & 223.8 & 8.76 \\
\hline 5th day & 269 & 281 & 245 & 245 & 262 & 257 & 259.8 & 12.81 \\
\hline 12th day & 301 & 323 & 305 & 295 & 340 & 299 & 310.5 & 15.91 \\
\hline 21th day & 312 & 321 & 306 & 286 & 299 & 301 & 304.2 & 10.92 \\
\hline
\end{tabular}

Firmness: liquid shortening

\begin{tabular}{|c|r|r|r|r|r|r|r|r|}
\hline 1st day & 169 & 188 & 176 & 165 & 166 & 172 & 172.7 & 7.78 \\
\hline 5th day & 195 & 209 & 209 & 206 & 198 & 208 & 204.2 & 5.58 \\
\hline 12th day & 214 & 235 & 219 & 213 & 243 & 216 & 223.3 & 11.47 \\
\hline 21th day & 234 & 277 & 237 & 252 & 279 & 238 & 252.8 & 18.69 \\
\hline
\end{tabular}

Firmness: liquid oil

\begin{tabular}{|c|r|r|r|r|r|r|r|r|}
\hline & \multicolumn{1}{|c|}{ L } & \multicolumn{1}{l|}{ C } & \multicolumn{1}{l|}{ R } & \multicolumn{1}{l|}{ L } & \multicolumn{1}{l|}{ C } & R & average & \multicolumn{1}{c|}{ S.D } \\
\hline 1st day & 255 & 365 & 279 & 257 & 302 & 274 & 288.7 & 37.53 \\
\hline 5th day & 319 & 360 & 314 & 330 & 405 & 310 & 339.7 & 33.52 \\
\hline 12th day & 426 & 462 & 389 & 399 & 485 & 421 & 430.3 & 33.63 \\
\hline 21th day & 455 & 562 & 424 & 477 & 612 & 431 & 493.5 & 69.79 \\
\hline
\end{tabular}

Firmness: liquid oil+emul.

\begin{tabular}{|c|r|r|r|r|r|r|r|r|}
\hline & \multicolumn{1}{|c|}{$\mathrm{L}$} & \multicolumn{1}{l|}{$\mathrm{C}$} & \multicolumn{1}{l|}{$\mathrm{R}$} & $\mathrm{L}$ & \multicolumn{1}{l|}{$\mathrm{C}$} & \multicolumn{1}{c|}{ R } & \multicolumn{1}{c|}{ average } & \multicolumn{1}{c|}{ S.D } \\
\hline 1st day & 170 & 165 & 173 & 165 & 158 & 172 & 167.2 & 5.15 \\
\hline 5th day & 173 & 192 & 180 & 177 & 182 & 204 & 184.7 & 10.42 \\
\hline 12th day & 227 & 256 & 240 & 229 & 232 & 226 & 235.0 & 10.46 \\
\hline 21th day & 218 & 210 & 229 & 235 & 246 & 232 & 228.3 & 11.64 \\
\hline
\end{tabular}


Table 16. The first set of cake scores

\begin{tabular}{|c|c|c|c|c|c|}
\hline A.Cells (30points) & Score Points & Plastic shortening & Liquid oil & Liquid shortening & Liquid oil+emul. \\
\hline 1. Uniformity(10points) (a) Even (normal) & 10 & 7 & 5 & 10 & 9 \\
\hline (b) Slightly uneven & 6 & & & & \\
\hline (c) Uneven & 2 & & & & \\
\hline (a) Dense(normal) & 10 & 9 & 5 & 9 & 7 \\
\hline (b)close & 8 & & & & \\
\hline (C) Slightly open & 6 & & & & \\
\hline Copen & 4 & & & & \\
\hline 3. Thickness of walls(10points) (a)Thin (normal) & 10 & 9 & 6 & 9 & 8 \\
\hline (b) Slightly thick & 6 & & & & \\
\hline (c) Thick & 2 & & & & \\
\hline B. Grain (16point) & & 14 & 10 & 15 & 13 \\
\hline 1. Sliky(normal) & 16 & & & & \\
\hline 2.Harsh & 10 & & & & \\
\hline 3.Coarse (corn bread) & 8 & & & & \\
\hline C. Texture (34points) & & & & & \\
\hline 1. Moistness(10 points) (a) Moist (normal) & 10 & 9 & 8 & 10 & 10 \\
\hline $\begin{array}{l}\text { (b) Slightly dry } \\
\end{array}$ & 8 & & & & \\
\hline (c) Gummy & 6 & & & & \\
\hline (d) Dry & 4 & & & & \\
\hline 2.Tenderness (14points) (a) Very tender (normal) & 14 & 12 & 10 & 14 & 14 \\
\hline (b) Tender & 12 & & & & \\
\hline (c) Slightly tough & 10 & & & & \\
\hline (d) tough & 4 & & & & \\
\hline 3. Softness (10points) (a) Soft (normal) & 10 & 10 & 6 & 10 & 10 \\
\hline (b) Slightly firm & 8 & & & & \\
\hline (c) Firm & 4 & & & & \\
\hline D. Crumb color (10points) & & 9 & 7 & 9 & 9 \\
\hline 1.Bright white (normal) & 10 & & & & \\
\hline 2.White & 8 & & & & \\
\hline 3. Slightly dull & 8 & & & & \\
\hline 4. Slightly creamy & 8 & & & & \\
\hline 5.Creamy & 6 & & & & \\
\hline 6. Slightly dull and slightly creamy & 4 & & & & \\
\hline E. Flavor (10points) & & & & & \\
\hline 1. Normal (no off-flavor due to flour) & 10 & 10 & 10 & 10 & 10 \\
\hline 2.Foreigh & 0 & & & & \\
\hline Total & 100 & 89 & 67 & 96 & 90 \\
\hline B & & 40 & 42 & 45 & 44 \\
\hline $\mathrm{C}$ & & 45 & 51 & 47 & 48 \\
\hline $\mathrm{D}$ & & 39 & 41 & 41 & 42 \\
\hline Volume $(B+C+D)$ & & 124 & 134 & 133 & 134 \\
\hline Symmetry(2C-B-D) & & 11 & 19 & 8 & 10 \\
\hline Uniformity(B-D) & & 1 & 1 & 4 & 2 \\
\hline note & & & \multicolumn{2}{|c|}{ tuneling problem } & sticky,fragil \\
\hline
\end{tabular}


Table 17. The second set of cake scores

\begin{tabular}{|c|c|c|c|c|c|}
\hline A.Cells (30points) & Score Points & Plastic shortening & Liquid oil & Liquid shortening & Liquid oil+emul. \\
\hline 1. Uniformity(10points) (a) Even (normal) & 10 & 7 & 2 & 8 & 9 \\
\hline (b) Slightly uneven & 6 & & & & \\
\hline (c) Uneven & 2 & & & & \\
\hline (a) Dense(normal) & 10 & 8 & 5 & 9 & 6 \\
\hline (b)close & 8 & & & & \\
\hline (C) Slightly open & 6 & & & & \\
\hline Copen & 4 & & & & \\
\hline 3. Thickness of walls(10points) (a)Thin (normal) & 10 & 8 & 2 & 10 & 6 \\
\hline (b) Slightly thick & 6 & & & & \\
\hline (c) Thick & 2 & & & & \\
\hline B. Grain (16point) & & 13 & 8 & 14 & 13 \\
\hline 1. Sliky(normal) & 16 & & & & \\
\hline 2.Harsh & 10 & & & & \\
\hline 3.Coarse (corn bread) & 8 & & & & \\
\hline C. Texture (34points) & & & & & \\
\hline 1. Moistness(10 points) (a) Moist (normal) & 10 & 8 & 8 & 10 & 10 \\
\hline $\begin{array}{l}\text { (b) Slightly dry } \\
\end{array}$ & 8 & & & & \\
\hline (C) Gummy & 6 & & & & \\
\hline (d) Dry & 4 & & & & \\
\hline 2.Tenderness (14points) (a) Very tender (normal) & 14 & 12 & 8 & 13 & 13 \\
\hline (b) Tender & 12 & & & & \\
\hline (C) Slightly tough & 10 & & & & \\
\hline (d) tough & 4 & & & & \\
\hline 3. Softness (10points) (a) Soft (normal) & 10 & 8 & 6 & 10 & 10 \\
\hline (b) Slightly firm & 8 & & & & \\
\hline (c) Firm & 4 & & & & \\
\hline D. Crumb color (10points) & & 9 & 7 & 9 & 9 \\
\hline 1.Bright white (normal) & 10 & & & & \\
\hline 2.White & 8 & & & & \\
\hline 3. Slightly dull & 8 & & & & \\
\hline 4. Slightly creamy & 8 & & & & \\
\hline 5.Creamy & 6 & & & & \\
\hline 6. Slightly dull and slightly creamy & 4 & & & & \\
\hline E. Flavor (10points) & & & & & \\
\hline 1. Normal (no off-flavor due to flour) & 10 & 10 & 10 & 10 & 10 \\
\hline 2.Foreigh & 0 & & & & \\
\hline Total & 100 & 83 & 56 & 93 & 86 \\
\hline B & & 39 & 39 & 42 & 41 \\
\hline $\mathrm{C}$ & & 44 & 41 & 48 & 45 \\
\hline $\mathrm{D}$ & & 38 & 40 & 41 & 41 \\
\hline Volume $(B+C+D)$ & & 121 & 120 & 131 & 127 \\
\hline Symmetry(2C-B-D) & & 11 & 3 & 13 & 8 \\
\hline Uniformity(B-D) & & 1 & 1 & 1 & 0 \\
\hline note & & \multicolumn{3}{|c|}{ tuneling problem } & sticky,fragil \\
\hline
\end{tabular}


Table 18. The third set of cake scores

\begin{tabular}{|c|c|c|c|c|c|}
\hline A.Cells (30points) & Score Points & Plastic shortening & Liquid oil & Liquid shortening & Liquid oil+emul. \\
\hline 1. Uniformity(10points) (a) Even (normal) & 10 & 7 & 5 & 9 & 9 \\
\hline (b) Slightly uneven & 6 & & & & \\
\hline (c) Uneven & 2 & & & & \\
\hline (a) Dense(normal) & 10 & 8 & 4 & 9 & 8 \\
\hline (b)close & 8 & & & & \\
\hline (c) Slightly open & 6 & & & & \\
\hline $\begin{array}{ll} & \text { (b) Slightly thick } \\
\end{array}$ & 6 & & & & \\
\hline (c) Thick & 2 & & & & \\
\hline B. Grain (16point) & & 13 & 8 & 14 & 13 \\
\hline 1. Sliky(normal) & 16 & & & & \\
\hline (b) Slightly dry & 8 & & & & \\
\hline (c) Gummy & 6 & & & & \\
\hline (d) Dry & 4 & & & & \\
\hline 2.Tenderness (14points) (a) Very tender (normal) & 14 & 12 & 8 & 13 & 13 \\
\hline (b) Tender & 12 & & & & \\
\hline (c) Slightly tough & 10 & & & & \\
\hline (d) tough & 4 & & & & \\
\hline 3. Softness (10points) (a) Soft (normal) & 10 & 8 & 5 & 10 & 10 \\
\hline $\begin{array}{l}\text { (b) Slightly firm } \\
\end{array}$ & 8 & & & & \\
\hline (c) Firm & 4 & & & & \\
\hline \multicolumn{6}{|l|}{ E. Flavor (10points) } \\
\hline 1. Normal (no off-flavor due to flour) & 10 & 10 & 10 & 10 & 10 \\
\hline 2.Foreigh & 0 & & & & \\
\hline Total & 100 & 83 & 53 & 93 & 85 \\
\hline $\mathrm{B}$ & & 40 & 43 & 44 & 42 \\
\hline $\mathrm{C}$ & & 41 & 50 & 46 & 47 \\
\hline $\mathrm{D}$ & & 38 & 42 & 44 & 42 \\
\hline Volume $(B+C+D)$ & & 119 & 135 & 134 & 131 \\
\hline Symmetry(2C-B-D) & & 4 & 15 & 4 & 10 \\
\hline Uniformity(B-D) & & 2 & 1 & 0 & 0 \\
\hline note & & & tuneling problem & & sticky,fragil \\
\hline
\end{tabular}

